\title{
Measuring Approach-Avoidance Motivation: Expanding the Dimensionality and the Implied Outcomes Problem
}

\author{
Mark David Scott \\ Dissertation submitted to the faculty at \\ Virginia Polytechnic Institute and State University \\ in partial fulfillment of the requirements for the degree of: \\ Doctor of Philosophy \\ in \\ Psychology
}
Neil M. A. Hauenstein, Committee Chair
Bethany C. Bray
Kirby Deater-Deckard
Roseanne J. Foti

September $28^{\text {th }}, 2011$

Blacksburg, Virginia

Keywords: approach-avoidance, motivation, dimensionality, implied outcomes, self-report 


\title{
Measuring Approach-Avoidance Motivation: Expanding the Dimensionality and the Implied Outcomes Problem
}

\author{
Mark David Scott
}

\begin{abstract}
The current study sought to examine how best to fully represent and measure approach-avoidance motivational orientation using self-reports. Participants responded to a variety of existing, revised, and new scales across the theoretical spectrum of approach-avoidance motivation. Exploratory factor analyses were conducted to identify the items to be retained for evaluating the adequacy of competing confirmatory measurement structures. Overall results supported the validity of the second-order approach-avoidance overarching framework and indicated that the use of items with clear specification of reward/punishment context improves the psychometric properties of approach-avoidance scales. Moreover, the newly developed scales reflecting constructs that represent increasing non-gains via approach and increasing non-losses via avoidance meaningfully expanded the approach-avoidance construct space. It also appeared that the proposed four-dimensional model of approach-avoidance is a viable alternative measurement structure. Finally, the current results suggested that contamination by implied outcomes does not invalidate approach-avoidance scales where reward/punishment context is specified. Implications and recommendations for future research are discussed.
\end{abstract}




\section{ACKNOWLEDGMENTS}

First and foremost, I would like to thank my advisor, Dr. Neil Hauenstein, for his mentorship, guidance, and patience. I am sincerely grateful for our time together (whether discussing trait theory versus cognitive theory or the Giants and Lions), and I look forward to continuing to unravel the "personality puzzle" with you in the future.

I would also like to thank my committee, Dr. Bethany Bray, Dr. Kirby Deater-Deckard, and Dr. Roseanne Foti, for their expertise; this dissertation undoubtedly benefited from your invaluable insights.

Greg, Conrad, and Pat: thank you guys so much for both your friendship and academic support. Know that you can always "call on me".

I would like to extend my deepest thanks to my parents, for instilling in me the wisdom to approach what should be approached, and to avoid what should be avoided. Sarah and Ian: I am now Dr. "you know what"; I could not have completed my doctoral studies without your love and confidence.

Finally, agapi mou, Rena: You are my best friend and my steady ground. This work is dedicated to you. $\Sigma$ ' $\alpha \gamma \alpha \pi \omega ́$.

"The heart of the prudent getteth knowledge; and the ear of the wise seeketh knowledge." (Proverbs 18:15) 


\section{Table of Contents}

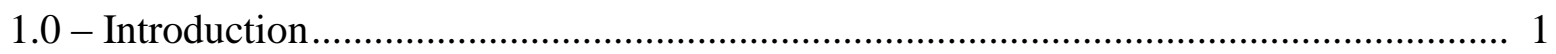

1.1 - Scott and Hauenstein (2011) ......................................................................... 1

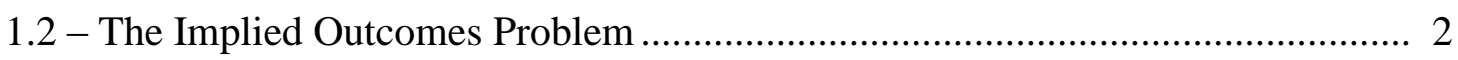

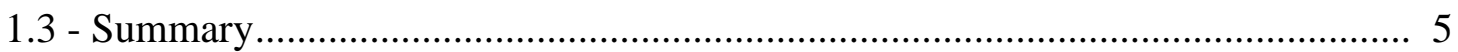

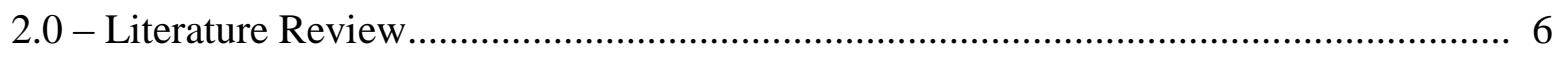

2.1 - Approach-Avoidance Theories ……………………................................. 6

2.2 - Prior Factor Analytic Research on Existing Approach-Avoidance Scales .......... 8

2.3 - Implied Outcomes ……………............................................................... 9

2.4 - Analytic Strategy for New Data Set................................................................11

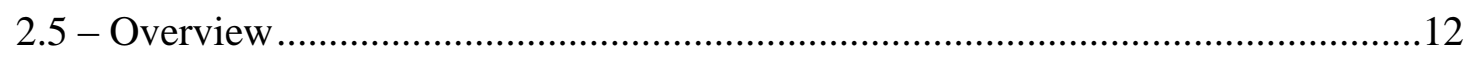

3.0 - Method for Scott and Hauenstein Data Set...........................................................13

3.1 - Participants..............................................................................................13

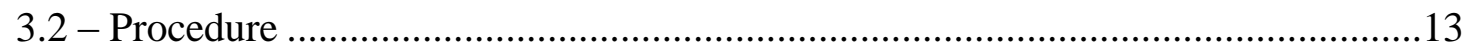

3.3 - Study 1 Approach-Avoidance Measures ……………….................................13

4.0 - Results of Hierarchical Analyses of Scott and Hauenstein Data Set .............................16

5.0 - Discussion of Hierarchical Analyses of Scott and Hauenstein Data Set ......................18

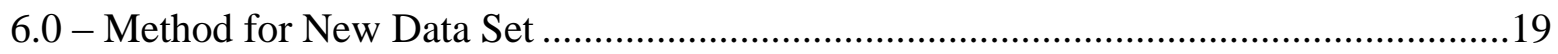

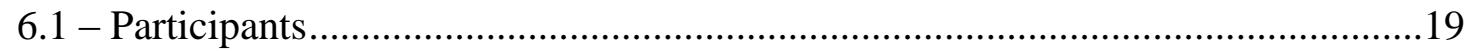

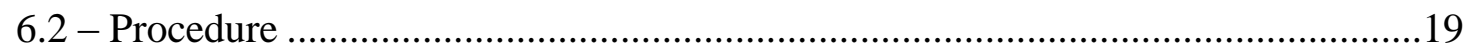

6.3 - Study 2 Approach-Avoidance Measures (See Appendix C)................................19

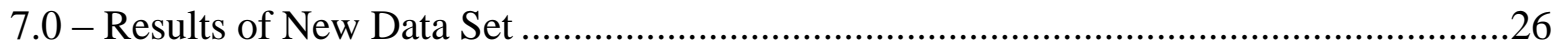

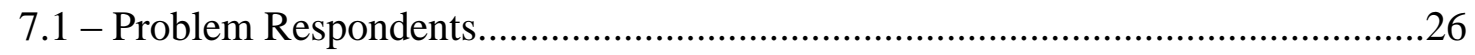


7.2 - Tests of Measurement Invariance Between Data Sets .......................................26

7.3 - Exploratory Factor Analyses of the Two-Dimensional Model.............................27

7.4 - Confirmatory Factor Analysis for the Two-Dimensional Model ........................28

7.5 - Hierarchical Approach-Avoidance Confirmatory Factor Analysis for the

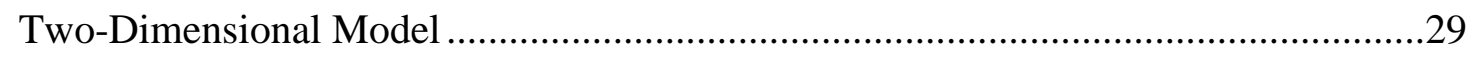

7.6 - Exploratory Factor Analyses of the Four-Dimensional Model.............................30

7.7 - Confirmatory Factor Analysis for the Four-Dimensional Model ..........................31

7.8 - Hierarchical Approach-Avoidance Confirmatory Factor Analysis for the

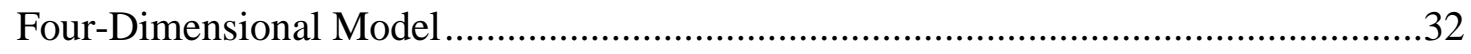

7.9 - Scale-Level Hierarchical Approach-Avoidance Confirmatory Factor Analysis

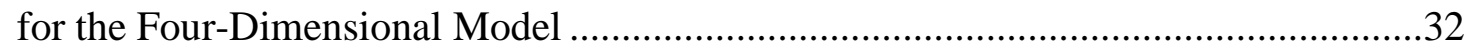

7.10 - Confirmatory Factor Analysis for the Implied Outcomes Model ........................33

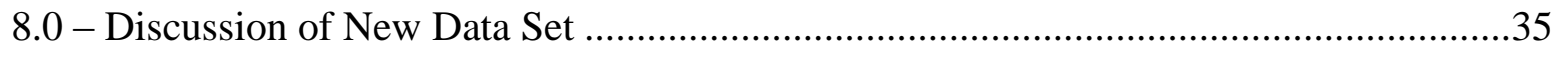

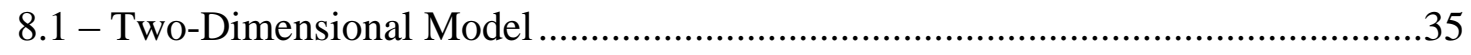

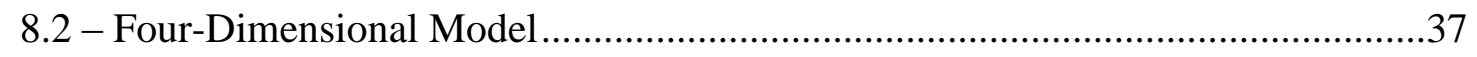

8.3 - The Potential Contamination of Implied Outcomes ………………………...........39

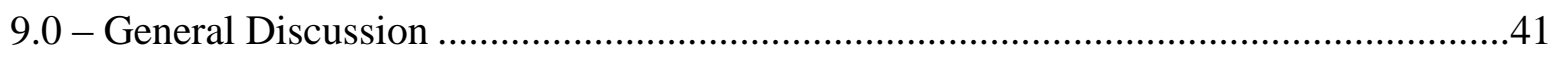

9.1 - Future Directions for Research on Measuring Approach-Avoidance...................41

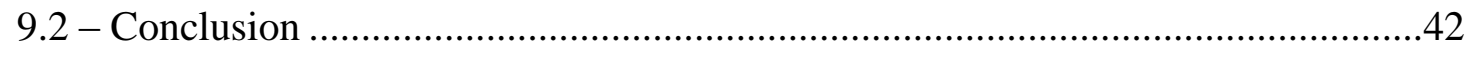

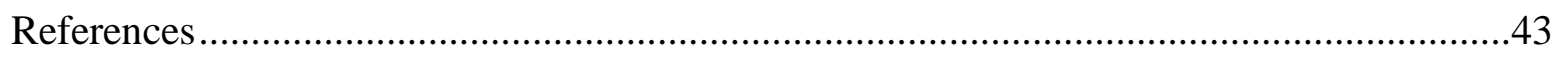




\section{List of Tables}

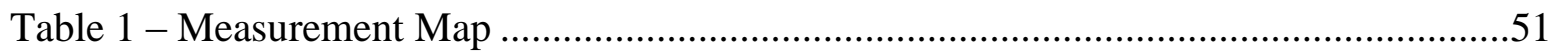

Table 2 - Factor Loadings Based on a Principal Axis Factoring with Direct Oblimin

Rotation for the Remaining 70 Items From the Two-Dimensional Model

$(\mathrm{N}=540)$

Table 3 - Items/Factors Retained in the Final EFA Solution for the Two-Dimensional

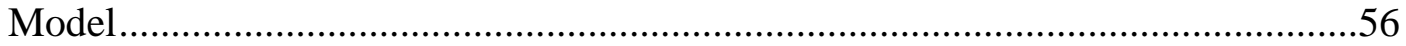

Table 4 - Factor Correlations From the Confirmatory Two-Dimensional Model.................57

Table 5 - Factor Loadings Based on a Principal Axis Factoring with Direct Oblimin

Rotation for the Remaining 120 Items From the Four-Dimensional Model

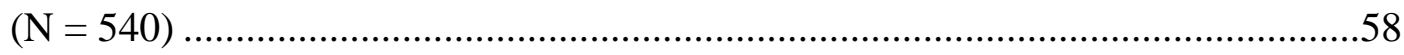

Table 6 - Items/Factors Retained in the Final EFA Solution for the Four-Dimensional

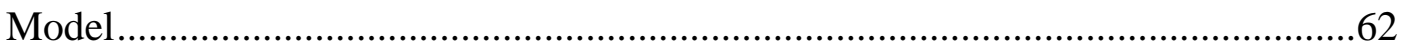

Table 7 - Factor Correlations From the Confirmatory Four-Dimensional Model ...............63 


\section{List of Figures}

Figure 1 - Summary of Results From Scott and Hauenstein (2011) ..............................64

Figure 2 - Two-Dimensional Model....................................................................65

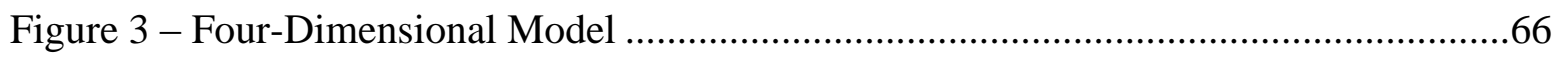

Figure 4 - Hierarchical "Sociability as Approach” Model Structural Diagram ..................68

Figure 5 - Hierarchical "Without Sociability” Model Structural Diagram ........................69

Figure 6 - Scree Plot of Initial Exploratory Factor Analysis Solution for the

Two-Dimensional Model......................................................................... 70

Figure 7 - Two-Dimensional Model Structural Diagram.......................................... 71

Figure 8 - Hierarchical Two-Dimensional Model Structural Diagram .............................72

Figure 9 - Scree Plot of Initial Exploratory Factor Analysis Solution for the

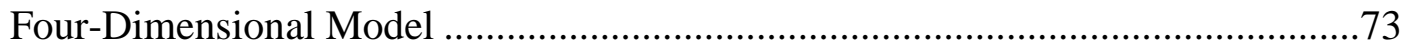

Figure 10 - Four-Dimensional Model Structural Diagram..........................................74

Figure 11 - Hierarchical Four-Dimensional Model Structural Diagram ...........................75

Figure 12 - Scale-Level Hierarchical Four-Dimensional Model Structural Diagram...........76

Figure 13 - Implied Outcomes Model Structural Diagram ..........................................77 


\section{List of Appendices}

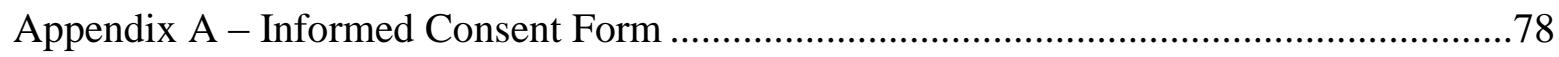

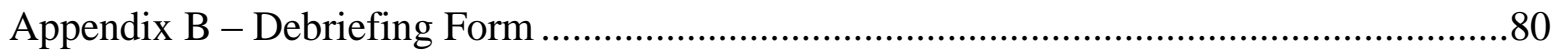

Appendix C - Full Item Content of the Approach-Avoidance Scales ..............................81 


\section{0 - Introduction}

Many theorists posit consistencies in human behavior result from individual propensities toward approaching reward and avoiding punishment (Carver, Sutton, \& Scheier, 2000; Davidson, 1998; Elliot \& Thrash, 2002; Fowles, 1987; Gray \& McNaughton, 2000; Tellegen, 1985). This distinction in motivation traces its roots to the ethical hedonism advocated by the ancient Greek philosopher Democritus (460-370 B.C.), and had been recognized by William James (1890, pp. 549-559) at the inception of scientific psychology. Approach-avoidance has been theorized in terms of distal biological determinants (e.g., behavioral activation/inhibition; Gray, 1991), stable trait structures (e.g., extraversion/neuroticism; Costa \& McCrae, 1992), personal motives (e.g., need for achievement; Atkinson, 1964), and proximal cognitive-affective processes (e.g., regulatory focus, goal orientation; Elliot, 1999; Higgins, 1999). Elliot and Thrash (2002) have suggested that "the approach-avoidance distinction is so conceptually central that it may be used to organize and integrate seemingly diverse approaches to personality" (p. 804).

\section{1 - Scott and Hauenstein (2011)}

Numerous self-report instruments have been developed based on the different theories of approach-avoidance. Scott and Hauenstein (2011) noted that approach-avoidance motivation is likely represented by fewer constructs than theorized in the approach-avoidance motivation literature; fewer constructs are likely because of two reasons. First, there are similarities in item content across scales designed to measure either biological or cognitive-affective sources of motivational orientation. Second, given the limitations of introspective insights, it is unlikely that individuals can psychologically differentiate the multitude of approach-avoidance constructs using self-report methods (cf. John \& Robins, 1994). Scott and Hauenstein administered seven approach-avoidance self-report measures designed to produce 14 different scale scores (see Figure 1) to a large sample of undergraduate students. Nine constructs emerged from factor analyses: Extraversion-Introversion (Sociability facet), Reward Responsiveness, Risk-Taking, Neuroticism-Emotional Stability (Negative Affect facet), Conscientiousness, Mastery Goal Orientation, Performance-Prove Goal Orientation, Performance-Avoid Goal Orientation, and Prevention Regulatory Focus. In Figure 1, the arrows link the self-report scales to the underlying nine factors. Notably, three traditional approach-avoidance constructs did not emerge Impulsivity, Punishment Sensitivity, and Promotion Regulatory Focus. Furthermore, the 
Conscientiousness factor that emerged from a subset of Need for Achievement items is not traditionally recognized as part of the approach-avoidance construct space (see Elliot \& Thrash, 2010).

However, Scott and Hauenstein (2011) did not address the fundamental issue of testing the fit of the emergent constructs to the overarching approach-avoidance measurement structure. This issue is most germane in relation to the Sociability factor, where retained items derived from three different scales/subscales, two of which were hypothesized to reflect approach motivation (Reward Responsiveness and Extraversion), whereas the third scale was hypothesized to reflect avoidance motivation (Punishment Sensitivity). Therefore, the first goal of the current study is to re-examine the data from Scott and Hauenstein in relation to the fit within the overarching approach-avoidance measurement structure.

\section{2 - The Implied Outcomes Problem}

Scott and Hauenstein (2011) used simple structure criteria to evaluate items so as to identify unique indicators of underlying constructs. Surprisingly, 84 (68\%) of the 124 items were excluded based on failure to meet simple structure criteria. Scott and Hauenstein noted that the retained items shared the common characteristic of implied positive/negative outcomes. For example, the retained extraversion item "I am the life of the party" taken from the International Personality Item Pool (IPIP; Goldberg, Johnson, Eber, Hogan, Ashton, Cloninger, \& Gough, 2006) implies acquisition of positive social outcomes related to popularity. In contrast, the dropped impulsivity-related item "I often act on the spur of the moment" taken from the Fun Seeking subscale of the BIS/BAS scales (Carver \& White, 1994) is ambiguous in implying a positive outcome or a negative outcome.

Motivational orientation is a propensity to pursue rewards and avoid punishments. Implied outcomes, such as being popular, do not reflect motivational orientation; rather implied outcomes represent self-regulatory effectiveness/ineffectiveness. The Scott and Hauenstein (2011) finding that items with clear implied outcomes were retained and items with ambiguous implied outcomes were not retained raises concerns that self-report approach-avoidance measures may be contaminated by desirability of implied outcomes. More generally, the Scott and Hauenstein (2011) findings suggest a conundrum for measuring approach-avoidance motivational orientation. Items that do not imply positive/negative outcomes are less likely to measure approach-avoidance motivation well because the respondent cannot distinguish the 
propensity to approach rewards from the propensity to avoid punishments. In contrast, although items that imply positive/negative outcomes allow the respondent to distinguish approaching rewards from avoiding punishments, the desirability of implied outcomes potentially contaminates the measurement of approach-avoidance motivational orientation.

The potential contamination of implied outcomes is further complicated by the presumed dimensionality of approach-avoidance motivation. Currently, the "two-dimensional model" assumes approach and avoidance represent two orthogonal dimensions (Elliot \& Thrash, 2002). Regardless of whether the conceptual foundation of approach-avoidance is biological/trait or cognitive-affective, approach scales (e.g., Extraversion-Introversion, Mastery Goal Orientation, Promotion Regulatory-Focus) are oriented such that increasing approach motivation is associated with implied increasing gains, and avoidance scales (e.g., Neuroticism-Emotional Stability, Performance-Avoid Goal Orientation, Prevention Regulatory Focus) are oriented such that increasing avoidance motivation is associated with implied increasing losses. The confounding of approach motivation with implied increasing gains and avoidance motivation with implied increasing losses prevents the empirical examination of the contaminating effects of implied outcomes.

Moreover, the two-dimensional model fails to recognize that goal pursuits predicated on approach motivational orientation can lead to failures in acquiring rewards (i.e., "missed opportunities"), and goal pursuits based on avoidance motivation can lead to a broader success at avoiding punishments (e.g., Brockner \& Higgins, 2001; Freitas, Liberman, \& Higgins, 2002; Kuhnen \& Knutson, 2005). I propose an alternative model, the "four-dimensional model" of approach-avoidance motivation, whereby both approach motivation and avoidance motivation are measured in relation to both implied success and implied failure. I believe that the fourdimensional model is a more complete representation of the approach-avoidance construct space. Furthermore, unlike the two-dimensional model, the four-dimensional model affords the opportunity to empirically examine contamination due to implied outcomes. I will borrow the terminology of regulatory focus theory (Higgins, 1998) to further explicate the four-dimensional model. My choice of Higgins' terminology is not an endorsement of regulatory focus theory over other conceptualizations of approach-avoidance. Rather, Higgins' framework was chosen because it facilitates clarity in explicating a broader representation of approach-avoidance motivational orientation. 
According to regulatory focus theory, people react not only to the presence of positive outcomes ("gains") and negative outcomes ("losses"), but also to the absence of positive outcomes ("non-gains") and negative outcomes ("non-losses"). In order to illustrate the difference between these various orientations, consider the following hypothetical examples: (1) Purchasing a book that costs $\$ 65$, and the bookstore offers a $\$ 5$ discount for paying in cash (as opposed to credit card) - getting the discount is interpreted as a gain, whereas not getting the discount is interpreted as a non-gain; (2) Purchasing a book that costs $\$ 60$, and the bookstore charges a $\$ 5$ penalty for paying with a credit card (as opposed to cash) - not paying the penalty is interpreted as a non-loss, whereas paying the penalty is interpreted as a loss (examples adapted from Idson, Liberman, \& Higgins, 2000).

Success and failure in a promotion focus (i.e., the regulatory focus manifestation of approach) are experienced as increasing gains and increasing non-gains, respectively. Conversely, success and failure in a prevention focus (i.e., the regulatory focus manifestation of avoidance) are experienced as increasing non-losses and increasing losses, respectively (Higgins, Friedman, Harlow, Idson, Ayduck, \& Taylor, 2001). Scales designed to measure approach motivation as both increasing gains and increasing non-gains and avoidance motivation as increasing losses and increasing non-losses allows for an empirical examination of the contaminating effects of implied outcomes. Specifically, positive outcomes are implied by the increasing gains dimension of approach motivation and the increasing non-losses dimension of avoidance motivation, and negative outcomes are implied by the increasing non-gains dimension of approach motivation and the increasing losses dimension of avoidance motivation.

The current study aims to empirically evaluate the implied outcomes problem using a new data set that includes items retained in the Scott and Hauenstein (2011) factor analyses solutions, as well as edited and newly developed items. This new item set was constructed to clearly specify implied outcomes and to represent approach motivation as both increasing gains and increasing non-gains and avoidance motivation as increasing losses and increasing nonlosses. Prior to evaluating the contaminating effects of implied outcomes, I will first test whether the four-dimensional model is a tenable model of approach-avoidance motivational orientation, both in terms of specifying the first-order approach-avoidance construct space, and fitting the first-order construct space to the overarching approach-avoidance framework using the new data set. 


\section{3 - Summary}

Ultimately, the current study addresses three important issues related to measuring approach-avoidance motivation using self-report scales: the validity of the approach-avoidance overarching framework as evaluated from two different data sets, the validity of the proposed four-dimensional model, and the extent to which implied outcomes contaminate self-reports of approach-avoidance motivation. 


\section{0 - Literature Review}

As traditionally theorized, approach and avoidance are independent psychobiological systems that underpin broad aspects of human motivation. In approach motivation, behavior is instigated by and directed toward an event/possibility; in avoidance motivation, behavior is instigated by and directed away from an event/possibility (Elliot, 1999). Approach and avoidance appear to have evolved to promote the growth of organisms and protect them from harm, respectively. As such, approach-avoidance is often construed as "the foundation on which other motivational distinctions rest" (Elliot \& Covington, 2001, p. 2).

\section{1 - Approach-Avoidance Theories}

Several theories have been designed to address approach-avoidance motivation systems. For example, reinforcement sensitivity theory (RST) is a neurobiological model of personality based upon individual differences in reactions to rewarding and punishing stimuli (Smillie, 2008). Within RST, approach processes regulate sensitivity to reinforcing stimuli and are mediated by a hypothesized neurobiological Behavioral Activation System (BAS), while avoidance processes regulate sensitivity to punishing stimuli and are mediated by a hypothesized neurobiological Behavioral Inhibition System (BIS; Gray, 1976; Gray, 1987). “Approachoriented" individuals have a reactive BAS and are instinctively oriented toward acquiring positive outcomes (e.g., monetary rewards for correct and fast responses on a difficult reaction time task). In contrast, "avoidance-oriented" individuals have a reactive BIS and are instinctively sensitive to avoiding negative outcomes (e.g., monetary punishments for incorrect responses or slow responses on a difficult reaction time task; Larsen, Chen, \& Zelenski, 2003). Research has demonstrated that BAS and BIS activity are related to individual differences in impulsivity, i.e., a tendency to initiate behavior without forethought as to the consequences of one's action (Gray, 1991).

Risk-taking models of approach-avoidance suggest that individuals differ in their "willingness to take physical, social, legal, and financial risks" (Zuckerman, 1994, p. 27), and that these differences represent an important facet of human motivation. Although certain aspects of risk-taking are intuitively "biological" in nature (e.g., precipitate recklessness), other aspects involve more conscious, cognitive-affective goal pursuit (e.g., long-term financial planning). Risk-tolerant individuals tend to aggressively approach novel situations and are focused on potential rewards to the point of endangering themselves or others (Nicholson, Soane, 
Fenton-O'Creevy, \& Willman, 2005). Conversely, risk-averse individuals are security-oriented and take precautions when confronted with uncertainty (Lopes, 1987).

Trait models propose that individual personalities are composed of broad traits (i.e., basic psychological tendencies encoded in natural language) that are highly stable across time and context (e.g., McCrae \& Costa, 1990; Thompson, 2008). Within the context of approachavoidance, the basic personality dimensions of extraversion and neuroticism are commonly theorized to represent the trait manifestations of reward sensitivity and punishment sensitivity, respectively (Smillie, 2008). In general, extraversion is defined using characteristics such as sociable and active. This trait is marked by a pronounced responsiveness to the external world. Neuroticism is defined using characteristics such as anxious and emotionally unstable. Individuals high in neuroticism tend to become more upset over "daily, ordinary stressors" than those low in this trait (Costa \& McCrae, 1992).

Although cognitive-affective models of approach-avoidance motivation systems argue that behaviors in achievement situations are context-sensitive, individuals achieve a degree of cross-situational behavioral consistency due to chronically accessible cognitive structures relevant to achievement contexts (Mischel, 1973; Mischel \& Shoda, 1995; Shoda \& Mischel, 1996). For example, within the context of Higgins' (1999) regulatory focus theory, an individual with a chronic promotion focus is oriented toward accomplishments, hopes, and aspirations (ideals). Conversely, an individual with a chronic prevention focus is oriented toward safety, responsibilities, and obligations (oughts).

Another cognitive-affective theory designed specifically to address approach-avoidance motivation systems, goal orientation, posits chronic preferences to access cognitive motivational tendencies to approach task competence (i.e., mastery goal orientation, performance-prove goal orientation) and cognitive motivational tendencies to avoid task incompetence (i.e., performanceavoid goal orientation; Elliot, 1999). A mastery goal orientation (MGO) involves a focus on an objective, intrapersonal standard while enhancing one's task competence by developing new skills (Dweck \& Leggett, 1988). A performance-prove goal orientation (PPGO) involves striving for success in regard to a normative competence standard, with a concentration on approaching competence relative to others (McGregor \& Elliot, 2002). Finally, a performanceavoid goal orientation (PVGO) involves striving for a normative competence standard, with a 
concentration on avoiding incompetence relative to others (Elliot, 1997; Elliot \& McGregor, 1999).

The guiding purpose of the current study is to examine how best to fully represent and measure approach-avoidance motivational orientation using self-reports. As evident, approachavoidance is not a monolithic conception - it represents the foundation of various basic theories of personality (Elliot \& Thrash, 2002). The above theories were chosen because they cover the breadth of the approach-avoidance nomological network. Although the theories have been studied in different contexts, individual difference measures of approach-avoidance motivation have been created based on each conceptualization.

\section{2 - Prior Factor Analytic Research on Existing Approach-Avoidance Scales}

$\underline{\text { Identification of the First-Order Factors }}$

The current study represents a continuation of prior factor analytic research on the broad spectrum of existing approach-avoidance scales (i.e., Scott and Hauenstein, 2011). The principal aim of this prior research was to identify the first-order factor structure and to evaluate convergent and discriminant validity of existing self-reports of approach-avoidance motivational orientation when looking across the theoretical spectrum, from the distal (traits/biological systems) to the intermediary (psychogenic needs) to the proximal (cognitive-affective constructs). The sample in Scott and Hauenstein was split into a validation sample and a holdout sample. For the validation sample, they were interested in identifying emergent factors across the spectrum of approach-avoidance motivational orientations. Results of exploratory factor analyses (EFAs) were cross-validated using confirmatory factor analyses (CFAs). As noted above, $68 \%$ of the initial item pool was excluded based on failure to meet simple structure criteria. This resulted in the omission of several traditional approach-avoidance constructs. Specifically, factors reflecting Punishment Sensitivity/Reactivity (i.e., BIS), Impulsivity (i.e., the Fun Seeking facet of BAS), and Regulatory Focus Promotion failed to emerge in the EFAs. Traditional approach-avoidance constructs that emerged included Extraversion-Introversion (Sociability facet), Risk-Taking, Neuroticism-Emotional Stability (Negative Affect facet), Reward Responsiveness, Performance-Prove Goal Orientation, Performance-Avoid Goal Orientation, Mastery Goal Orientation, and Regulatory Focus Prevention.

Scott and Hauenstein (2011) suggested that ambiguity about implied outcomes was a likely cause of the majority of items failing simple structure criteria. Items that do not imply 
positive/negative outcomes appear to be poor indicators of approach-avoidance motivation because the respondent cannot distinguish the propensity to approach rewards from the propensity to avoid punishments. Moreover, recognizing the importance of reward/punishment context points to the fact that there is a notable absence of scales that measure increasing nongains when regulating behavior in the approach mode, and scales that measure increasing nonlosses when regulating behavior in the avoidance mode (see Idson, Liberman, \& Higgins, 2000). Fit Within the Second-Order Approach-Avoidance Structure

Empirical demonstrations of a two-factor approach-avoidance "meta-structure" underpinning various subfacets of motivational orientation are provided by Elliot and colleagues. For example, Elliot and Thrash (2002) found that measures of extraversion, neuroticism, positive emotionality, negative emotionality, BAS, and BIS are underpinned by two second-order factors representing approach temperament and avoidance temperament. Likewise, Elliot and Thrash (2010) found empirical support for the premise that approach and avoidance temperament represent the basic elements of goal orientation constructs. These findings suggest that it should be possible to replicate a second-order approach-avoidance structure in the current study with both the Scott and Hauenstein (2011) data set and the new data set. If the variance in scales oriented toward gains (and non-gains) can be explained by a common second-order factor, and the variance in scales oriented toward losses (and non-losses) can be explained by a common second-order factor, the argument can be made that approach and avoidance motivational orientation represent a principal source of item responses.

\section{3 - Implied Outcomes}

Outcome valence based on an implied reward or punishment is not recognized as a feature of modern approach-avoidance theories. For example, Elliot and Thrash (2002) stress the view that approach-avoidance motivational systems represent propensities that mediate responses to potential outcomes (i.e., reward or punishment is not assured). Moreover, Smillie (2008) is careful to differentiate the core of approach-avoidance - i.e., the "operational parameters" - from the "functional outcomes" of goal pursuits. Berkman and Lieberman (2010) have provided empirical neurobiological support for this notion by demonstrating that a hypothesized left-right prefrontal asymmetry is associated with approach-avoidance motivation independent of outcome valence. 
It should be noted that positive and negative valence, as presently conceptualized, may represent a number of potential contaminants to the measurement of approach-avoidance. For example, illusory superiority (see Colvin, Block, \& Funder, 1995), social desirability (see Paulhus, 1991), or other general response biases could all be the genesis of outcome valence. The current research does not aim to parse these different causes of outcome valence; rather these various measurement contaminants serve as non-specified indicators of the broader concepts of positive/negative valence.

I argue that within the framework of introspective self-reports, approach-avoidance motivational orientation has meaning in relation to specified reward/punishment contexts. This proposal is in line with current conceptualizations of approach-avoidance, in which approach tendencies are inherently associated with rewarding stimuli, while avoidance tendencies are inherently associated with punishing stimuli (Elliot, 1999). However, specifying implied rewards/punishments likely contaminates approach-avoidance self-reports with outcome valence. On this issue, Smillie (2008) argued that it seems "biologically and cognitively implausible" to suggest that individuals can introspect directly about their approach-avoidance propensities. Accordingly, Smillie speculated that in the context of self-reports, individuals are more likely reporting on the discernible positive or negative consequences of approach-avoidance than the motivational processes themselves. This problem is exacerbated by the current two-dimensional model of approach-avoidance that does not permit empirical examination of the potential contamination due to implied outcomes.

$\underline{\text { Two-Dimensional Model }}$

Regarding the two-dimensional model, a higher score on an approach item typically implies self-regulatory effectiveness in reward contexts (i.e., gains), whereas a higher score on an avoidance item typically implies self-regulatory ineffectiveness in punishment contexts (i.e., losses; see Figure 2). The two-dimensional model does not permit testing of implied outcome contamination because approach constructs are conflated with implied positive outcomes and avoidance constructs are conflated with implied negative outcomes.

Items representing non-gains and non-losses are not recognized in the two-dimensional approach-avoidance framework. This is because current self-report scales do not explicitly specify when an individual's approach-avoidance propensities tend to result in the absence of positive or negative outcomes. For example, the retained BAS item "When I get something I 
want, I feel excited and energized" taken from the BIS/BAS scales (Carver \& White, 1994) specifies an unequivocal increasing gains reward context (in this case, "When I get something I want"). However, the BIS/BAS scales do not contain any items that specify an increasing nongains reward context (e.g., "When I fail to get something I want").

Four-Dimensional Model

The four-dimensional model results in a first-order measurement structure of gains, nongains, losses, and non-losses. Higher scores on approach items reflect either increasing gains or increasing non-gains, while higher scores on avoidance items reflect either increasing losses or increasing non-losses (see Figure 3). The four-dimensional model permits an empirical examination of contamination due to implied outcomes because both approach and avoidance motivation are measured using scales that imply both positive outcomes (i.e., gains and nonlosses) and negative outcomes (i.e., non-gains and losses).

\section{4 - Analytic Strategy for New Data Set}

A new data set was used to assess the validity of the proposed four-dimensional model, and to evaluate the contaminating effects of implied outcomes. In this new data set, a large sample of undergraduates responded to approach-avoidance motivation items that included the retained items from the Scott and Hauenstein (2011) factor analyses solutions, and edited and newly developed approach-avoidance items. The edited and new items were constructed to clearly specify implied outcomes and to produce scales that represent approach motivation as both increasing gains and increasing non-gains, and avoidance motivation as increasing losses and increasing non-losses.

The analytic strategy for the new data set includes EFAs and CFAs. The goal of these factor analyses is to assess the psychometric properties of the edited/new items and to establish whether the proposed four-dimensional model of approach-avoidance is a viable alternative measurement structure. Presuming good fit for the first-order factor structure of the fourdimensional model, I will then evaluate the inclusion of second-order factors representing Gains, Non-Gains, Losses, and Non-Losses and attempt to fit the factor analyses solutions to the overarching approach-avoidance framework. Finally, in an effort to empirically demonstrate that outcome valence is not significantly contaminating self-reported approach-avoidance motivational orientation, the fit of hierarchical four-dimensional models will be compared to that 
of a hierarchical implied outcomes measurement structure of gains/non-losses and losses/nongains.

\section{5 - Overview}

The guiding purpose of the current study is to examine how best to measure approachavoidance motivational orientation using self-reports. There are three phases to this effort: (1) test competing CFAs using both the Scott and Hauenstein (2011) data set and the new data set to evaluate fit within the overarching approach-avoidance structure; (2) using the new data set, evaluate the validity of the proposed four-dimensional model; (3) evaluate the potential contamination of implied outcomes in the measurement of approach-avoidance motivational orientation.

As a measurement study, there are no formal hypotheses. However, I posit that approach and avoidance motivational orientation are a principal cause of self-report item responses. As such, for both data sets, I anticipate good fit - according to conventional criteria - for the itemlevel and scale-level hierarchical CFAs used to test the overarching approach-avoidance measurement structure. Based on Meredith's (1993) standards, I expect measurement invariance between the Scott and Hauenstein (2011) data set and the new data set, suggesting that items common to both data sets perform similarly. Additionally, I anticipate that the use of items with specified implied outcomes will improve the psychometric properties of approach-avoidance scales (as indicated by an increased item retention rate relative to the Scott and Hauenstein data and the emergence of all "traditional" approach-avoidance constructs in the factor analyses solutions for the new data). I also expect that the newly developed scales reflecting constructs that represent non-gains via approach and non-losses via avoidance will expand the approachavoidance construct space by emerging as meaningful factors that have adequate discriminant validity from gains scales and losses scales. Finally, while approach-avoidance measures may be contaminated by outcome valence based on an implied reward or punishment, I expect "below acceptable" fit (according to conventional criteria) for the second-order hierarchical CFA used to test the overarching implied outcomes measurement structure of gains/non-losses and losses/nongains. 


\section{0 - Method for Scott and Hauenstein Data Set}

\section{1 - Participants}

Participants were 1876 undergraduate students enrolled at a large public university in the Mid-Atlantic region; 379 participants were excluded (via listwise deletion in SPSS) due to missing data. The responses from 621 participants (42\% of the final sample) were randomly selected for the validation sample and the responses of the remaining 876 participants (58\% of the final sample) were used for the holdout sample. Participants were given extra course credit for participation.

\section{2 - Procedure}

Participants volunteered to participate through a university online research portal, and were subsequently directed to a survey website. The approach-avoidance motivational orientation items were presented in a random order.

\section{3 - Study 1 Approach-Avoidance Measures}

A total of 128 approach-avoidance items were included in the survey. Participants were asked to respond to each item using a five-point Likert scale, $1=$ strongly agree to $5=$ strongly disagree. Several scales phrased item stems as questions ["Do you sometimes do things for quick gains?"]. Question item stems were modified to statement item stems ["I sometimes do things for quick gains"] to allow responding on the Likert scale for all items.

\section{Reinforcement Sensitivity}

The two most popular reinforcement sensitivity scales were included, the BIS/BAS scales (Carver \& White, 1994) and the Sensitivity to Punishment and Sensitivity to Reward Questionnaire (SPSRQ; Torrubia, Avila, Molto, \& Caseras, 2001).

\section{BIS/BAS Scales}

In developing the BIS/BAS scales, Carver and White (1994) emphasized the role of BIS and BAS independent of context. The BIS scale (seven items) measures concerns regarding the occurrence of aversive, anxiety-provoking events and one's sensitivity and responses to such events ["I feel worried when I think I have done poorly at something important"]. The BAS scale was developed to measure potentially rewarding events and how people affectively respond to them along three sub-dimensions: The Drive subscale (four items) measures persistence in pursuing desired goals ["I go out of my way to get things I want"], the Fun Seeking subscale (four items) measures desire for and willingness to approach potentially rewarding events ["I 
often act on the spur of the moment"], and the Reward Responsiveness subscale (five items) measures positive responses to the occurrence or anticipation of reward ["When I get something I want, I feel excited and energized"].

\section{SPSRQ}

The major contrast between the SPSRQ (Torrubia et al., 2001) and the BIS/BAS scales is the inclusion of greater contextual information in the SPSRQ items. The SPSRQ is a 48-item questionnaire that consists of the Sensitivity to Punishment subscale (SP; 24 items), which measures BIS functioning ["Do you generally avoid speaking in public?"], and the Sensitivity to Reward subscale (SR; 24 items), which measures BAS functioning ["Do you sometimes do things for quick gains?'].

Personality Traits

The Extraversion (10 items) and Neuroticism (10 items) subscales from the IPIP Big-Five factor markers (Goldberg et al., 2006) were included as trait measures of approach-avoidance motivation. An example of an Extraversion item is "I am the life of the party.", and an example of a Neuroticism item is "I worry about things."

Psychogenic Needs

The Ray Achievement Motivation scale (nAch) is a 14-item scale ["Do you tend to plan ahead for your job or career?']. This scale was chosen because of its brevity, its consistent reliability, and its generally superior construct validity relative to other nAch instruments (Ray, 1979).

\section{Chronic Preferences}

Regarding chronic preferences for motivational orientation, scales measuring goal orientation and regulatory focus were included.

\section{Goal Orientation}

The Horvath, Scheu, and DeShon (2001) goal orientation scale is a 15-item questionnaire that consists of three subscales: five items measuring MGO ["The opportunity to learn new things is important to me"], five items measuring PPGO ["I want others to recognize that I am one of the best"], and five items measuring PVGO ["I try to avoid discovering that others are better than me"]. While a variety of self-report instruments have been developed for the purpose of assessing chronic goal orientation (e.g., Button, Mathieu, \& Zajac, 1996; Elliot \& Church, 1997; VandeWalle, 1997), the Horvath et al. measure was deemed most appropriate for the 
present study, as it assesses the three-factor conceptualization and contains no domain specificity. Moreover, the Horvath et al. measure incorporates the psychometrically best performing items from other popular goal orientation scales.

\section{Regulatory Focus Questionnaire}

The Higgins et al. (2001) Regulatory Focus Questionnaire (RFQ) is an 11-item questionnaire made up of two subscales. The 6-item Promotion subscale (PRO) measures approach motivational orientation ["Do you often do well at different things that you try?"] and the 5-item Prevention subscale (PRE) measures avoidance motivational orientation ["How often did you obey rules and regulations that were established by your parents?']. 


\section{0 - Results of Hierarchical Analyses of Scott and Hauenstein Data Set}

The first goal of the current study is to reanalyze the Scott and Hauenstein (2011) data in relation to the overarching approach-avoidance structure. Competing confirmatory models of approach-avoidance were tested - using the holdout sample of 876 participants - in AMOS version 18.0 (SPSS Inc., Chicago, IL) by comparing the Akaike Information Criterion (AIC) across models, with a lower AIC indicating better model fit. While this method is most suitable for comparing non-nested models (Kline, 1998), it does not allow for significance testing. Assessment of overall model fit was based on both absolute and relative fit indices. Absolute indices included the $\chi^{2}$ likelihood ratio test and the root mean square error of approximation (RMSEA) (Cudeck \& Browne, 1983; Steiger, 1988). Given the large sample size, the $\chi^{2}$ likelihood ratio test was interpreted with caution. A good fit of the model was indicated by a RMSEA of less than .08 (MacCallum, Browne, \& Sugawara, 1996). The Comparative Fit Index (CFI) (Bentler, 1990) was used to compare the $\chi^{2}$ from the tested model to one from the null model. A CFI value greater than .90 was considered indicative of good model fit.

In order to identify the CFAs in the current research, the metric of the latent factors was set by constraining a loading for each factor to 1 . Furthermore, factor variances and error variances were freely estimated, while error paths were set to 1. It should also be noted that the factor loadings reported in all of the structural diagrams are standardized, and can therefore exceed a magnitude of 1 .

The first model specified the eight factors from the final EFA solution (excluding the Conscientiousness factor) as first-order factors, with the underlying items as manifest indicators; the latent variables were allowed to correlate. According to conventional criteria, a good fit was indicated for this model with $\chi^{2}[712]=1514.820, \mathrm{p}<.001, \mathrm{CFI}=.926$, RMSEA $=.040$, and $\mathrm{AIC}=1968.820$.

The second model specified a second-order approach-avoidance "meta factor", denoted as the underlying causal mechanism for the eight first-order constructs. Again, the underlying items were specified as manifest indicators of the first-order constructs. The results for this model indicated a "below acceptable" fit with $\chi^{2}[732]=1937.721, \mathrm{p}<.001, \mathrm{CFI}=.893$, RMSEA $=.047$, and $\mathrm{AIC}=2351.721$.

The third and fourth models both specified two second-order factors, one for Approach and one for Avoidance. In the third model, Sociability was specified as an approach construct, 
and in the fourth model, Sociability was specified as an avoidance construct. For the third model, Sociability, Risk-Taking, Reward Responsiveness, Performance-Prove Goal Orientation, and Mastery Goal Orientation were specified as approach constructs, and Negative Affect, Performance-Avoid Goal Orientation, and Regulatory Focus Prevention were specified as avoidance constructs. The underlying items were specified as manifest indicators of the firstorder constructs. According to conventional criteria, a good fit was indicated for this model with $\chi^{2}[731]=1763.129, \mathrm{p}<.001, \mathrm{CFI}=.907, \mathrm{RMSEA}=.044$, and $\mathrm{AIC}=2179.129$.

The structural diagram for the hierarchical "Sociability as Approach" model is presented in Figure 4. The standardized factor loading estimates between the first-order factors and manifest indicators were low to high, ranging from .157 to 1.125. When factors are considered oblique, the standardized factor loading estimates are regression coefficients, and can therefore exceed a magnitude of 1 . That a certain standardized estimate was greater than 1 in the current model does not necessarily imply a problem with the data, although this may indicate that this variable (i.e., "Regulatory Focus Prevention 2") can likely be explained by other variables within this analysis (Babakus, Ferguson, \& Joreskog, 1987). The estimates between the second-order and first-order factors were low to high, ranging from .207 to .805 . Finally, the correlation between the second-order factors was -.218, indicating that Approach and Avoidance are orthogonal factors in this model.

Again, the only difference between the third model and fourth model was that Sociability was specified as an avoidance construct instead of an approach construct in the latter. The results for the fourth model indicated marginally decreased fit from the third model with $\chi^{2}$ [731] $=1777.779, \mathrm{p}<.001, \mathrm{CFI}=.906, \mathrm{RMSEA}=.044$, and $\mathrm{AIC}=2193.779$.

Finally, a fifth model was tested without the Sociability items. The results for this model indicated the best fit for this series of competing CFAs with $\chi^{2}[456]=959.662, \mathrm{p}<.001, \mathrm{CFI}=$ .934, RMSEA $=.040$, and AIC $=1279.662$.

The structural diagram for the hierarchical "Without Sociability" model is presented in Figure 5. The standardized factor loading estimates between the first-order factors and manifest indicators were low to high, ranging from .161 to .983. The estimates between the second-order and first-order factors were low to high, ranging from .283 to .830 . Finally, the correlation between the second-order factors was -.178, indicating that Approach and Avoidance are orthogonal factors in this model. 


\section{0 - Discussion of Hierarchical Analyses of Scott and Hauenstein Data Set}

As noted above, the first goal of the current study is to re-examine the data from Scott and Hauenstein (2011) in relation to the fit within the overarching approach-avoidance measurement structure. There is empirical precedent for this aim as prior research has demonstrated that the shared variance in a variety of approach-avoidance constructs can be explained by two second-order factors representing approach temperament and avoidance temperament (Elliot \& Thrash, 2002, 2010). The unacceptable fit for the second model supports ruling out a solitary second-order approach-avoidance "meta factor" as the causal mechanism underlying the eight first-order approach-avoidance factors. Conversely, the good fit (according to conventional criteria) for the third, fourth, and fifth models corroborates the prior research.

The issue of fitting the emergent constructs to the overarching approach-avoidance measurement structure is most germane in relation to Scott and Hauenstein's (2011) Sociability factor, where retained items derived from three different scales/subscales, two of which were hypothesized to reflect approach motivation (Reward Responsiveness and Extraversion), while the third scale was hypothesized to reflect avoidance motivation (Punishment Sensitivity). The better fit of the fifth model, which excluded Sociability, compared to the third and fourth models that specified Sociability as either an approach construct or an avoidance construct reflects the debate between Eysenck (e.g., 1967, 1971) and Gray (e.g., 1970, 1991) on the ambiguous role of extraversion within the approach-avoidance framework. However, this finding is surprising in light of current trait theories that maintain that extraversion is directly and exclusively linked to reward sensitivity (Costa \& McCrae, 1992; Lucas, Diener, Grob, Suh, \& Shao, 2000).

I expect that the scales developed for the new data set will more accurately capture the discriminant nuances of the various approach-avoidance constructs. Accordingly, this should reduce redundancy in the approach-avoidance construct space and allow for the clear emergence of an approach-oriented Extraversion factor. 


\section{0 - Method for New Data Set}

\section{1 - Participants}

Participants were 1010 undergraduate students enrolled at a large public university in the Mid-Atlantic region; missing data was nonexistent, as participants were required to complete all items prior to submitting their results. A random 58\% of the total sample (581 participants) was used for the EFAs, while the remaining $42 \%$ of the total sample (429 participants) was used as a hold-out sample for the CFAs. Participants completed all questionnaires online and were given extra course credit for participation.

\section{2 - Procedure}

The archival data was collected using the following procedure: The questionnaire was administered on an online survey software program. After following the website link to the survey provided from the Virginia Tech SONA system (the Psychology Department's online experiment management program), participants were provided with an online version of the "Informed Consent Form" (Appendix A). After reading and electronically signing the informed consent form, participants were then presented with brief directions for survey completion, which read as follows: "Please indicate your level of agreement with all of the following statements by selecting the corresponding response. There are no right or wrong answers - just answer what you think is true for you." All approach-avoidance items were measured using the following scale: 1 - Strongly disagree; 2 - Disagree; 3 - Neither agree nor disagree; 4 - Agree; 5 - Strongly agree. The ordering of measures was randomized for each participant using the online survey software program's advanced logic features. However, in an effort to assess response consistency, six items from the IPIP Extraversion scale (Goldberg et al., 2006) were constrained to be repeated within the first and second halves of the inventory (for additional details, see the section below on Problem Respondents). At the completion of the survey, the participants were provided with an online version of the "Debriefing Form" (Appendix B).

\section{3 - Study 2 Approach-Avoidance Measures (See Appendix C)}

The new data set includes approach-avoidance self-reports from existing scales, revised scales, and new scales. New scales were created for proposed constructs that currently lack a validated self-report instrument. Furthermore, new items were added to existing scales to increase the number of items and to clarify reward/punishment context. For example, an item from the Impulsivity subscale of the Personality Research Form (PRF; Jackson, 1984) includes 
the traditionally negatively-valenced term "hasty", which could be interpreted in terms of increasing non-gains via impulsivity or increasing losses via impulsivity. However, the new item "I miss out on opportunities because I'm impulsive" was written to emulate the existing PRF items while more explicitly specifying a singular reward/punishment context (in this case, "missed opportunities" as an increasing non-gains reward context). As such, the general strategy for editing and creating new items was to clarify reward/punishment context in relation to gains, non-gains, losses, and non-losses.

Table 1 indicates constructs that were measured using existing scales, and constructs where existing items were modified or new items were written (designated as "New Items"). As evident, certain constructs have "context fully specified" (i.e., there is a facet identified under each heading of gains, non-gains, losses, and non-losses). These constructs include:

Reinforcement Sensitivity, Impulsivity, Regulatory Focus, Extraversion, and Risk-Taking. Constructs for which "context is not fully specified" include: Mastery Goal Orientation, Performance Goal Orientation, and Neuroticism.

Reinforcement Sensitivity

Reinforcement Sensitivity - Gains

Three marker items from the Reward Responsiveness subscale of the BIS/BAS scales (Carver \& White, 1994) were used to measure increasing gains via reinforcement sensitivity. These items were chosen because they were retained in the Scott and Hauenstein (2011) factor analyses solutions. In addition, five new items were written to reflect increasing gains through sensitivity to rewards (e.g., "I intensely feel the excitement of earning a reward").

\section{Reinforcement Sensitivity - Non-Gains}

Eight new items were created to measure increasing non-gains via reinforcement sensitivity (e.g., "I have difficulty controlling my excitement"). This new scale was designed to measure perceived missed opportunities due to overexcitement to acquire potential rewards.

\section{Reinforcement Sensitivity - Losses}

Eight new items were created to measure increasing losses via reinforcement sensitivity (e.g., "I am overanxious about potential threats"). Although a factor containing items purported to measure this construct emerged in the Scott and Hauenstein (2011) factor analyses, the language of those items appears to assess social withdrawal more than BIS (e.g., "I am a shy person"). Therefore, new items were created to measure reinforcement sensitivity-losses. These 
items were constructed to measure the failure to avoid punishments due to an overreliance on anxiety-based avoidance motivation.

\section{Reinforcement Sensitivity - Non-Losses}

Eight new items were created to measure increasing non-losses via reinforcement sensitivity (e.g., "My keen sense of threats has kept me safe"). This new scale was designed to measure the perceived ability to accurately assess and avoid potential threats as a result of instinctive vigilance.

Impulsivity

Impulsivity is a traditional approach-avoidance construct that did not emerge in the Scott and Hauenstein (2011) factor analyses. Therefore, I included impulsivity items from other existing scales and constructed new impulsivity items.

Impulsivity - Gains

Eight new items were written to measure increasing gains via impulsivity (e.g., "I make decisions quickly and effectively"). The scale was designed to measure an individual's decisive nature while clearly specifying the rewards that one might accrue from such a nature.

\section{Impulsivity - Non-Gains}

Three new items were written to complement five existing items from the Impulsivity subscale of the PRF (Jackson, 1984) to measure increasing non-gains via impulsivity. The PRF items were chosen because they imply negative outcomes due to hastiness. It should be noted that the PRF items are not included in Appendix $\mathrm{C}$ due to copyright constraints. The new items were written to emulate the existing items with a greater emphasis on clear specification of the reward context as non-gains (e.g., "I miss out on opportunities because I'm impulsive").

\section{Impulsivity - Losses}

Eight new items were created to measure increasing losses via impulsivity (e.g., "I tend to over-analyze"). This new scale was designed to measure low impulsivity as causing the failure to avoid punishment. [See Gray and McNaughton (2000) for a neuropsychological-based discussion on this "analysis paralysis" phenomenon.]

\section{Impulsivity - Non-Losses}

Eight new items were created to measure increasing non-losses via impulsivity (e.g., "I avoid mistakes by being patient"). This new scale was designed to measure low impulsivity as the cause of avoiding punishment. 


\section{$\underline{\text { Regulatory Focus }}$}

Although Higgins' (1999) regulatory focus theory inherently recognizes the overarching four-factor structure of gains, non-gains, losses, and non-losses, existing self-report measures purported to reflect the theory appear not to capture all of these construct manifestations. The most frequently used regulatory focus measure is the RFQ, which contains the Promotion subscale and Prevention subscale, each intended to reflect subjective histories of success in goal attainment (Higgins et al., 2001). In the Scott and Hauenstein (2011) study, every item from the Promotion subscale failed the simple structure criteria. Although items on the Prevention subscale emerged as a separate factor, the estimate of construct relevant variance may have been inflated because all Prevention items reference the parental relationship. Scott and Hauenstein suggested that future research should clarify that which makes chronic regulatory focus distinct from other approach-avoidance constructs within the overarching four-factor structure of gains, non-gains, losses, and non-losses.

Like other approach-avoidance theories, promotion and prevention regulatory focus relate to proximal rewards and punishments, respectively. However, regulatory focus is distinguished from other approach-avoidance constructs by the inclusion of broader life goals. Therefore, the content domains of new promotion regulatory focus items developed for the current study emphasized aspirations and future-oriented ideals. Similarly, the content domains for the new prevention focus items emphasized broad "life responsibilities" (cf. Crowe \& Higgins, 1997; Higgins, 1999).

\section{Regulatory Focus - Gains}

Eight new items were created to measure increasing gains via regulatory focus (e.g., "Pursuing my hopes and aspirations is when I'm most effective"). This scale was designed to measure increasing gains due to the pursuit of broader life goals.

\section{Regulatory Focus - Non-Gains}

Eight new items were created to measure increasing non-gains via regulatory focus (e.g., "I have missed out on opportunities by chasing my dreams"). This scale was designed to measure increasing non-gains due to the pursuit of broader life goals.

\section{Regulatory Focus - Losses}


Eight new items were created to measure increasing losses via regulatory focus (e.g., "I focus too much on the person others tell me I ought to be"). This scale was designed to measure increasing losses due to the pursuit of perceived life obligations.

\section{Regulatory Focus - Non-Losses}

Eight new items were created to measure increasing non-losses via regulatory focus (e.g., "I effectively avoid letting others down"). This scale was designed to measure increasing nonlosses due to the pursuit of perceived life obligations.

\section{Mastery Goal Orientation}

The Horvath et al. (2001) goal orientation measure was included in the Scott and Hauenstein (2011) construct validation study, and all items were loaded on the assigned goal orientation subscale, and each goal orientation subscale was found to have adequate discriminant validity from the other factors. Given that reward/punishment context is represented or implied in each goal orientation item and taking into account the construct validity evidence for goal orientation, the Horvath et al. (2001) scale was included without any item modifications.

\section{Mastery Goal Orientation - Gains}

The five-item MGO subscale from the Horvath et al. (2001) scale was included as a measure of increasing gains via mastery goal orientation.

\section{Performance Goal Orientation}

\section{Performance Goal Orientation - Gains}

The five-item PPGO subscale from the Horvath et al. (2001) scale was included as a measure of increasing gains via performance goal orientation.

\section{Performance Goal Orientation - Non-Gains}

Eight new items were created to measure increasing non-gains via performance goal orientation. A recent meta-analysis found equivocal criterion-related validity for PPGO as a predictor of goal setting, self-efficacy, and various performance categories (Payne, Youngcourt, $\&$ Beaubien, 2007). The consistently small and variable relationships between PPGO scores and important organizational criteria suggest possible criterion deficiency regarding goal orientation related to performance.

Research has shown that a competitive nature can manifest as hyper-competitiveness, thereby increasing non-gains (e.g., Ryckman, Thornton, \& Butler, 1994). Greater precision and clarification of reward context may reduce criterion deficiency and improve the criterion-related 
validity of PPGO scores. Accordingly, new PPGO items were created to frame performance goals in terms of increasing non-gains (e.g., "I miss out on opportunities by being overly competitive"). To illustrate this concept, consider an individual whose desire to "win at all costs" hurts his or her chances at forming new relationships.

\section{Performance Goal Orientation - Losses}

The five-item PVGO subscale from the Horvath et al. (2001) scale was included as a measure of increasing losses via performance goal orientation.

$\underline{\text { Extraversion }}$

\section{Extraversion - Gains/Losses}

As noted above, the results from the hierarchical analyses of the Scott and Hauenstein (2011) data lend support to the proposal that extraversion may not be exclusively associated with either approach or avoidance (e.g., Gray, 1991). Accordingly, six items from the Extraversion IPIP Big-Five factor inventory (Goldberg et al., 2006) were utilized as a measure of increasing gains and increasing losses due to varying levels of extraversion.

\section{Extraversion - Non-Gains}

Eight new items were created to measure increasing non-gains via extraversion (e.g., "I miss out on things by not listening well”).

\section{Extraversion - Non-Losses}

Furthermore, eight new items were created to measure increasing non-losses via extraversion (e.g., "I use silence to gather my thoughts").

$\underline{\text { Neuroticism }}$

\section{Neuroticism - Losses}

Six items from the neuroticism IPIP Big-Five factor inventory (Goldberg et al., 2006) were utilized as a measure of increasing losses due to neuroticism. As neuroticism reflects needless anxiety that should manifest only as increased losses (i.e., this trait is strictly maladaptive and does not have meaning in reward contexts; Gunthert, Cohen, \& Armeli, 1999), I did not use the same scale to measure increasing gains. Likewise, I did not create scales to measure increasing non-losses or increasing non-gains via neuroticism.

\section{$\underline{\text { Risk-Taking }}$}

Individual differences in risk-taking have long been considered a critical aspect of approach-avoidance motivation (e.g., Knowles, Cutter, Walsh, \& Casey, 1973). However, the 
risk-taking construct has yet to be psychometrically assessed within the overarching four-factor structure of gains, non-gains, losses, and non-losses.

\section{Risk-Taking - Gains}

To measure increasing gains via risk-taking, four new items were created and used with two existing items from the Drive subscale of the BIS/BAS scales (Carver \& White, 1994) and two existing items from the Reward Sensitivity subscale of the SPSRQ (Torrubia et al., 2001). The existing items were chosen because they emerged clearly in prior factor analytic research (i.e., Scott \& Hauenstein, 2011). The new items were written to emulate the existing items with a greater emphasis on reward context (e.g., "I prefer riskier investments that have the potential for big returns").

\section{Risk-Taking - Non-Gains}

Eight new items were created to measure increasing non-gains via risk-taking. This new scale attempts to capture a void in risk-taking self-reports, i.e., a propensity to miss out on opportunities because of a reckless nature (e.g., "I tend to overlook 'a sure thing' because of my risky nature").

\section{Risk-Taking - Losses}

Eight new items were created to measure increasing losses via risk-taking (e.g., "Taking too many precautions has held me back in life"). This scale was developed to test the dimensionality of risk-taking, as risk aversion is traditionally interpreted as the low pole of risk tolerance measures (see Rohrmann, 2005).

\section{Risk-Taking - Non-Losses}

Eight new items were created to measure increasing non-losses via risk-taking. This new scale was designed to measure the propensity to avoid punishments through prudence (e.g., "I avoid losses by investing conservatively”). 


\section{0 - Results of New Data Set}

\section{1 - Problem Respondents}

Responses in the new data set were visually inspected for problematic, systematic response patterns that likely indicated participants were responding without reading the questions. Furthermore, six items from the IPIP Extraversion scale (Goldberg et al., 2006) were repeated within the first and second halves of the assessment. Within-test consistency was assumed if at least four of the six repeated item responses were identical or "near identical" (i.e., plus or minus one response option). A failure to meet this response consistency criterion (adapted from Edwards, 1957) resulted in the participant's data being excluded from analysis. On the basis of this within-test consistency criteria, 41 participants' data were excluded from the EFAs, resulting in an initial validation sample size of $n=540$. The number of participants used in the present study met the factor analysis criterion of greater than 2 cases for each item and a minimum sample size of 250 (Cattell, 1978; Kline, 1979; MacCallum, Widaman, Zhang, \& Hong, 1999).

\section{2 - Tests of Measurement Invariance Between Data Sets}

Tests of measurement invariance between the Scott and Hauenstein (2011) data set and the new data set were conducted to examine if common items performed similarly in both data sets (common items are indicated by asterisks in Appendix C). I tested for configural and factorial invariance in AMOS version 18.0 (SPSS Inc., Chicago, IL).

Two groups were created, one representing the common items and their underlying latent variables in the context of the original Scott and Hauenstein (2011) data, set and one representing the common items and their underlying latent variables in the new data set. According to conventional criteria, a good fit was indicated for this free model with $\chi^{2}[556]=787.936, p<$ $.001, \mathrm{CFI}=.957$, and RMSEA $=.029$. In the context of configural invariance testing, good model fit indicates that one is working with roughly equivalent groups with regards to the factor structure. However, in order to obtain a stricter assessment of measurement invariance, several parameters must be constrained to be equal across groups (Meredith, 1993).

Therefore, to test for strong factorial invariance (see Meredith, 1993) across groups, the model's factor loadings and loading intercepts were constrained to be equal across groups. Again, according to conventional criteria, a good fit was indicated for this constrained model with $\chi^{2}[582]=999.521, \mathrm{p}<.001, \mathrm{CFI}=.931$, and RMSEA $=.036$. Because the current research 
does not aim to assess differences in prediction across groups, strong factorial invariance is the strictest form of measurement invariance necessary (i.e., testing for strict factorial invariance and/or structural invariance is not required; Byrne, Shavelson, \& Muthen, 1989).

\section{3 - Exploratory Factor Analyses of the Two-Dimensional Model}

The first set of factor analyses assessed the two-dimensional model (see Figure 2). Items representing non-gains and non-losses are not recognized in this current approach-avoidance framework and were therefore not included in these analyses.

An exploratory analysis including all 91 of the gains and losses items from the new data set (see Appendix C) was run to examine the factor structure for the two-dimensional model. A Bartlett test of sphericity was applied to test whether correlations differed significantly from zero $(\mathrm{p}=.000)$. Furthermore, a Kaiser-Meyer-Olkin (KMO) measure of sampling adequacy was applied to index the proportion of variance among the variables that might be common variance (i.e., that might be indicative of underlying or latent common factors; KMO = .912). EFAs using principal axis factoring (PAF) were carried out in SPSS version 18.0 (SPSS Inc., Chicago, IL). After extraction, the resulting factors were obliquely rotated via direct oblimin procedure.

An initial 10-factor solution (explaining $55.1 \%$ of the variance) was deemed to provide the best fit based on factor interpretability and an examination of the scree plot (see Figure 6). Upon examination of this initial solution, 21 items were eliminated because they did not contribute to simple structure, i.e., these items failed to meet a minimum criteria of having a primary factor loading of .4 or above, and no cross-loading of .3 or more. As such, an item that fails the simple structure criteria cannot be interpreted as lacking construct validity for any motivational orientation construct; however, such items are, at best, not unique indicators of an approach-avoidance construct. I chose the simple structure criteria because my goal is to identify unique indicators of each factor.

Neuroticism did not emerge as a separate factor; instead the Neuroticism items loaded with the Reinforcement Sensitivity-Losses items. Furthermore, the Losses facet of Impulsivity and the Gains facet of Risk-Taking did not emerge. The remaining scales emerged with varying degrees of item retention.

I repeated the EFA on the 70 retained items from the initial EFA. Both the Bartlett test of sphericity $(\mathrm{p}=.000)$ and the KMO measure of sampling adequacy $(\mathrm{KMO}=.901)$ suggested satisfactory factorability. As with the initial EFA, 10 factors were retained (explaining $60.6 \%$ of 
the variance). The resulting factors were obliquely rotated using direct oblimin. The pattern matrix for this revised solution is presented in Table 2. It should be noted that Table 2 is constructed so that the factors and the corresponding items relevant to each factor are grouped by theoretical perspective as opposed to extraction order. The factor labels chosen were synonymous with scale labels. Table 3 indicates the number of items retained from each factor (the total number of items initially) / and coefficient alpha of the retained items; the Neuroticism items are counted with the Reinforcement Sensitivity-Losses items.

\section{4 - Confirmatory Factor Analysis for the Two-Dimensional Model}

CFAs were conducted to cross-validate the final EFA solutions using an independent sample. The basic question answered with these CFAs is whether a factor structure specified in advance matches the exploratory, data-driven results (Byrne, 1989; Pedhazur \& Schmelkin, 1991). On the basis of the within-test consistency criteria outlined above (adapted from Edwards, 1957), 37 participants' data were excluded from the CFAs, resulting in a hold-out sample size of $n=392$. CFAs were carried out in AMOS version 18.0 (SPSS Inc., Chicago, IL) with all parameters estimated using maximum likelihood estimation. The AIC was compared across competing models, with a lower AIC indicating better model fit. Again, while this method is most suitable for comparing non-nested models (Kline, 1998), it does not allow for significance testing. It should be noted that while the AIC will be reported for all confirmatory models, it would be inappropriate to compare the AIC between the two-dimensional model and the four-dimensional model in light of the large difference in number of specified manifest variables. Assessment of overall model fit was based on both absolute and relative fit indices.

Item parcels were created by combining 2-3 adjacent items within scales to create score aggregates that could then be subjected to CFA (Bandalos \& Finney, 2001). Combining items into parcels results in more parsimonious model tests. Fitting more parsimonious models to reproduce fewer estimated population values in the matrix of associations reduces the effects of sampling error in the estimation process (Gorsuch, 1983).

On the basis of the EFA results, the confirmatory analysis for the two-dimensional model specified six first-order approach factors worded as implied gains, Reinforcement SensitivityGains (i.e., Reward Sensitivity), Extraversion-Gains, Impulsivity-Gains, Regulatory Focus-Gains (i.e., Promotion Regulatory Focus), Mastery Goal Orientation-Gains, Performance Goal Orientation-Gains (i.e., PPGO), and four first-order avoidance factors worded as implied losses, 
Reinforcement Sensitivity-Losses (i.e., Punishment Sensitivity), Regulatory Focus-Losses (i.e., Prevention Regulatory Focus), Performance Goal Orientation-Losses (i.e., PVGO), and RiskTaking-Losses. The 70 items retained from the final EFA solution were combined into parcels and utilized as manifest indicators; the latent variables were allowed to correlate. According to conventional criteria, a good fit was indicated for this model with $\chi^{2}[254]=505.014, p<.001$, $\mathrm{CFI}=.965, \mathrm{RMSEA}=.050$, and $\mathrm{AIC}=751.014$.

The structural diagram for the two-dimensional model is presented in Figure 7. The standardized factor loading estimates between the first-order factors and manifest indicators were uniformly high, ranging from .757 to .949 . Factor intercorrelations were estimated for this model, but are presented in a separate table due to space constraints.

The factor intercorrelation matrix for the two-dimensional model is presented in Table 4. The factor intercorrelations were low to moderate - ranging from .006 to .594 - thereby suggesting that the factors are distinct, yet interrelated (Brown, 2006). The low correlations were found between the Gains and Losses factors; the moderate correlations were found within the Gains and Losses factors. This pattern of correlations is indicative of a second-order approach-avoidance structure.

\section{5 - Hierarchical Approach-Avoidance Confirmatory Factor Analysis for the Two- Dimensional Model}

To test the two-dimensional model within the overarching approach-avoidance measurement structure a hierarchical CFA was conducted in which a second-order Approach factor was specified as underpinning the emergent first-order gains factors and a second-order Avoidance factor was specified as underpinning the emergent first-order losses factors. The 70

items retained from the final EFA solution were merged into parcels (by combining 2-3 adjacent items within scales to create score aggregates) and utilized as manifest indicators; the latent variables were allowed to correlate. According to conventional criteria, a good fit was indicated for this hierarchical model with $\chi^{2}[288]=576.366, \mathrm{p}<.001, \mathrm{CFI}=.960, \mathrm{RMSEA}=.051$, and $\mathrm{AIC}=754.366$.

The structural diagram for the hierarchical two-dimensional model is presented in Figure 8. The standardized factor loading estimates between the first-order factors and manifest indicators were uniformly high, ranging from .757 to .949 . The estimates between the secondorder and first-order factors were also uniformly high, ranging from .655 to .777 . Finally, the 
correlation between the second-order factors was -.014, indicating that Approach and Avoidance are orthogonal factors in this model.

\section{6 - Exploratory Factor Analyses of the Four-Dimensional Model}

The next set of EFAs was conducted to identify the items to be retained for evaluating the adequacy of the four-dimensional model (see Figure 3). The initial exploratory analysis included all 179 of the approach-avoidance items from the new data set (see Appendix C). A Bartlett test of sphericity was applied to test whether correlations differed significantly from zero $(p=.000)$. Furthermore, a KMO measure of sampling adequacy was applied to index the proportion of variance among the variables that might be common variance (i.e., that might be indicative of underlying or latent common factors; KMO = .872). EFAs using PAF were carried out in SPSS version 18.0 (SPSS Inc., Chicago, IL). After extraction, the resulting factors were obliquely rotated via direct oblimin procedure.

An initial 17-factor solution (explaining 53.6\% of the variance) was deemed to provide the best fit based on factor interpretability and an examination of the scree plot (see Figure 9). Upon examination of this initial solution, 59 items were eliminated because they did not contribute to simple structure, i.e., these items failed to meet a minimum criteria of having a primary factor loading of .4 or above, and no cross-loading of .3 or more. As such, an item that fails the simple structure criteria cannot be interpreted as lacking construct validity for any motivational orientation construct; however, such items are, at best, not unique indicators of an approach-avoidance construct. I chose the simple structure criteria because my goal is to identify unique indicators of each factor.

Seven of the eight proposed approach-avoidance constructs were represented by at least one factor. Again, Neuroticism did not emerge as a separate factor; instead the Neuroticism items loaded with the Reinforcement Sensitivity-Losses items. Of the four approach-avoidance constructs theorized to be represented by four facets (i.e., Gains, Non-Gains, Losses, NonLosses), all four facets emerged for Reinforcement Sensitivity and Regulatory Focus. The Losses and Non-Losses facets of Impulsivity and the Gains and Non-Gains facets of Risk-Taking

did not emerge. The three traditional goal orientation scales (Mastery, Performance-Prove, and Performance-Avoid) emerged, but all the new items designed to measure Performance Goal Orientation-Non-Gains failed to meet simple structure criteria. For Extraversion, the traditional items emerged as a factor. Of the newly developed scales for Extraversion, the 
Extraversion-Non-Losses facet emerged, but the Extraversion-Non-Gains facet did not emerge.

I repeated the EFA on the 120 retained items from the initial EFA. Both the Bartlett test of sphericity $(\mathrm{p}=.000)$ and the KMO measure of sampling adequacy (KMO = .880) suggested satisfactory factorability. As with the initial EFA, 17 factors were retained (explaining $60.2 \%$ of the variance). The resulting factors were obliquely rotated using direct oblimin. The pattern matrix for this revised solution is presented in Table 5. It should be noted that Table 5 is constructed so that the factors and the corresponding items relevant to each factor are grouped by theoretical perspective as opposed to extraction order. The factor labels chosen were synonymous with scale labels. Table 6 indicates the number of items retained from each factor (the total number of items initially) / and coefficient alpha of the retained items; the Neuroticism items are counted with the Reinforcement Sensitivity_Losses items.

\section{7 - Confirmatory Factor Analysis for the Four-Dimensional Model}

On the basis of the EFA results, the confirmatory analysis for the four-dimensional model specified six first-order increasing gains factors (for Reinforcement Sensitivity, Impulsivity, Regulatory Focus, Mastery Goal Orientation, Performance Goal Orientation, and Extraversion), three first-order increasing non-gains factors (for Reinforcement Sensitivity, Impulsivity, and Regulatory Focus), four first-order increasing losses factors (for Reinforcement Sensitivity, Regulatory Focus, Performance Goal Orientation, and Risk-Taking), and four first-order increasing non-losses factors (for Reinforcement Sensitivity, Regulatory Focus, Extraversion, and Risk-Taking). The 120 items retained from the final EFA solution were merged into parcels (by combining 2-3 adjacent items within scales to create score aggregates) and utilized as manifest indicators; the latent variables were allowed to correlate. According to conventional criteria, a good fit was indicated for this model with $\chi^{2}[853]=1414.472, \mathrm{p}<.001, \mathrm{CFI}=.956$, RMSEA $=.041$, and AIC $=1962.472$.

The structural diagram for the four-dimensional model is presented in Figure 10. The standardized factor loading estimates between the first-order factors and manifest indicators were uniformly high, ranging from .755 to .949 . Factor intercorrelations were estimated for this model, but are presented in a separate table due to space constraints.

The factor intercorrelation matrix for the four-dimensional model is presented in Table 7. The factor intercorrelations were low to moderate - ranging from .001 to .604 - thereby 
suggesting that the factors are distinct, yet interrelated (Brown, 2006). The low correlations were found between the Gains and Losses factors, the Gains and Non-Losses factors, the Losses and Non-Gains factors, and the Non-Gains and Non-Losses factors; the moderate correlations were found within and between the Gains and Non-Gains factors and within and between the Losses and Non-Losses factors. This pattern of correlations is indicative of a second-order approach-avoidance structure.

\section{8 - Hierarchical Approach-Avoidance Confirmatory Factor Analysis for the Four- Dimensional Model}

To test the four-dimensional model a hierarchical CFA was conducted in which four second-order factors representing Gains, Non-Gains, Losses, and Non-Losses were specified as underpinning the emergent first-order gains, non-gains, losses, and non-losses factors, respectively. Again, the 120 items retained from the final EFA solution were merged into parcels and utilized as manifest indicators; the latent variables were allowed to correlate. According to conventional criteria, a good fit was indicated for this hierarchical model with $\chi^{2}$ $[966]=1726.432, \mathrm{p}<.001, \mathrm{CFI}=.941, \mathrm{RMSEA}=.045$, and $\mathrm{AIC}=2048.432$.

The structural diagram for this hierarchical model is presented in Figure 11. The standardized factor loading estimates between the first-order factors and manifest indicators were uniformly high, ranging from .758 to .947 . The estimates between the second-order and firstorder factors were moderate to high, ranging from .651 to .790. Finally, the correlations between the second-order factors indicate that Gains and Non-Gains are highly related (-.744), while Losses and Non-Losses are highly related (-.838); the remaining second-order factor interrelationships are orthogonal in this model (correlations ranged from -.002 to .079).

\section{9 - Scale-Level Hierarchical Approach-Avoidance Confirmatory Factor Analysis for the Four-Dimensional Model}

To test the validity of the four-dimensional model within the overarching approachavoidance measurement structure a scale-level hierarchical CFA was conducted in which a second-order Approach factor was specified as underpinning a first-order Gains factor and firstorder Non-Gains factor and a second-order Avoidance factor was specified as underpinning a first-order Losses factor and first-order Non-Losses factor. Scale averages were created with the 120 items retained from the final EFA solution and utilized as manifest indicators; the latent variables were allowed to correlate. According to conventional criteria, a good fit was indicated 
for this scale-level hierarchical model with $\chi^{2}[114]=308.502, \mathrm{p}<.001, \mathrm{CFI}=.915, \mathrm{RMSEA}=$ .065 , and $\mathrm{AIC}=416.502$.

The structural diagram for this scale-level hierarchical model is presented in Figure 12. The standardized factor loading estimates between the first-order factors and manifest indicators were moderate to high, ranging from .614 to .740 . The estimates between the second-order and first-order factors were moderate to high, ranging from -.422 to 1.780 . When factors are considered oblique, the standardized factor loading estimates are regression coefficients, and can therefore exceed a magnitude of 1 . That certain standardized estimates were greater than 1 in this model is likely due to the strong associations between Gains and Non-Gains and Losses and Non-Losses (i.e., Non-Gains/Non-Losses scores are relatively indicative of Gains/Losses scores). Finally, the correlation between the second-order factors was .010, indicating that Approach and Avoidance are orthogonal factors in this model.

\subsection{0 - Confirmatory Factor Analysis for the Implied Outcomes Model}

Given the empirical support for the four-dimensional model, the final goal of the current research is to examine the potential contamination of implied outcomes in the measurement of approach-avoidance. A confirmatory analysis for the implied outcomes model specified a second-order Positive Valence factor as underpinning the first-order gains and non-losses factors and a second-order Negative Valence factor as underpinning the first-order losses and non-gains factors. Specifically, Reinforcement Sensitivity (Gains and Non-Losses), Impulsivity (Gains), Regulatory Focus (Gains and Non-Losses), Mastery Goal Orientation (Gains), Performance Goal Orientation (Gains), Extraversion (Gains and Non-Losses), and Risk-Taking (Non-Losses) were specified as loading on Positive Valence. Reinforcement Sensitivity (Losses and Non-Gains), Impulsivity (Non-Gains), Regulatory Focus (Losses and Non-Gains), Performance Goal Orientation (Losses), and Risk-Taking (Losses) were specified as loading on Negative Valence. The 120 items retained from the final EFA solution were merged into parcels (by combining 2-3 adjacent items within scales to create score aggregates) and utilized as manifest indicators; the latent variables were allowed to correlate. According to conventional criteria, a "below acceptable" fit was indicated for this model with $\chi^{2}[971]=2745.038, \mathrm{p}<.001, \mathrm{CFI}=.862$, RMSEA $=.068$, and $\mathrm{AIC}=3057.038$.

The structural diagram for the implied outcomes model is presented in Figure 13. The standardized factor loading estimates between the first-order factors and manifest indicators were 
moderate to high, ranging from .393 to 1.657. Again, that certain standardized estimates were greater than 1 in this model may be indicative of measurement redundancy (Babakus, Ferguson, \& Joreskog, 1987). For example, based on factor intercorrelations (see Table 7), a portion of the variance in Impulsivity - Gains scores can likely be explained by Impulsivity - Non-Gains scores. The estimates between the second-order and first-order factors were low to high, ranging from .007 to .794 . As evident, uniformly low first-order to second-order factor loadings were observed for the Gains and Non-Gains factors. Conversely, uniformly high first-order to secondorder factor loadings were observed for the Losses and Non-Losses factors. Consequently, it appears that neither Gains and Non-Losses nor Losses and Non-Gains share a common source. Finally, the correlation between the second-order factors was -.838, indicating that Positive Valence and Negative Valence are not orthogonal factors in this model. 


\section{0 - Discussion of New Data Set}

\section{1 - Two-Dimensional Model}

Prior two-dimensional research has found that self-reported BAS, extraversion, MGO, and PPGO are underpinned by an approach temperament, while self-reported BIS, neuroticism, and PVGO are underpinned by an avoidance temperament (Elliot \& Thrash, 2002, 2010). However, Scott and Hauenstein (2011) found that the majority of items from the most popular approach-avoidance scales do not meet simple structure criteria when analyzed together; they also found that the traditional approach-avoidance constructs of Punishment Sensitivity, Impulsivity, and Regulatory Focus Promotion did not emerge.

The EFA results for the new data set indicate that the specification of implied outcomes within the two-dimensional framework of gains and losses resulted in a higher item retention rate, 77\% versus 32\% in Scott and Hauenstein (2011), and at least one facet of all traditional approach-avoidance constructs emerged in the new data set. Greater item retention and expanded construct domains are likely due to the inclusion implied outcomes in the item stems, allowing respondents to distinguish the propensity to approach rewards from the propensity to avoid punishments. Furthermore, the retained gains and losses items from the EFAs fit the firstorder gains/losses measurement structure, while the gains and losses constructs also fit the second-order approach/avoidance measurement structure. As such, the inclusion of implied outcomes in the items did not negatively impact the internal structure of approach-avoidance scales. However, in the context of the two-dimensional model, it is impossible to empirically establish the extent to which the inclusion of implied outcomes biases the measurement of approach-avoidance motivation.

The broad implication from these results is that specifying reward/punishment context may be associated with an expansion of the approach-avoidance construct space. This should not be surprising, as contemporary conceptualizations of approach-avoidance posit that approach tendencies are inherently associated with rewarding stimuli, while avoidance tendencies are inherently associated with punishing stimuli (Elliot, 1999). While it is tenuous to propose a precise cause for the higher item retention rate in the current results, it should be expected that the specification of reward/punishment context would improve the measurement of approachavoidance. 
One of the problematic findings of the above reanalysis of the Scott and Hauenstein (2011) results was that Sociability could not be confidently located in the approach-avoidance construct space. In fact, the best fit with the approach-avoidance measurement model occurred when the Sociability items were dropped from the CFA. In the new data set, Extraversion-Gains emerged as a separate factor in the new data set, and this first-order factor loaded on the secondorder Approach factor. The new scales written to measure Reinforcement Sensitivity-Gains and Reinforcement Sensitivity-Losses appear to discriminate the nuances of BAS and BIS, respectively. As such, the item content of those scales should not overlap with items intended to explicitly assess extraversion, thereby allowing for the emergence of a "clean", approachoriented Extraversion factor in the new data set.

This finding is in line with the recent literature on extraversion and approach-avoidance. Although Eysenck (e.g., 1967, 1971) and Gray (e.g., 1970, 1991) have long debated the role of extraversion within the approach-avoidance framework, current trait theories maintain that extraversion is directly and exclusively linked to reward sensitivity (Costa \& McCrae, 1992; Lucas, Diener, Grob, Suh, \& Shao, 2000). Accordingly, research has shown that high extraversion scorers have a tendency to seek out rewarding social interactions (Eaton \& Funder, 2003), respond more positively to rewards (Watson \& Clark, 1997), and condition faster to rewards (Zinbarg \& Revelle, 1989). The same research demonstrated that low extraversion scorers' positive emotion systems are less responsive and the psychological benefits of reward pursuit are fewer. Current trait theories also propose that extraversion is independent of punishment sensitivity. For example, research has shown that extraversion predicts metabolic activity in response to rewarding stimuli, but not punishing stimuli (Canli, 2004).

Finally, in Scott and Hauenstein (2011), Punishment Sensitivity and Extraversion items loaded onto the same factor; in the new data set Punishment Sensitivity and Neuroticism items loaded onto the same factor. This finding should not be entirely surprising considering the large correlations found between self-report measures of BIS and Neuroticism in prior approachavoidance research (e.g., Carver \& White, 1994). The new Reinforcement Sensitivity-Losses scale was written to capture instinctive anxiety-based motivational tendencies (e.g., "I startle too easily"). I anticipated that this scale would prove meaningfully different from existent measures of Neuroticism-Losses, which appear to reflect more conscious anxiety-based processes (e.g., "I get caught up in my problems"). However, in light of the current and prior research, and 
contemporary trait theories of anxiety (see McCrae \& Costa, 1999), it may be nearly impossible to separate certain aspects of biology and traits via self-report.

\section{2 - Four-Dimensional Model}

As was the case with the two-dimensional model, the EFA results for the fourdimensional model also showed a higher item retention rate relative to Scott and Hauenstein (2011), 67\% versus 32\%. Furthermore, the approach-avoidance construct space was meaningfully expanded as three (Reinforcement Sensitivity - Non-Gains, Impulsivity - NonGains, and Regulatory Focus - Non-Gains) of the six newly created non-gains via approach scales and four (Reinforcement Sensitivity - Non-Losses, Regulatory Focus - Non-Losses, Extraversion - Non-Losses, and Risk-Taking - Non-Losses) of the five newly created non-losses via avoidance scales emerged as unique factors in the new data set. The addition of these new constructs did not change the fundamental meaning of the traditional gains via approach and losses via avoidance constructs; the traditional gains/losses constructs emerged similarly in both the two-dimensional model and four-dimensional model EFAs.

The new subfacets of approach-avoidance appear to tap into distinctive and important aspects of human motivation. For example, trait researchers have long been interested in studying the adaptive benefits of an introverted nature (e.g., Eysenck, 1971; Furnham, Forde, \& Cotter, 1998; Osborn, Field, \& Veres, 1998). The results of the current research suggest that the losses effectively avoided by those with introverted tendencies can be accurately measured via self-reports. Similarly, research has shown that non-losses can increase when a prevention focus manifests as following rules and fulfilling obligations and expectations (Forster, Grant, Idson, \& Higgins, 2001). Again, the current results suggest that this component of human motivation can be captured via self-reports. Moreover, individuals tend to accrue non-gains when the BAS manifests as overexcitement (i.e., an inappropriate reaction to trivial rewards; Gray \& McNaughton, 2000); accordingly, preliminary construct validity evidence was found for the Reinforcement Sensitivity - Non-Gains scale.

The emergence of non-losses and non-gains factors is consistent with Higgins' (1997) regulatory focus theory wherein positively and negatively evaluated consequences are independently associated with both approach motivation and avoidance motivation. Most of the prior research in this realm has operationalized gains, non-gains, losses, and non-losses in terms of experimental manipulations (e.g., priming participants with a hypothetical scenario; Idson, 
Liberman, \& Higgins, 2000). The current results add to the approach-avoidance literature by demonstrating the validity of the four-dimensional model in the context of chronic preferences via self-report scales.

Several of the new approach-avoidance scales failed to emerge in the EFAs, including Performance Goal Orientation - Non-Gains, Extraversion - Non-Gains, Impulsivity - NonLosses, and Risk-Taking - Non-Gains. The failed emergence of these constructs could be attributable to several causes. It is possible that these newly proposed constructs are not valid approach-avoidance constructs. For example, in the case of Extraversion - Non-Gains, individuals may not recognize a propensity to miss out on opportunities through undesirable social intrusiveness. Alternatively, the constructs may be valid, but respondents are unable to differentiate them via self-reports (i.e., the non-emergent scales represent redundant psychometric construct space). It should be noted that there is theoretical and empirical precedent for this proposal, especially in regards to risk-taking constructs (e.g., Rohrmann, 2005). Finally, the constructs may be both valid and psychometrically discriminant, but the items from the proposed scales are not accurate indicators.

A closer examination of item-level descriptive statistics showed overall acceptable internal consistency, variance, and skew for the dropped approach-avoidance scales. However, items from these scales tended to have multiple and high EFA cross-loadings, thereby suggesting that such items are not unique indicators of a solitary approach-avoidance construct. Accordingly, this gives credence to the idea that respondents may be unable to differentiate certain approach-avoidance constructs via self-reports.

The hierarchical structure of the retained gains, non-gains, losses, and non-losses items (based on the EFAs) was tested in a three part sequence. First, a CFA was conducted to replicate the EFA results allocating items to the first-order constructs (see Figure 10). Second, item-level data was fit to a hierarchical model where Gains, Non-Gains, Losses, and Non-Losses were specified as the second-order constructs (see Figure 11). The third CFA used the scale-level scores as indicators and fit Gains, Non-Gains, Losses, and Non-Losses as the first-order constructs and Approach and Avoidance as the second-order constructs (see Figure 12). Overall, the results of these analyses suggest that the proposed four-dimensional model of approachavoidance is a viable alternative measurement structure. 
While the high negative correlations between Gains and Non-Gains and Losses and NonLosses indicate common sources (i.e., Approach and Avoidance, respectively), the clear emergence of separate Gains, Non-Gains, Losses, and Non-Losses factors in the above fourdimensional model EFA implies that Non-Gains/Non-Losses items are not simply reverse-scored items for Gains/Losses. Accordingly, the four-dimensional model provides a more complete representation of approach-avoidance motivational orientation in the context of self-reports.

\section{3 - The Potential Contamination of Implied Outcomes}

The poor fit indicated for the implied outcomes model suggests that this theorized measurement structure is not consistent with the observed data. Correspondingly, the path estimates for this positive/negative valence model show that neither Gains and Non-Losses nor Losses and Non-Gains share a common source (see Figure 13). Conversely, results from the confirmatory analysis for the hierarchical four-dimensional model show that both Gains and Non-Gains and Losses and Non-Losses are underpinned by Approach and Avoidance, respectively (see Figure 12). An examination of the four-dimensional model factor intercorrelations (see Table 7) supports these findings, as uniformly low correlations were found between the Gains and Non-Losses factors and between the Losses and Non-Gains factors; in contrast, uniformly moderate correlations were found between the Gains and Non-Gains factors and between the Losses and Non-Losses factors. These findings are encouraging as outcome valence is not recognized as a feature of modern approach-avoidance theories (e.g., Elliot \& Thrash, 2002).

In the CFA of the implied outcomes model, the Losses and Non-Losses factors were associated with uniformly high second-order to first-order loading estimates, while the Gains and Non-Gains factors were associated with uniformly low estimates (see Figure 13). Therefore, the two second-order factors in this model predominantly represent aggregate Losses and aggregate Non-Losses. The reason that the Gains and Non-Gains scales were not well represented in the implied outcomes model may be due to the higher average correlations amongst and between the Losses and Non-Losses scales (see Table 7).

The findings from the hierarchical four-dimensional model suggest that Avoidance drives the responses on the first-order Losses and Non-Losses constructs. However, it appears that the results of the implied outcomes model in regards to Losses and Non-Losses are spurious because of the high negative correlation between Positive Valence and Negative Valence (-.838). This 
suggests misspecification in the implied outcomes model - i.e., that Approach and Avoidance are missing from the measurement structure.

I have argued that within the framework of introspective self-reports, approach-avoidance motivational orientation has meaning in relation to specified reward/punishment contexts that allow the respondent to distinguish the propensity to approach rewards from the propensity to avoid punishments. The current results provide initial evidence that it is possible to increase the construct validity of approach-avoidance self-reports through the specification of reward/punishment context without significant contamination of outcome valence. 


\section{0 - General Discussion}

\section{1 - Future Directions for Research on Measuring Approach-Avoidance}

There is much debate in the personality literature regarding how best to measure approach-avoidance. Harbaugh, Mayr, and Burghart (2007) argue that approach-avoidance is accurately assessed through neuroimaging paradigms (e.g., fMRI). Hariri and Holmes (2006) discuss the potential of studying psychogenomic markers of approach-avoidance (e.g., 5-HTT, DRD2). Although self-report scales remain a popular methodology in the approach-avoidance literature, researchers are cautious to note that respondents may merely be reporting on the positive or negative end states of their motivational orientations (e.g., Smillie, 2008).

The current study provides initial evidence that contamination by implied outcomes does not invalidate approach-avoidance scales. However, more research is needed on the implied outcomes problem and should involve both psychometric and experimental paradigms. Regarding future psychometric research, scales could be created that explicitly assess positive/negative valence (e.g., "Good/bad things tend to happen to me"). Latent factors could be created from these scales and specified as underpinning item parcels of the retained approachavoidance scales from the present research. Overall low/inconsistent factor loadings would substantiate the current results regarding the implied outcomes problem.

Additional future research should further examine the implied outcomes problem utilizing an experimental manipulation paradigm (e.g., priming participants with a hypothetical scenario - see above section on "The Implied Outcomes Problem" for examples). Previous research using this methodology has demonstrated that the pleasure of a gain is generally greater than the pleasure of a non-loss, while the pain of a loss is generally greater than the pain of a non-gain (Idson, Liberman, \& Higgins, 2000). In view of these findings, researchers should now examine the degree of orthogonality between the effects of gains and non-losses primes, and the effects of losses and non-gains primes; high orthogonality would bolster the claim that contamination by implied outcomes does not invalidate approach-avoidance scales.

Regarding specific research aims, future studies should explore the discriminant validity between the new scales derived from this study and scales of traditional personality traits outside the realm of approach-avoidance (e.g., conscientiousness, agreeableness, and openness to experience; Goldberg, 1981; McCrae \& Costa, 1999). For example, based on item wording, there may exist a strong relationship between self-reported Conscientiousness and self-reported 
Regulatory Focus - Non-Losses. Evidence of discriminant validity would support the proposition that the emergent factors in the current research are correctly identified as part of the approach-avoidance construct space.

Furthermore, there is a rich literature on the association between approach-avoidance constructs and various organizational performance criteria (e.g., Bandura, 1999; Barrick \& Mount, 1991; Barrick, Mount, \& Judge, 2001; Elliot, 1999; Furnham, 1992; Humphreys \& Revelle, 1984; Koy \& Yeo, 2008; Locke \& Latham, 1990; Vancouver, 2000; van der Linden, Beckers, \& Taris, 2007; VandeWalle, 1997). As such, future research should examine the extent to which the newly developed scales reflecting increasing non-gains via approach and increasing non-losses via avoidance contribute meaningful variance to the prediction of such criteria (e.g., job performance) beyond that accounted for by existing approach-avoidance scales. Any meaningful correlations with a "real-world" outcome variable will also allay concerns regarding factor analytic reification errors (i.e., treating abstract concepts as if they are concrete objects).

\section{2 - Conclusion}

The current study sought to examine how best to fully represent and measure approachavoidance motivational orientation using self-reports. Overall results supported the validity of the second-order approach-avoidance overarching framework and indicated that the use of items with clear specification of reward/punishment context improves the psychometric properties of approach-avoidance scales. Moreover, the newly developed scales reflecting constructs that represent increasing non-gains via approach and increasing non-losses via avoidance meaningfully expanded the approach-avoidance construct space. It also appeared that the proposed four-dimensional model of approach-avoidance is a viable alternative measurement structure. Finally, while future research in this area is recommended, the current results suggested that contamination by implied outcomes does not invalidate approach-avoidance scales where reward/punishment context is specified. 


\section{References}

Atkinson, J. W. (1964). An introduction to motivation. Princeton, NJ: Van Nostrand.

Babakus, E., Ferguson, C. E. J., \& Joreskog, K. G. (1987). The sensitivity of confirmatory maximum likelihood factor analysis to violations of measurement scale and distributional assumptions. Journal of Marketing Research, 24, 222-228.

Bandalos, D. L., \& Finney, S. J. (2001). Item parceling issues in structural equation modeling. In G. A. Marcoulides (Ed.), New developments and techniques in structural equation modeling (pp. 269-296). Mahwah, NJ: Erlbaum.

Bandura, A. (1999). Social cognitive theory of personality. In L. A. Pervin, \& O. P. John (Eds.), Handbook of personality: Theory and research. New York: Guilford Press.

Barrick, M. R., \& Mount, M. K. (1991). The big five personality dimensions and job performance: A meta-analysis. Personnel Psychology, 44, 1-26.

Barrick, M. R., Mount, M. K., \& Judge, T. A. (2001). Personality and performance at the beginning of the new millennium: What do we know and where do we go next? International Journal of Selection and Assessment, 9, 9-30.

Bentler, P. M. (1990). Comparative fit indexes in structural models. Psychological Bulletin, 107, 238-246.

Berkman, E. T., \& Lieberman, M. D. (2010). Approaching the bad and avoiding the good: Lateral prefrontal cortical asymmetry distinguishes between action and valence. Journal of Cognitive Neuroscience, 22, 1970-1979.

Brockner, J., \& Higgins, E. T. (2001). Regulatory focus theory: Its implications for the study of emotions in the workplace. Organizational Behavior and Human Decision Processes, 86, 35-66.

Brown, T. A. (2006). Confirmatory factor analysis for applied research. New York: Guilford Press.

Button, S. B., Mathieu, J. E., \& Zajac, D. M. (1996). Goal orientation in organizational research: A conceptual and empirical foundation. Organizational Behavior and Human Decision Processes, 67, 26-48.

Byrne, B. M. (1989). A primer of LISREL: Basic applications and programming for confirmatory factor analytic models. New York: Springer-Verlag. 
Byrne, B. M., Shavelson, R. J., \& Muthen, B. (1989). Testing for the equivalence of factor covariance and mean structures: The issue of partial measurement invariance. Psychological Bulletin, 105, 456-466.

Canli, T. (2004). Functional brain mapping of extraversion and neuroticism: Learning from individual differences in emotion processing. Journal of Personality, 72, 1105-1132.

Carver, C. S., Sutton, S. K., \& Scheier, M. F. (2000). Action, emotion, and personality: Emerging conceptual integration. Personality and Social Psychology Bulletin, 26, 741-751.

Carver, C. S., \& White, T. (1994). Behavioral inhibition, behavioral activation, and affective responses to impending reward and punishment: The BIS/BAS scales. Journal of Personality and Social Psychology, 67, 319-333.

Cattell, R. B. (1978). The scientific use of factor analysis. New York: Plenum.

Colvin, C. R., Block, J., \& Funder, D. C. (1995). Overly positive self-evaluations and personality: Negative implications for mental health. Journal of Personality and Social Psychology, 68, 1152-1162.

Costa, P. T., \& McCrae, R. R. (1992). Four ways five factors are basic. Personality and Individual Differences, 13, 653-665.

Crowe, E., \& Higgins, E. T. (1997). Regulatory focus and strategic inclinations: Promotion and prevention in decision making. Organizational Behavior and Human Decision Processes, 69, 117-132.

Cudeck, R., \& Browne, M. W. (1983). Cross-validation of covariance structures. Multivariate Behavioral Research, 18, 147-167.

Davidson, R. J. (1998). Affective style and affective disorders: Perspectives from affective neuroscience. Cognition and Emotion, 12, 307-330.

Dweck, C. S., \& Leggett, E. L. (1988). A social-cognitive approach to motivation and personality. Psychological Review, 95, 256-273.

Eaton, L. G., \& Funder, D. C. (2003). The creation and consequences of the social world: An interactional analysis of extraversion. European Journal of Personality, 17, 375-395.

Edwards, A. L. (1957). Manual of the Edwards Personal Preference Schedule. New York: Psychological Corporation. 
Elliot, A. J. (1997). Integrating the "classic" and "contemporary" approaches to intrinsic motivation: A hierarchical model of approach and avoidance achievement motivation. In M. Maehr, \& P. Pintrich (Eds.), Advances in motivation and achievement (pp. 303-337). Greenwich, CT: JAI.

Elliot, A. J. (1999). Approach and avoidance motivation and achievement goals. Educational Psychologist, 34, 169-189.

Elliot, A. J., \& Church, M. A. (1997). A hierarchical model of approach and avoidance achievement motivation. Journal of Personality and Social Psychology, 72, 218-232.

Elliot, A. J., \& Covington, M. V. (2001). Approach and avoidance motivation. Educational Psychology Review, 13, 73-92.

Elliot, A. J., \& McGregor, H. A. (1999). Test anxiety and the hierarchical model of approach and avoidance achievement motivation. Journal of Personality and Social Psychology, 76, 628-644.

Elliot, A. J., \& Thrash, T. M. (2002). Approach-avoidance motivation in personality: Approach and avoidance temperaments and goals. Journal of Personality and Social Psychology, $82,804-818$.

Elliot, A. J., \& Thrash, T. M. (2010). Approach and avoidance temperament as basic dimensions of personality. Journal of Personality, 78, 865-906.

Eysenck, H. J. (1967). The biological basis of personality. Springfield, IL: Thomas.

Eysenck, H. J. (1971). Readings in extraversion-introversion. New York: Wiley.

Forster, J., Grant, H., Idson, L. C., \& Higgins, E. T. (2001). Success/failure feedback, expectancies, and approach/avoidance motivation: How regulatory focus moderates classic relations. Journal of Experimental Social Psychology, 37, 253-260.

Fowles, D. C. (1987). Application of a behavioral theory of motivation to the concepts of anxiety and impulsivity. Journal of Research in Personality, 21, 417-435.

Freitas, A. L., Liberman, N., \& Higgins, E. T. (2002). Regulatory fit and resisting temptation during goal pursuit. Journal of Experimental Social Psychology, 38, 291-298.

Furnham, A. (1992). Personality at work. London: Routledge.

Furnham, A., Forde, L., \& Cotter, T. (1998). Personality and intelligence. Personality and Individual Differences, 24, 187-192. 
Goldberg, L. R. (1981). Language and individual differences: The search for universals in personality lexicons. In L. Wheeler (Ed.), Review of Personality and Social Psychology (Vol. 2, pp. 141-165). Beverly Hills, CA: Sage.

Goldberg, L. R., Johnson, J. A., Eber, H. W., Hogan, R., Ashton, M. C., Cloninger, C. R., \& Gough, H. C. (2006). The International Personality Item Pool and the future of public-domain personality measures. Journal of Research in Personality, 40, 84-96.

Gorsuch, R. L. (1983). Factor analysis. Hillsdale, NJ: Erlbaum.

Gray, J. A. (1970). The psychophysiological basis of introversion-extraversion. Behaviour Research and Therapy, 8, 249-266.

Gray, J. A. (1976). The behavioral inhibition system: A possible substrate for anxiety. In M. P. Feldman, \& A. Broadhurst (Eds.), Theoretical and experimental bases of the behavioral therapies (pp. 3-41). London: Wiley.

Gray, J. A. (1987). The psychology of fear and stress. Cambridge, UK: Cambridge University Press.

Gray, J. A. (1991). Neural systems, emotion, and personality. In J. Madden, IV (Ed.), Neurobiology of learning, emotion, and affect (pp. 273 - 306). New York: Raven Press.

Gray, J. A., \& McNaughton, N. (2000). The neuropsychology of anxiety. Oxford: Oxford University Press.

Gunthert, K. C., Cohen, L. H., \& Armeli, S. (1999). The role of neuroticism in daily stress and coping. Journal of Personality and Social Psychology, 77, 1087-1100.

Harbaugh, W. T., Mayr, U., \& Burghart, D. R. (2007). Neural responses to taxation and voluntary giving reveal motives for charitable donations. Science, 316, 1622-1625.

Hariri, A. R., \& Holmes, A. (2006). Genetics of emotional regulation: The role of the serotonin transporter in neural function. Trends in Cognitive Sciences, 10, 182-191.

Higgins, E. T. (1997). Beyond pleasure and pain. American Psychologist, 52, 1280-1300.

Higgins, E. T. (1998). Promotion and prevention: Regulatory focus as a motivational principle. In M. P. Zanna (Ed.), Advances in Experimental Social Psychology (Vol. 30, pp. 1-46). San Diego, CA: Academic Press.

Higgins, E. T. (1999). Persons and situations: Unique explanatory principles or variability in general principles. In D. Cervone, \& Y. Shoda (Eds.), Social-cognitive bases of consistency, variability, and organization (pp. 61-93). New York: Guilford. 
Higgins, E. T., Friedman, R. S., Harlow, R. E., Idson, L. C., Ayduck, O. N., \& Taylor, A. (2001). Achievement orientations from subjective histories of success: Promotion pride versus prevention pride. European Journal of Social Psychology, 31, 3-23.

Horvath, M., Scheu, C. R., \& DeShon, R. P. (2001, April). Goal orientation: Integrating theory and measurement. Paper presented at the $16^{\text {th }}$ annual conference of the Society for Industrial and Organizational Psychology, San Diego, CA.

Humphreys, M. S., \& Revelle, W. (1984). Personality, motivation, and performance: A theory of the relationship between individual differences and information processing. Psychological Review, 91, 153-184.

Idson, L. C., Liberman, N., \& Higgins, E. T. (2000). Distinguishing gains from nonlosses and losses from nongains: A regulatory focus perspective on hedonic intensity. Journal of Experimental Social Psychology, 36, 252-274.

Jackson, D. N. (1984). Personality Research Form manual. Port Huron, MI: Research Psychologists Press.

James, W. (1890). The principles of psychology (Vol. 2). New York: Holt.

John, O. P., \& Robins, R. W. (1994). Accuracy and bias in self-perception: Individual differences in self-enhancement and the role of narcissism. Journal of Personality and Social Psychology, 66, 206-219.

Kline, P. (1979). Psychometrics and psychology. London: Academic Press.

Kline, R. B. (1998). Principles and practice of structural equation modeling. New York: Guilford Press.

Knowles, E. S., Cutter, H. S. G., Walsh, D. H., \& Casey, N. A. (1973). Risk-taking as a personality trait. Social Behavior and Personality, 1, 123-136.

Koy, A., \& Yeo, G. (2008). BIS sensitivity, negative affect and performance: Dynamic and multilevel relationships. Human Performance, 21, 198-225.

Kuhnen, C. M., \& Knutson, B. (2005). The neural basis of financial risk taking. Neuron, 47, 763-770.

Larsen, R. J., Chen, B., \& Zelenski, J. (2003). Response to punishment and reward in the emotional Stroop paradigm: Relations to BIS and BAS. Unpublished manuscript.

Locke, E. A., \& Latham, G. P. (1990). A theory of goal setting and task performance. Englewood Cliffs, NJ: Prentice Hall. 
Lopes, L. L. (1987). Between hope and fear: The psychology of risk. Advances in Experimental Social Psychology, 20, 255-295.

Lucas, R. E., Diener, E., Grob, A., Suh, E. M., \& Shao, L. (2000). Cross-cultural evidence for the fundamental features of extraversion. Journal of Personality and Social Psychology, 79, 452-468.

MacCallum, R. C., Browne, M. W., \& Sugawara, H. M. (1996). Power analysis and determination of sample size for covariance structure modeling. Psychological Methods, $1,130-149$.

MacCallum, R. C., Widaman, K. F., Zhang, S., \& Hong, S. (1999). Sample size in factor analysis. Psychological Methods, 4, 84-99.

Matthews, G., \& Gilliland, K. (1999). The personality theories of H. J. Eysenck and J. A. Gray: A comparative review. Personality and Individual Differences, 26, 583-626.

McCrae, R. R., \& Costa, P. T. (1990). Personality in adulthood. New York: Guilford.

McCrae, R. R., \& Costa, P. T. (1999). A Five-Factor Theory of personality. In L. A. Pervin, \& O. P. John (Eds.), Handbook of personality: Theory and research ( $2^{\text {nd }}$ ed., pp. 139-153). New York: Guilford.

McGregor, H. A., \& Elliot, A. J. (2002). Achievement goals as predictors of achievementrelevant processes prior to task engagement. Journal of Educational Psychology, 94, 381-395.

Meredith, W. (1993). Measurement invariance, factor analysis, and factorial invariance. Psychometrika, 58, 525-543.

Mischel, W. (1973). Toward a cognitive social learning reconceptualization of personality. Psychological Review, 80, 252-283.

Mischel, W., \& Shoda, Y. (1995). A cognitive-affective system theory of personality: Reconceptualizing situations, dispositions, dynamics, and invariance in personality structure. Psychological Review, 102, 246-268.

Nicholson, N., Soane, E., Fenton-O'Creevy, M., \& Willman, P. (2005). Personality and domainspecific risk taking. Journal of Risk Research, 8, 157-176.

Osborn, S. M., Field, H. S., \& Veres, J. G. (1998). Introversion-extraversion, self-monitoring, and applicant performance in a situational panel interview: A field study. Journal of Business and Psychology, 13, 143-156. 
Paulhus, D. L. (1991). Measurement and control of response bias. In J. P. Robinson, P. R. Shaver, \& L. S. Wrightsman (Eds.), Measures of personality and social psychological attitudes (pp. 17-59). San Diego, CA: Academic Press.

Payne, S. C., Youngcourt, S. S., \& Beaubien, J. M. (2007). A meta-analytic examination of the goal orientation nomological net. Journal of Applied Psychology, 92, 128-150.

Pedhazur, E., \& Schmelkin, L. P. (1991). Measurement, design, and analysis: An integrated approach. Hillsdale, NJ: Lawrence Erlbaum.

Ray, J. J. (1979). A quick measure of achievement motivation: Validated in Australia and reliable in Britain and South Africa. Australian Psychologist, 14, 337-344.

Rohrmann, B. (2005). Risk attitude scales: Concepts, questionnaires, utilizations. Melbourne, Austrailia: The University of Melbourne. Retrieved June 10, 2011, from http://www.rohrmannresearch.net

Ryckman, R. M., Thornton, B., \& Butler, J. C. (1994). Personality correlates of the Hypercompetitive Attitude Scale: Validity tests of Horney's theory of neurosis. Journal of Personality Assessment, 62, 84-94.

Scott, M. D., \& Hauenstein, N. M. A. (2011, April). Construct validation of biological and cognitive-affective approach-avoidance measures. Paper presented at the $26^{\text {th }}$ annual conference of the Society for Industrial and Organizational Psychology, Chicago, IL.

Shoda, Y., \& Mischel, W. (1996). Toward a unified, intra-individual dynamic conception of personality. Journal of Research in Personality, 30, 414-428.

Smillie, L. D. (2008). What is reinforcement sensitivity? Neuroscience paradigms for approachavoidance process theories of personality. European Journal of Personality, 22, 359-384.

Steiger, J. H. (1988). Aspects of person-machine communication in structural modeling of correlations and covariances. Multivariate Behavioral Research, 23, 281-290.

Tellegen, A. (1985). Structure of mood and personality and their relevance to assessing anxiety, with an emphasis on self-report. In A. H. Tuma, \& J. D. Maser (Eds.), Anxiety and the anxiety disorders (pp. 681-706). Hillsdale, NJ: Erlbaum.

Thompson, E. R. (2008). Development and validation of an international English Big-Five minimarkers. Personality and Individual Differences, 45, 542-548. 
Torrubia, R., Avila, C., Molto, J., \& Caseras, X. (2001). The Sensitivity to Punishment and Sensitivity to Reward Questionnaire (SPSRQ) as a measure of Gray's anxiety and impulsivity dimensions. Personality and Individual Differences, 31, 837-862.

Vancouver, J. B. (2000). Self-regulation in organizational settings: A tale of two paradigms. In M. Boekaerts, P. R. Pintrich, \& M. Zeidner (Eds.), Self-regulation: Directions and challenges for future research (pp. 303-336). New York: Academic Press.

van der Linden, D., Beckers, D. G. J., \& Taris, T. W. (2007). Reinforcement sensitivity theory at work: Punishment sensitivity as a dispositional source of job-related stress. European Journal of Personality, 21, 889-909.

VandeWalle, D. M. (1997). Development and validation of a work domain goal orientation instrument. Educational and Psychological Measurement, 57, 995-1015.

Watson, D., \& Clark, L. A. (1997). Extraversion and its positive emotional core. In R. Hogan, J. Johnson, \& S. Briggs (Eds.), Handbook of personality psychology (pp. 767-793). San Diego, CA: Academic Press.

Zinbarg, R., \& Revelle, W. (1989). Personality and conditioning: A test of four models. Journal of Personality and Social Psychology, 57, 301-314.

Zuckerman, M. (1991). Psychobiology of personality. Cambridge, UK: Cambridge University Press. 
Table 1

Measurement Map

\begin{tabular}{|c|c|c|c|c|}
\hline & Gains & Non-Gains & Losses & Non-Losses \\
\hline $\begin{array}{c}\text { Reinforcement } \\
\text { Sensitivity }\end{array}$ & Existing/New Items & New Items & New Items & New Items \\
\hline Impulsivity & New Items & New Items & New Items & New Items \\
\hline Regulatory Focus & New Items & New Items & New Items & New Items \\
\hline $\begin{array}{c}\text { Mastery Goal } \\
\text { Orientation }\end{array}$ & Existing Items & -- & -- & -- \\
\hline $\begin{array}{c}\text { Performance Goal } \\
\text { Orientation }\end{array}$ & Existing Items & New Items & Existing Items & -- \\
\hline Extraversion & Existing Items* & New Items & Existing Items $*$ & New Items \\
\hline Neuroticism & -- & -- & Existing Items & -- \\
\hline Risk-Taking & Existing/New Items & New Items & New Items & New Items \\
\hline
\end{tabular}

Note. *Extraversion - Gains and Extraversion - Losses measured using identical items. 
Table 2

Factor Loadings Based on a Principal Axis Factoring with Direct Oblimin Rotation for the Remaining 70 Items From the Two-Dimensional Model $(N=540)$

\begin{tabular}{|c|c|c|c|c|c|c|c|c|c|c|}
\hline Item & $\begin{array}{l}\text { Factor 1: } \\
\text { RS-Gains }\end{array}$ & $\begin{array}{l}\text { Factor 2: } \\
\text { RS-Losses }\end{array}$ & $\begin{array}{l}\text { Factor 3: } \\
\text { IMP-Gains }\end{array}$ & $\begin{array}{l}\text { Factor 4: } \\
\text { RF-Gains }\end{array}$ & $\begin{array}{l}\text { Factor 5: } \\
\text { RF-Losses }\end{array}$ & $\begin{array}{l}\text { Factor 6: } \\
\text { MGO-Gains }\end{array}$ & $\begin{array}{l}\text { Factor 7: } \\
\text { PGO-Gains }\end{array}$ & $\begin{array}{l}\text { Factor 8: } \\
\text { PGO-Losses }\end{array}$ & $\begin{array}{l}\text { Factor 9: } \\
\text { EXT-Gains }\end{array}$ & $\begin{array}{l}\text { Factor 10: } \\
\text { RT-Losses }\end{array}$ \\
\hline \multicolumn{11}{|c|}{ Items Loading on Reinforcement Sensitivity Construct } \\
\hline RS-G1 & .556 & & & & & & & & & \\
\hline RS-G8 & .529 & & & & & & & & & \\
\hline RS-G3 & .523 & & & & & & & & & \\
\hline RS-G5 & .509 & & & & & & & & & \\
\hline RS-G7 & .508 & & & & & & & & & \\
\hline RS-G2 & .506 & & & & & & & & & \\
\hline RS-G6 & .491 & & & & & & & & & \\
\hline NEU-L3 & & -.741 & & & & & & & & \\
\hline NEU-L2 & & -.730 & & & & & & & & \\
\hline NEU-L5 & & -.694 & & & & & & & & \\
\hline NEU-L1 & & -.683 & & & & & & & & \\
\hline PR-L4 & & -.675 & & & & & & & & \\
\hline NEU-L6 & & -.670 & & & & & & & & \\
\hline NEU-L4 & & -.665 & & & & & & & & \\
\hline PR-L2 & & -.597 & & & & & & & & \\
\hline
\end{tabular}




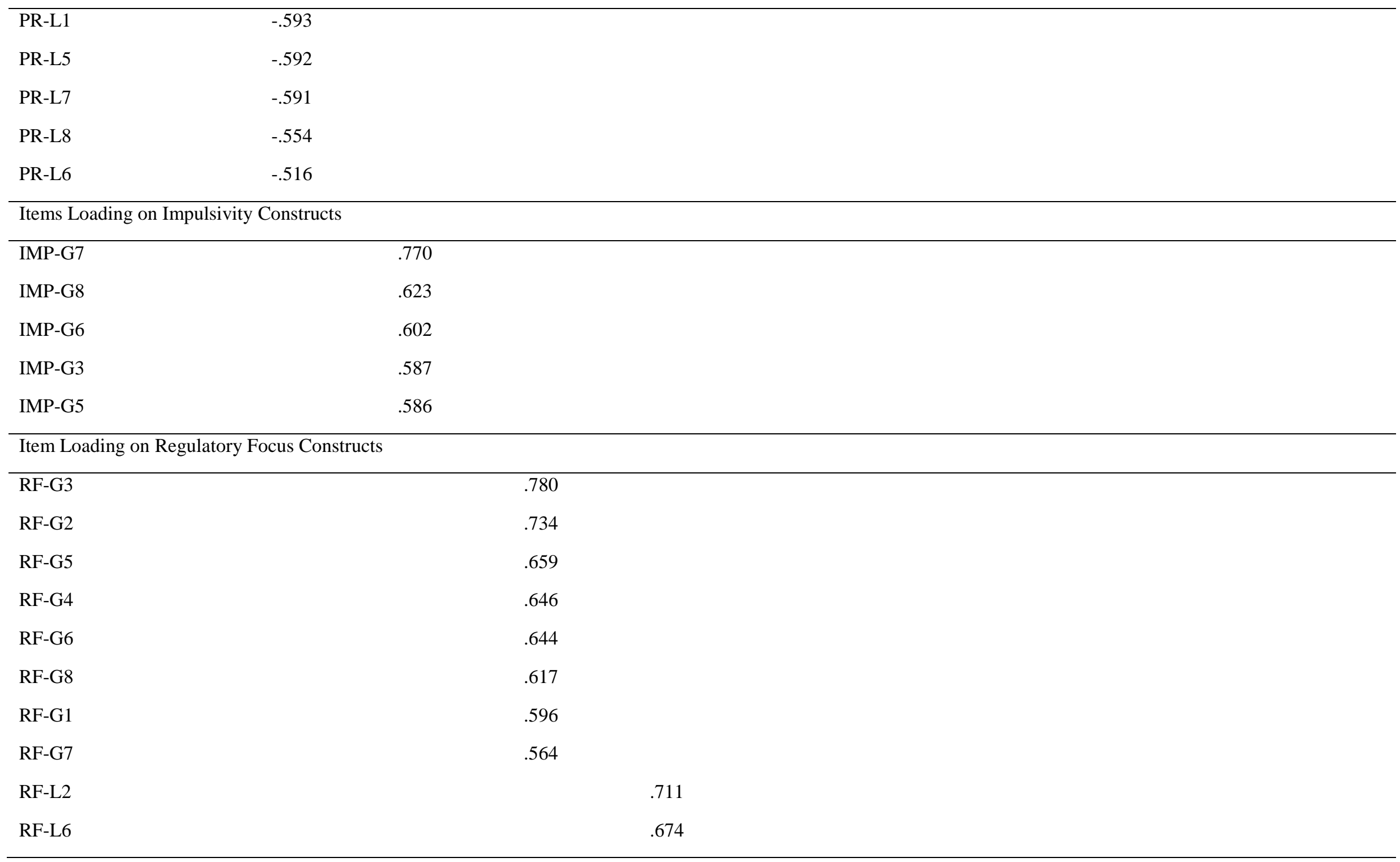




\begin{tabular}{|c|c|c|c|c|}
\hline RF-L4 & .669 & & & \\
\hline RF-L7 & .627 & & & \\
\hline RF-L3 & .580 & & & \\
\hline RF-L1 & .571 & & & \\
\hline RF-L5 & .557 & & & \\
\hline RF-L8 & .533 & & & \\
\hline \multicolumn{5}{|c|}{ Items Loading on Mastery Goal Orientation Constructs } \\
\hline MGO1 & & .788 & & \\
\hline MGO2 & & .748 & & \\
\hline MGO4 & & .729 & & \\
\hline MGO3 & & .724 & & \\
\hline MGO5 & & .604 & & \\
\hline \multicolumn{5}{|c|}{ Items Loading on Performance Goal Orientation Constructs } \\
\hline PGO-G3 & & & -.923 & \\
\hline PGO-G2 & & & -.783 & \\
\hline PGO-G1 & & & -.697 & \\
\hline PGO-G4 & & & -.696 & \\
\hline PGO-G5 & & & -.628 & \\
\hline PGO-L4 & & & & .701 \\
\hline PGO-L2 & & & & .665 \\
\hline PGO-L1 & & & & .628 \\
\hline PGO-L3 & & & & .539 \\
\hline
\end{tabular}


Items Loading on Extraversion Constructs

\begin{tabular}{|c|c|}
\hline EXT-G3 & .757 \\
\hline EXT-G2 & .742 \\
\hline EXT-G4 & .648 \\
\hline EXT-G1 & .643 \\
\hline EXT-G5 & .628 \\
\hline EXT-G6 & .592 \\
\hline
\end{tabular}

Items Loading on Risk-Taking Constructs

\begin{tabular}{|c|c|}
\hline RT-L5 & .734 \\
\hline RT-L2 & .721 \\
\hline RT-L8 & .720 \\
\hline RT-L1 & .689 \\
\hline RT-L4 & .687 \\
\hline RT-L7 & .670 \\
\hline RT-L6 & .648 \\
\hline RT-L3 & .632 \\
\hline
\end{tabular}

Note. Factor loadings < .4 are suppressed. RS = Reinforcement Sensitivity; IMP = Impulsivity; RF = Regulatory Focus; MGO = Mastery Goal Orientation; PGO = Performance Goal Orientation; EXT = Extraversion; RT = Risk-Taking; NEU = Neuroticism; G = Gains; NG = Non-Gains; L = Losses; NL = Non-Losses . 
Table 3

Items/Factors Retained in the Final EFA Solution for the Two-Dimensional Model

\begin{tabular}{|c|c|c|c|c|}
\hline & Gains & Non-Gains & Losses & Non-Losses \\
\hline $\begin{array}{c}\text { Reinforcement } \\
\text { Sensitivity }\end{array}$ & $7(8) / .83$ & -- & $13(14) / .92$ & -- \\
\hline Impulsivity $^{\text {Regulatory }} \begin{array}{c}\text { Focus } \\
\text { Mastery Goal } \\
\text { Orientation }\end{array}$ & $5(8) / .84$ & -- & $0(8) / \mathrm{NA}$ & -- \\
\hline $\begin{array}{c}\text { Performance } \\
\text { Goal } \\
\text { Orientation }\end{array}$ & $5(8) / .89$ & -- & $8(8) / .86$ & -- \\
\hline Extraversion & $6(6) / .86$ & -- & -- & -- \\
\hline Risk-Taking & $0(8) / \mathrm{NA}$ & -- & $5(5) / .83$ & -- \\
\hline \multicolumn{2}{c}{} & -- & $8(8) / .92$ & - \\
\hline
\end{tabular}

${ }^{a}$ Neuroticism-Losses items loaded on the Reinforcement Sensitivity-Losses factor. 
Table 4

Factor Correlations From the Confirmatory Two-Dimensional Model

\begin{tabular}{|c|c|c|c|c|c|c|c|c|c|c|}
\hline & $\begin{array}{l}\text { Factor } \\
1: \\
\text { RS- } \\
\text { Gains }\end{array}$ & $\begin{array}{l}\text { Factor 2: } \\
\text { RS- } \\
\text { Losses }\end{array}$ & $\begin{array}{l}\text { Factor 3: } \\
\text { IMP- } \\
\text { Gains }\end{array}$ & $\begin{array}{l}\text { Factor 4: } \\
\text { RF- } \\
\text { Gains }\end{array}$ & $\begin{array}{l}\text { Factor 5: } \\
\text { RF- } \\
\text { Losses }\end{array}$ & $\begin{array}{l}\text { Factor 6: } \\
\text { MGO- } \\
\text { Gains }\end{array}$ & $\begin{array}{l}\text { Factor 7: } \\
\text { PGO- } \\
\text { Gains }\end{array}$ & $\begin{array}{l}\text { Factor 8: } \\
\text { PGO- } \\
\text { Losses }\end{array}$ & $\begin{array}{l}\text { Factor 9: } \\
\text { EXT- } \\
\text { Gains }\end{array}$ & $\begin{array}{l}\text { Factor } \\
10: \\
\text { RT- } \\
\text { Losses }\end{array}$ \\
\hline Factor 1 & 1.00 & & & & & & & & & \\
\hline Factor 2 & .006 & 1.00 & & & & & & & & \\
\hline Factor 3 & .431 & .080 & 1.00 & & & & & & & \\
\hline Factor 4 & .513 & -.016 & .523 & 1.00 & & & & & & \\
\hline Factor 5 & .033 & .535 & .052 & -.010 & 1.00 & & & & & \\
\hline Factor 6 & .494 & .021 & .524 & .542 & .036 & 1.00 & & & & \\
\hline Factor 7 & .510 & .161 & .497 & .425 & .126 & .478 & 1.00 & & & \\
\hline Factor 8 & -.068 & .479 & .031 & -.065 & .468 & -.068 & .199 & 1.00 & & \\
\hline Factor 9 & .508 & -.068 & .569 & .503 & -.029 & .507 & .434 & -.097 & 1.00 & \\
\hline Factor 10 & -.117 & .475 & -.026 & -.101 & .594 & -.013 & .073 & .572 & -.121 & 1.00 \\
\hline
\end{tabular}

Note . RS = Reinforcement Sensitivity; IMP = Impulsivity; RF = Regulatory Focus; MGO = Mastery Goal Orientation; $\mathrm{PGO}=$ Performance Goal Orientation; EXT $=$ Extraversion; RT $=$ Risk-Taking. 
Table 5

Factor Loadings Based on a Principal Axis Factoring with Direct Oblimin Rotation for the Remaining 120 Items From the FourDimensional Model $(N=540)$

\begin{tabular}{|c|c|c|c|c|c|c|c|c|c|c|c|c|c|c|c|c|c|}
\hline Item & $\begin{array}{l}\text { Factor } \\
1: \\
\text { RS- } \\
\text { Gains }\end{array}$ & $\begin{array}{l}\text { Factor } \\
2: \\
\text { RS- } \\
\text { Non- } \\
\text { gains }\end{array}$ & $\begin{array}{l}\text { Factor } \\
3: \\
\text { RS- } \\
\text { Losses }\end{array}$ & $\begin{array}{l}\text { Factor } \\
\text { 4: } \\
\text { RS- } \\
\text { Non- } \\
\text { losses }\end{array}$ & $\begin{array}{l}\text { Factor } \\
5: \\
\text { IMP- } \\
\text { Gains }\end{array}$ & $\begin{array}{l}\text { Factor } \\
\text { 6: } \\
\text { IMP- } \\
\text { Non- } \\
\text { gains }\end{array}$ & $\begin{array}{l}\text { Factor } \\
7: \\
\text { RF- } \\
\text { Gains }\end{array}$ & $\begin{array}{l}\text { Factor } \\
8: \\
\text { RF- } \\
\text { Non- } \\
\text { gains }\end{array}$ & $\begin{array}{l}\text { Factor } \\
9: \\
\text { RF- } \\
\text { Losses }\end{array}$ & $\begin{array}{l}\text { Factor } \\
10: \\
\text { RF- } \\
\text { Non- } \\
\text { losses }\end{array}$ & $\begin{array}{l}\text { Factor } \\
11: \\
\text { MGO- } \\
\text { Gains }\end{array}$ & $\begin{array}{l}\text { Factor } \\
12: \\
\text { PGO- } \\
\text { Gains }\end{array}$ & $\begin{array}{l}\text { Factor } \\
13: \\
\text { PGO- } \\
\text { Losses }\end{array}$ & $\begin{array}{l}\text { Factor } \\
14: \\
\text { EXT- } \\
\text { Gains }\end{array}$ & $\begin{array}{l}\text { Factor } \\
15: \\
\text { EXT- } \\
\text { Non- } \\
\text { losses }\end{array}$ & $\begin{array}{l}\text { Factor } \\
16: \\
\text { RT- } \\
\text { Losses }\end{array}$ & $\begin{array}{l}\text { Factor } \\
\text { 17: } \\
\text { RT- } \\
\text { Non- } \\
\text { Losses }\end{array}$ \\
\hline \multicolumn{18}{|c|}{ Items Loading on Reinforcement Sensitivity Constructs } \\
\hline RS-G2 & .722 & & & & & & & & & & & & & & & & \\
\hline RS-G1 & .719 & & & & & & & & & & & & & & & & \\
\hline RS-G3 & 647 & & & & & & & & & & & & & & & & \\
\hline RS-G8 & .541 & & & & & & & & & & & & & & & & \\
\hline RS-NG6 & & -.708 & & & & & & & & & & & & & & & \\
\hline RS-NG4 & & -.688 & & & & & & & & & & & & & & & \\
\hline RS-NG5 & & -.648 & & & & & & & & & & & & & & & \\
\hline RS-NG7 & & -.648 & & & & & & & & & & & & & & & \\
\hline RS-NG8 & & -.621 & & & & & & & & & & & & & & & \\
\hline RS-NG1 & & -.583 & & & & & & & & & & & & & & & \\
\hline RS-NG3 & & -.558 & & & & & & & & & & & & & & & \\
\hline RS-NG2 & & -.530 & & & & & & & & & & & & & & & \\
\hline NEU-L3 & & & -.689 & & & & & & & & & & & & & & \\
\hline NEU-L2 & & & -.688 & & & & & & & & & & & & & & \\
\hline NEU-L5 & & & -.656 & & & & & & & & & & & & & & \\
\hline RS-L4 & & & -.645 & & & & & & & & & & & & & & \\
\hline NEU-L4 & & & -.638 & & & & & & & & & & & & & & \\
\hline NEU-L6 & & & -.631 & & & & & & & & & & & & & & \\
\hline NEU-L1 & & & -.630 & & & & & & & & & & & & & & \\
\hline RS-L1 & & & -.572 & & & & & & & & & & & & & & \\
\hline RS-L5 & & & -.569 & & & & & & & & & & & & & & \\
\hline RS-L2 & & & -.568 & & & & & & & & & & & & & & \\
\hline RS-L7 & & & -.555 & & & & & & & & & & & & & & \\
\hline RS-L8 & & & -.532 & & & & & & & & & & & & & & \\
\hline
\end{tabular}




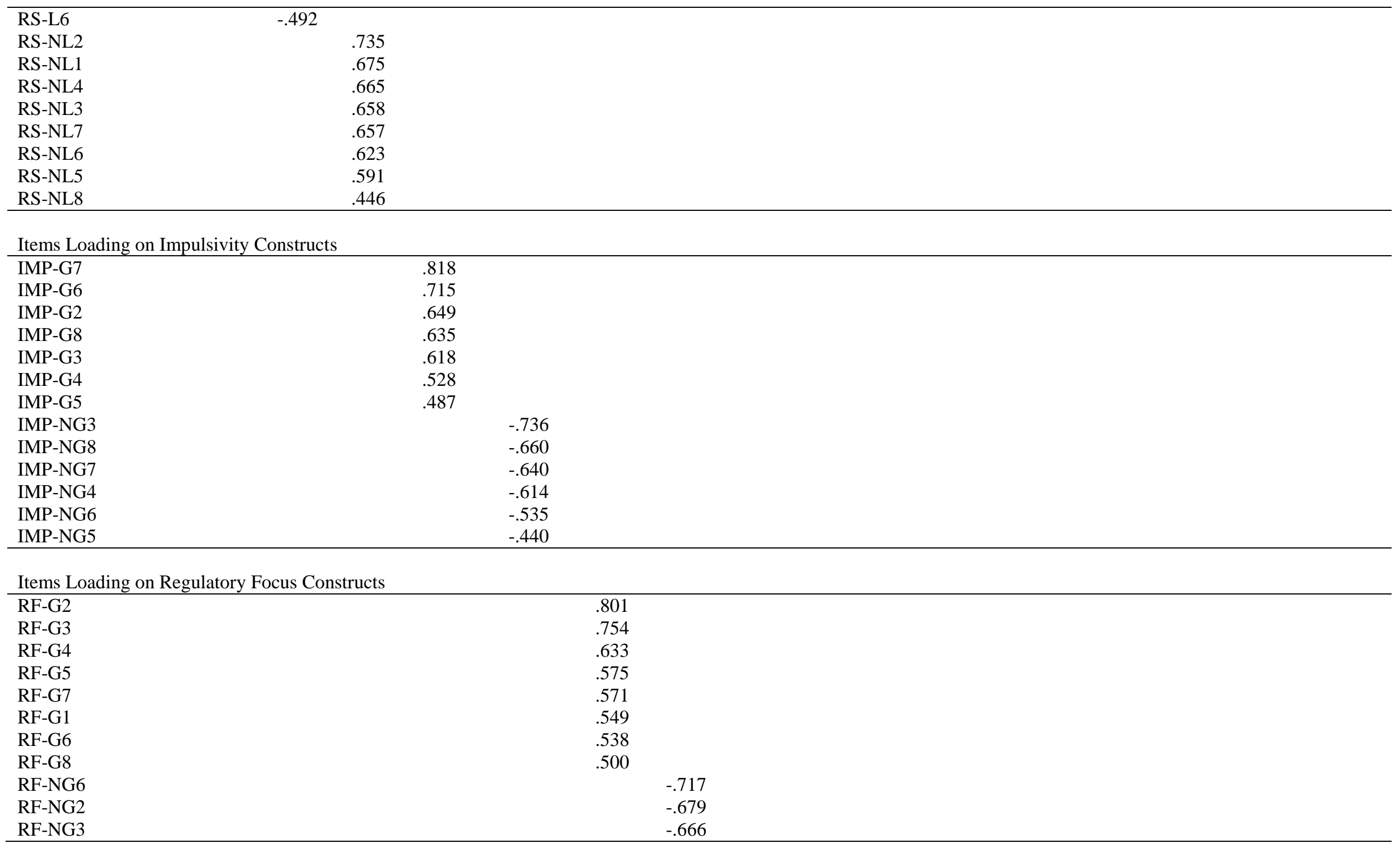




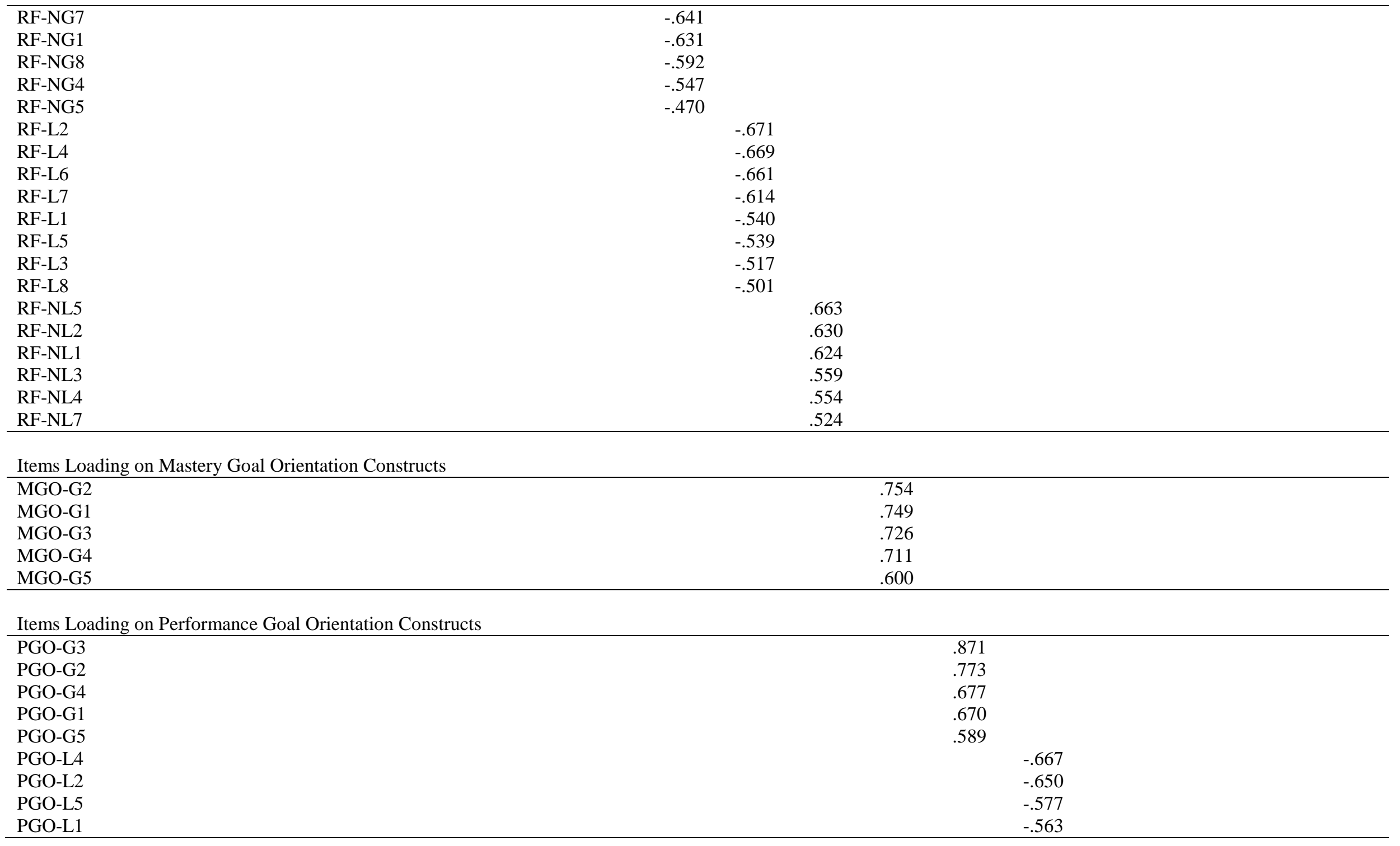


Items Loading on Extraversion Constructs

\begin{tabular}{ll}
\hline EXT-G3 & .714 \\
EXT-G2 & .712 \\
EXT-G1 & .642 \\
EXT-G5 & .577 \\
EXT-G4 & .568 \\
EXT-G6 & .553
\end{tabular}

EXT-G6

EXT-NL4

EXT-NL7

EXT-NL3

EXT-NL2

EXT-NL8

EXT-NL6

EXT-NL1

EXT-NL5

\section{Items Loading on Risk-Taking Constructs}

\section{RT-L8}

RT-L5

RT-L6

RT-L2

RT-L7

RT-L1

RT-L4

RT-L3

RT-NL7

RT-NL8

RT-NL4

RT-NL6

RT-NL5

RT-NL2

RT-NL3

Note. Factor loadings <.4 are suppressed. RS = Reinforcement Sensitivity; IMP = Impulsivity; RF = Regulatory Focus; MGO = Mastery Goal Orientation; PGO = Performance Goal Orientation; EXT = Extraversion; RT = Risk-Taking; NEU = Neuroticism; G = Gains; NG = Non-Gains; L = Losses; NL = Non-Losses. 
Table 6

Items/Factors Retained in the Final EFA Solution for the Four-Dimensional Model

\begin{tabular}{|c|c|c|c|c|}
\hline & Gains & Non-Gains & Losses & Non-Losses \\
\hline $\begin{array}{c}\text { Reinforcement } \\
\text { Sensitivity }\end{array}$ & $4(8) / .87$ & $8(8) .87$ & $13(14) / .92$ & $8(8) / .86$ \\
\hline Impulsivity $^{\text {Regulatory }}$ & $7(8) / .85$ & $6(8) / .86$ & $0(8) / \mathrm{NA}$ & $0(8) / \mathrm{NA}$ \\
\hline Focus & $8(8) / .89$ & $8(8) / .81$ & $8(8) / .86$ & $6(8) / .85$ \\
\hline $\begin{array}{c}\text { Mastery Goal } \\
\text { Orientation }\end{array}$ & $5(5) / .88$ & -- & -- & -- \\
\hline $\begin{array}{c}\text { Performance } \\
\text { Goal } \\
\text { Orientation }\end{array}$ & $5(5) / .88$ & $0(8) / \mathrm{NA}$ & $5(5) / .83$ & -- \\
\hline Extraversion & $6(6) / .86$ & $0(8) / \mathrm{NA}$ & -- & $8(8) / .85$ \\
\hline Risk-Taking & $0(8) / \mathrm{NA}$ & $0(8) / \mathrm{NA}$ & $8(8) / .92$ & $7(8) / .88$ \\
\hline
\end{tabular}

${ }^{\text {a }}$ Neuroticism-Losses items loaded on the Reinforcement Sensitivity-Losses factor. 
Table 7

Factor Correlations From the Confirmatory Four-Dimensional Model

\begin{tabular}{|c|c|c|c|c|c|c|c|c|c|c|c|c|c|c|c|c|c|}
\hline & $\begin{array}{l}\text { Factor 1: } \\
\text { RS- } \\
\text { Gains }\end{array}$ & $\begin{array}{l}\text { Factor 2: } \\
\text { RS-Non- } \\
\text { Gains }\end{array}$ & $\begin{array}{l}\text { Factor 3: } \\
\text { RS- } \\
\text { Losses }\end{array}$ & $\begin{array}{l}\text { Factor 4: } \\
\text { RS-Non- } \\
\text { Losses }\end{array}$ & $\begin{array}{l}\text { Factor 5: } \\
\text { IMP- } \\
\text { Gains }\end{array}$ & $\begin{array}{l}\text { Factor 6: } \\
\text { IMP- } \\
\text { Non- } \\
\text { Gains }\end{array}$ & $\begin{array}{l}\text { Factor 7: } \\
\text { RF- } \\
\text { Gains }\end{array}$ & $\begin{array}{l}\text { Factor 8: } \\
\text { RF-Non- } \\
\text { Gains }\end{array}$ & $\begin{array}{l}\text { Factor 9: } \\
\text { RF- } \\
\text { Losses }\end{array}$ & $\begin{array}{l}\text { Factor } \\
10: \\
\text { RF-Non- } \\
\text { Losses }\end{array}$ & $\begin{array}{l}\text { Factor } \\
11: \\
\text { MGO- } \\
\text { Gains }\end{array}$ & $\begin{array}{l}\text { Factor } \\
12: \\
\text { PGO- } \\
\text { Gains }\end{array}$ & $\begin{array}{l}\text { Factor } \\
13: \\
\text { PGO- } \\
\text { Losses }\end{array}$ & $\begin{array}{l}\text { Factor } \\
\text { 14: EXT- } \\
\text { Gains }\end{array}$ & $\begin{array}{l}\text { Factor } \\
\text { 15: EXT- } \\
\text { Non- } \\
\text { Losses }\end{array}$ & $\begin{array}{l}\text { Factor } \\
\text { 16: RT- } \\
\text { Losses }\end{array}$ & $\begin{array}{l}\text { Factor } \\
\text { 17: RT- } \\
\text { Non- } \\
\text { Losses }\end{array}$ \\
\hline Factor 1 & 1.00 & & & & & & & & & & & & & & & & \\
\hline Factor 2 & -.216 & 1.00 & & & & & & & & & & & & & & & \\
\hline Factor 3 & .006 & .045 & 1.00 & & & & & & & & & & & & & & \\
\hline Factor 4 & .069 & -.099 & -.470 & 1.00 & & & & & & & & & & & & & \\
\hline Factor 5 & .445 & -.400 & .107 & -.058 & 1.00 & & & & & & & & & & & & \\
\hline Factor 6 & -.390 & .450 & .046 & .059 & -.405 & 1.00 & & & & & & & & & & & \\
\hline Factor 7 & .513 & -.370 & -.016 & .104 & .512 & -.449 & 1.00 & & & & & & & & & & \\
\hline Factor 8 & -.246 & .562 & .006 & .054 & -.471 & .534 & -.298 & 1.00 & & & & & & & & & \\
\hline Factor 9 & .034 & .080 & .534 & -.472 & .053 & -.023 & -.009 & -.013 & 1.00 & & & & & & & & \\
\hline Factor 10 & .184 & -.054 & -.395 & .531 & -.075 & -.065 & .136 & .021 & -.348 & 1.00 & & & & & & & \\
\hline Factor 11 & .494 & -.388 & .020 & -.002 & .543 & -.567 & .542 & -.369 & .036 & .148 & 1.00 & & & & & & \\
\hline Factor 12 & .511 & -.286 & .160 & -.095 & .491 & -.428 & .426 & -.269 & .126 & -.101 & .478 & 1.00 & & & & & \\
\hline Factor 13 & -.072 & .079 & .486 & -.452 & .032 & .146 & -.069 & .022 & .474 & -.586 & -.064 & .199 & 1.00 & & & & \\
\hline Factor 14 & .509 & -.264 & -.069 & -.049 & .545 & -.496 & .504 & -.394 & -.030 & -.018 & .507 & .433 & -.099 & 1.00 & & & \\
\hline Factor 15 & .109 & -.148 & -.544 & .593 & -.094 & -.058 & .121 & .001 & -.446 & .566 & .062 & -.121 & -.466 & -.172 & 1.00 & & \\
\hline Factor 16 & -.118 & .081 & .474 & -.453 & .001 & .063 & -.100 & .005 & .595 & -.556 & -.012 & .075 & .575 & -.122 & -.432 & 1.00 & \\
\hline Factor 17 & .057 & -.138 & -.533 & .571 & -.113 & .007 & -.003 & .006 & -.404 & .557 & -.008 & -.171 & -.456 & -.100 & .604 & -.350 & 1.00 \\
\hline
\end{tabular}

Note. RS = Reinforcement Sensitivity; IMP = Impulsivity; RF = Regulatory Focus; MGO = Mastery Goal Orientation; PGO = Performance Goal Orientation; EXT = Extraversion; RT = Risk-Taking. 
Figure 1

Summary of Results From Scott and Hauenstein (2011)

\section{Subscales - Items Retained}

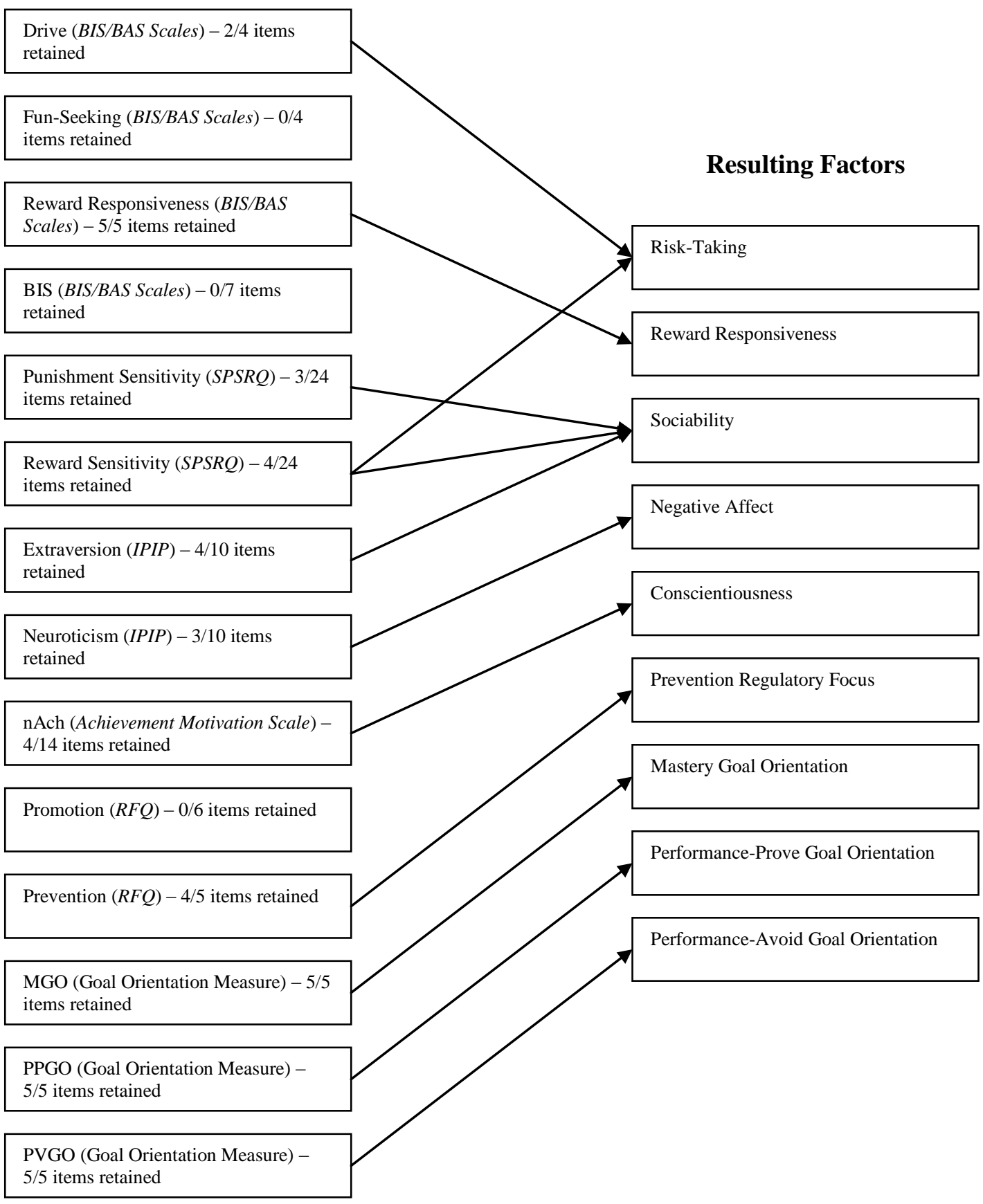


Figure 2

Two-Dimensional Model

Increasing Gains Via Approach Example:

I intensely feel the excitement of earning a reward.

\begin{tabular}{ccccc}
$\longrightarrow$ & 2 & 3 & 4 & 5 \\
Stronglydisagree & Disagree & Neither agree nor disagree & Agree & Stronglyagree \\
& & & & \\
\hline
\end{tabular}

*increasing gains

Increasing Losses Via Avoidance Example:

I am overly sensitive to punishments.

$\begin{array}{ccccc}\longrightarrow & 2 & 3 & 4 & 5 \\ \text { Strongly disagree } & \text { Disagree } & \text { Neither agree nor disagree } & \text { Agree } & \text { Strongly agree } \\ & & & & \\ & & & \\ \end{array}$

*increasing losses 
Figure 3

Four-Dimensional Model

Increasing Gains Via Approach Example:

I have a clear vision of my life goals.

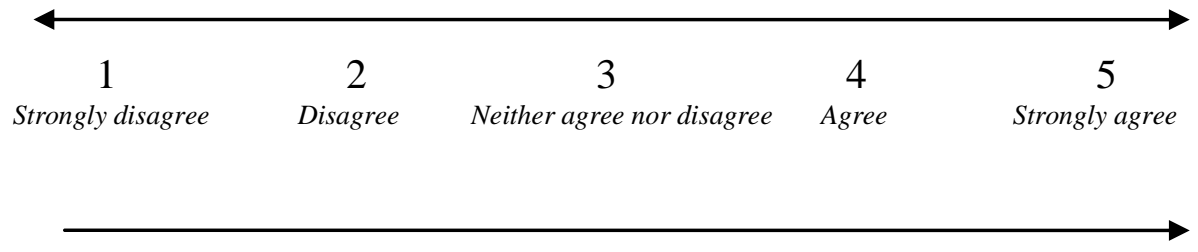

*increasing gains

Increasing Non-Gains Via Approach Example:

I waste time daydreaming.

$\begin{array}{ccccc}\longrightarrow & 2 & 3 & 4 & 5 \\ \text { Strongly disagree } & \text { Disagree } & \text { Neither agree nor disagree } & \text { Agree } & \text { Stronglyagree } \\ & & & & \\ \end{array}$

*increasing non-gains

Increasing Losses Via Avoidance Example:

I blindly follow social norms.

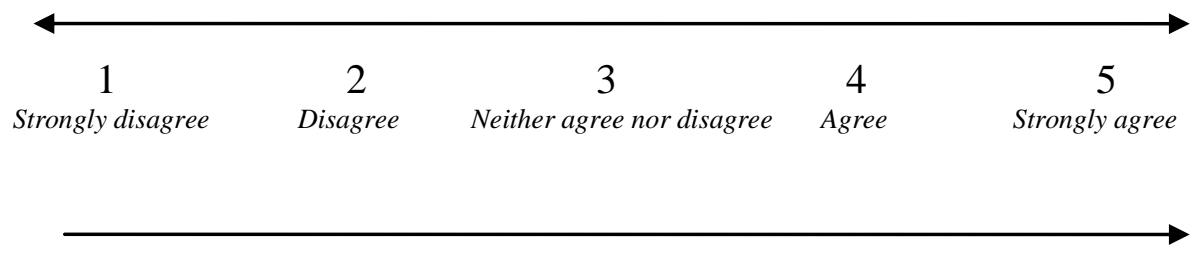

*increasing losses 
Increasing Non-Losses Via Avoidance Example:

I can be counted on.

\begin{tabular}{ccccc}
$\longrightarrow$ & 2 & 3 & 4 & 5 \\
Strongly disagree & Disagree & Neither agree nor disagree & Agree & Strongly agree \\
& & & & \\
& & & \\
\hline
\end{tabular}

*increasing non-losses 
Figure 4

Hierarchical "Sociability as Approach” Model Structural Diagram

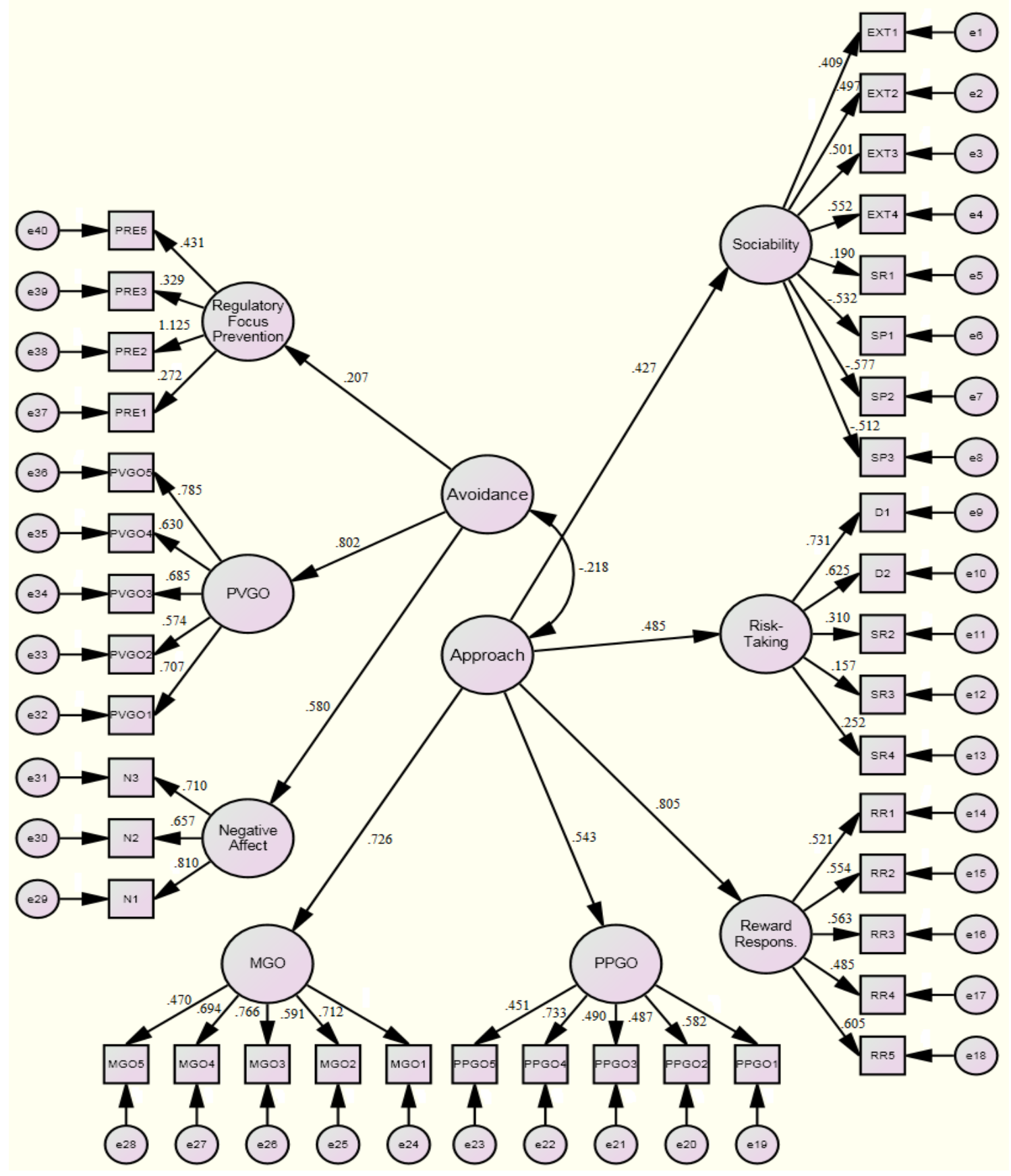

Note. Standardized factor loading estimates and inter-factor correlations are displayed. e $=$ error; EXT $=$ Extraversion; SR = Sensitivity to Reward; SP = Sensitivity to Punishment; D = Behavioral Activation System - Drive; Reward Respons., $\mathrm{RR}=$ Reward Responsiveness; $\mathrm{PPGO}=$ Performance-Prove Goal Orientation; $\mathrm{MGO}=$ Mastery Goal Orientation; $\mathrm{N}=$ Neuroticism; PVGO = Performance-Avoid Goal Orientation; PRE = Regulatory Focus Prevention. 
Figure 5

Hierarchical “Without Sociability” Model Structural Diagram

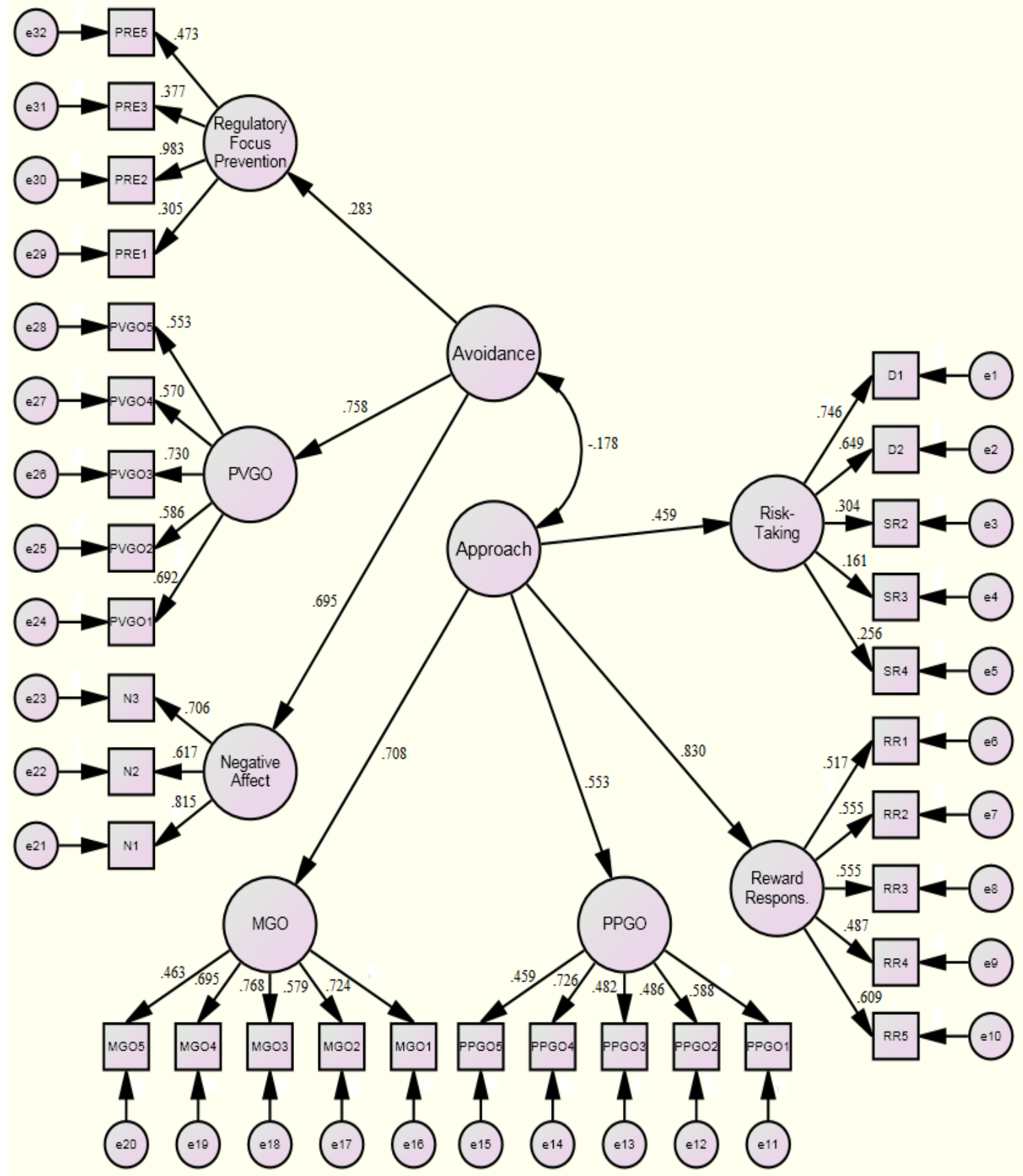

Note. Standardized factor loading estimates and inter-factor correlations are displayed. e = error; $\mathrm{D}=$ Behavioral Activation System - Drive; SR = Sensitivity to Reward; Reward Respons., RR = Reward Responsiveness; PPGO = Performance-Prove Goal Orientation; MGO = Mastery Goal Orientation; N = Neuroticism; PVGO = Performance-Avoid Goal Orientation; PRE = Regulatory Focus Prevention. 
Figure 6

Scree Plot of Initial Exploratory Factor Analysis Solution for the Two-Dimensional Model

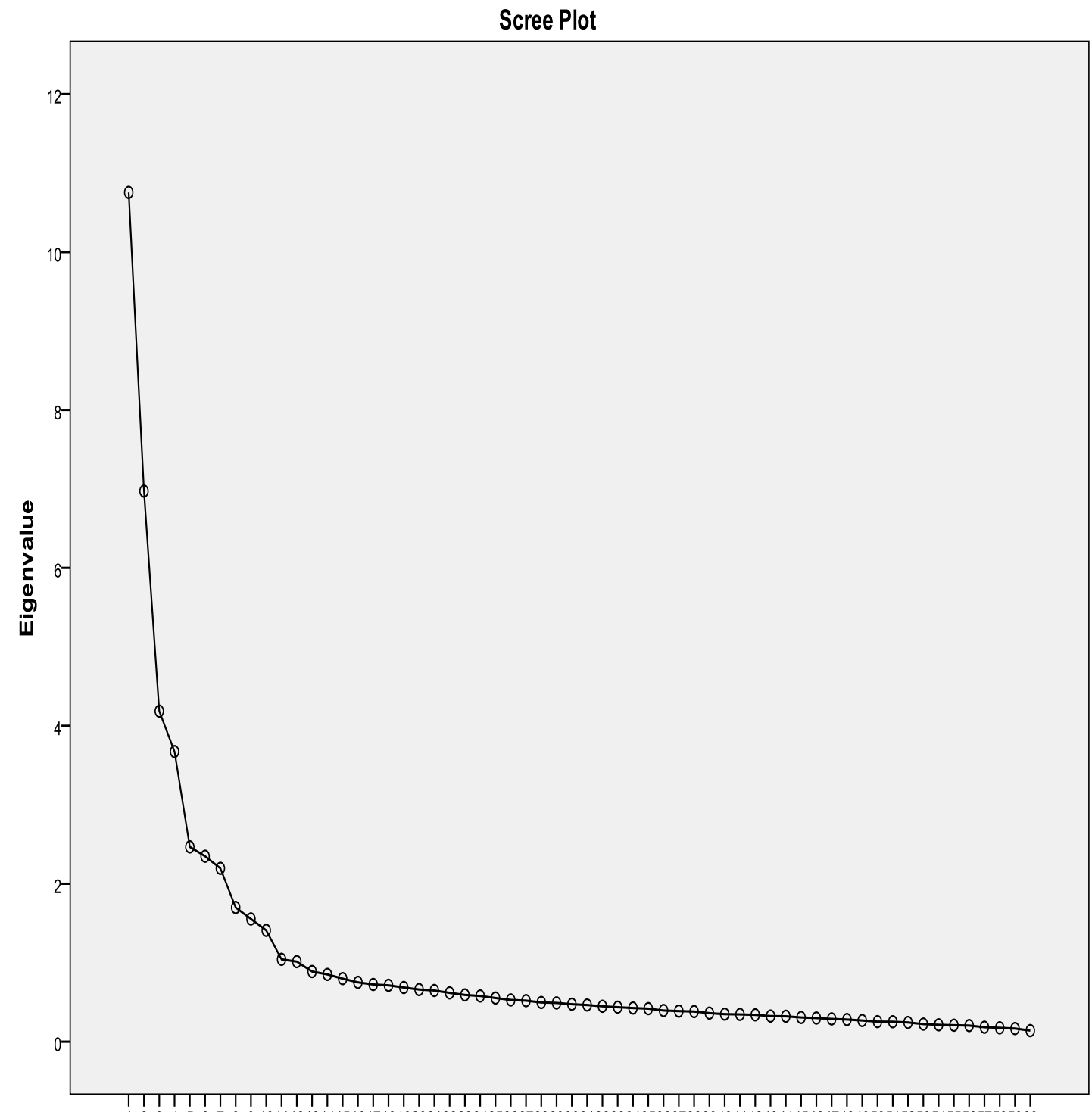

123456789101112131415161718192021222324252627282930313233343536373839404142434445464748495051525354555657585960

\section{Factor Number}


Figure 7

Two-Dimensional Model Structural Diagram
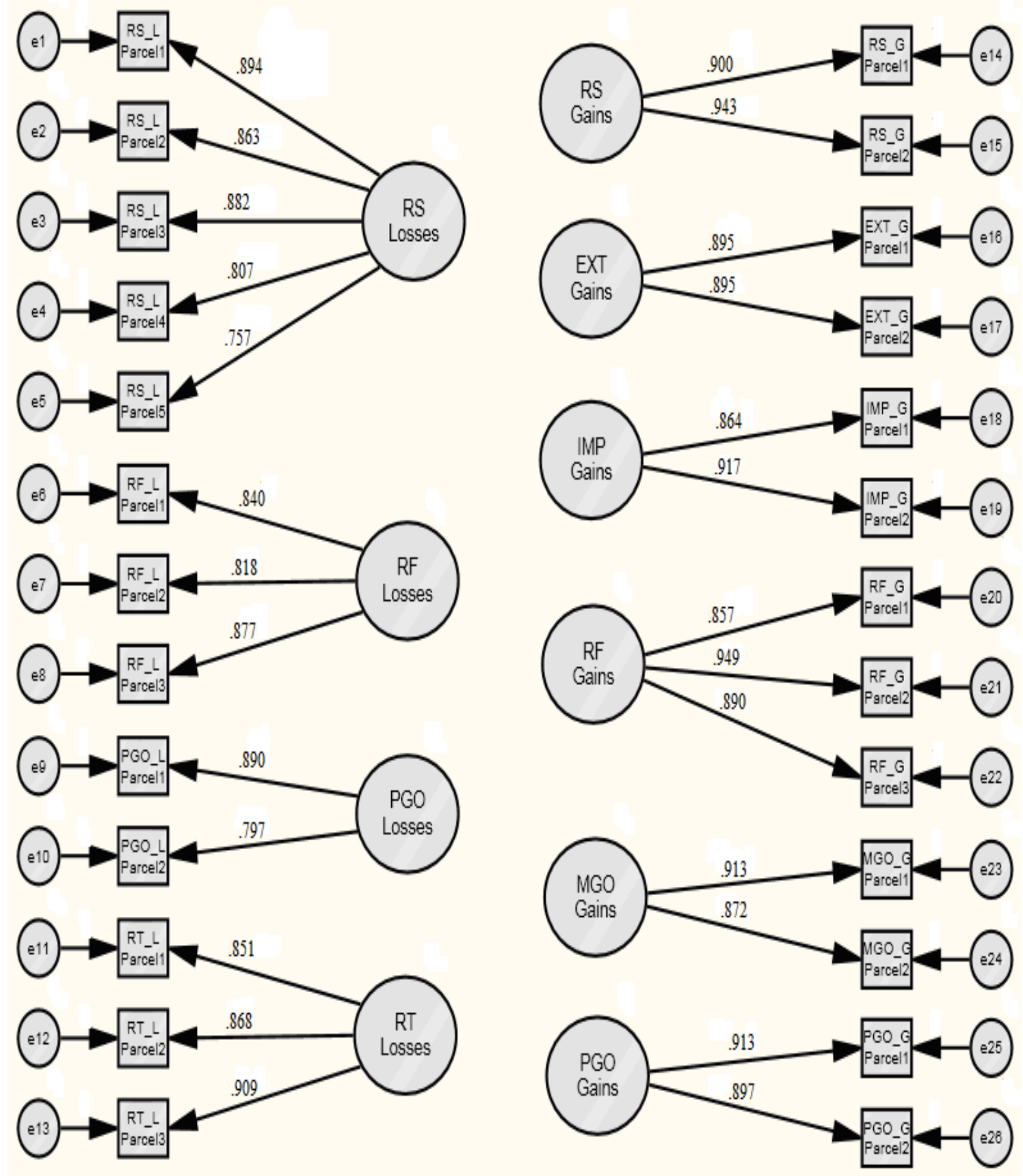

Note. Standardized factor loading estimates are displayed. Inter-factor correlations were estimated, but are provided in Table 4 due to space constraints. e = error; RS = Reinforcement Sensitivity; RF = Regulatory Focus; PGO = Performance Goal Orientation; RT = Risk-Taking; EXT = Extraversion; IMP = Impulsivity; $\mathrm{MGO}=$ Mastery Goal Orientation; L = Losses; $\mathrm{G}=$ Gains. 
Figure 8

Hierarchical Two-Dimensional Model Structural Diagram

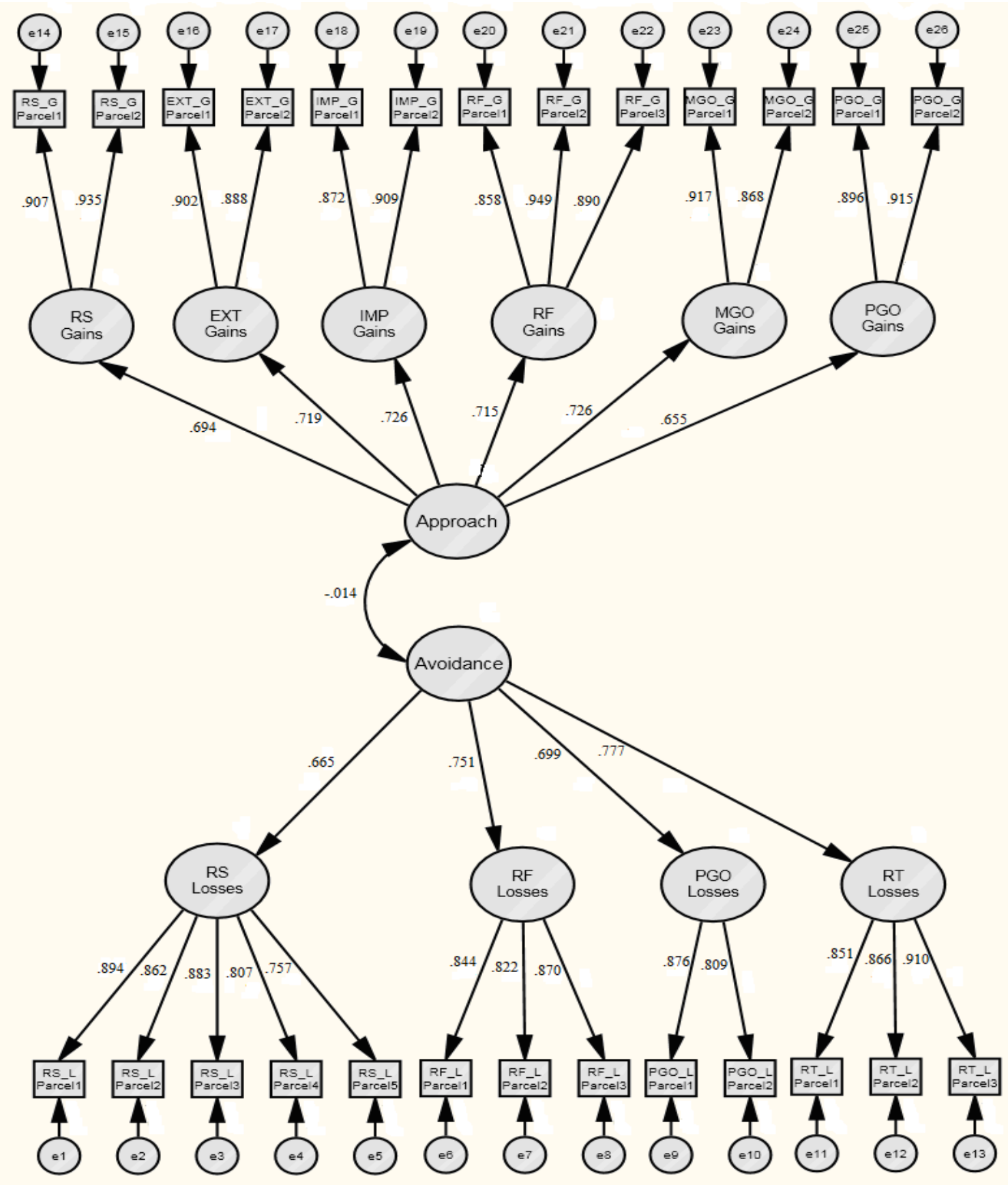

Note. Standardized factor loading estimates and inter-factor correlations are displayed. $\mathrm{e}=$ error; $\mathrm{RS}=$ Reinforcement Sensitivity; RF = Regulatory Focus; PGO = Performance Goal Orientation; RT = Risk-Taking; EXT = Extraversion; IMP $=$ Impulsivity; MGO = Mastery Goal Orientation; $\mathrm{L}=$ Losses; $\mathrm{G}=$ Gains. 
Figure 9

Scree Plot of Initial Exploratory Factor Analysis Solution for the Four-Dimensional Model

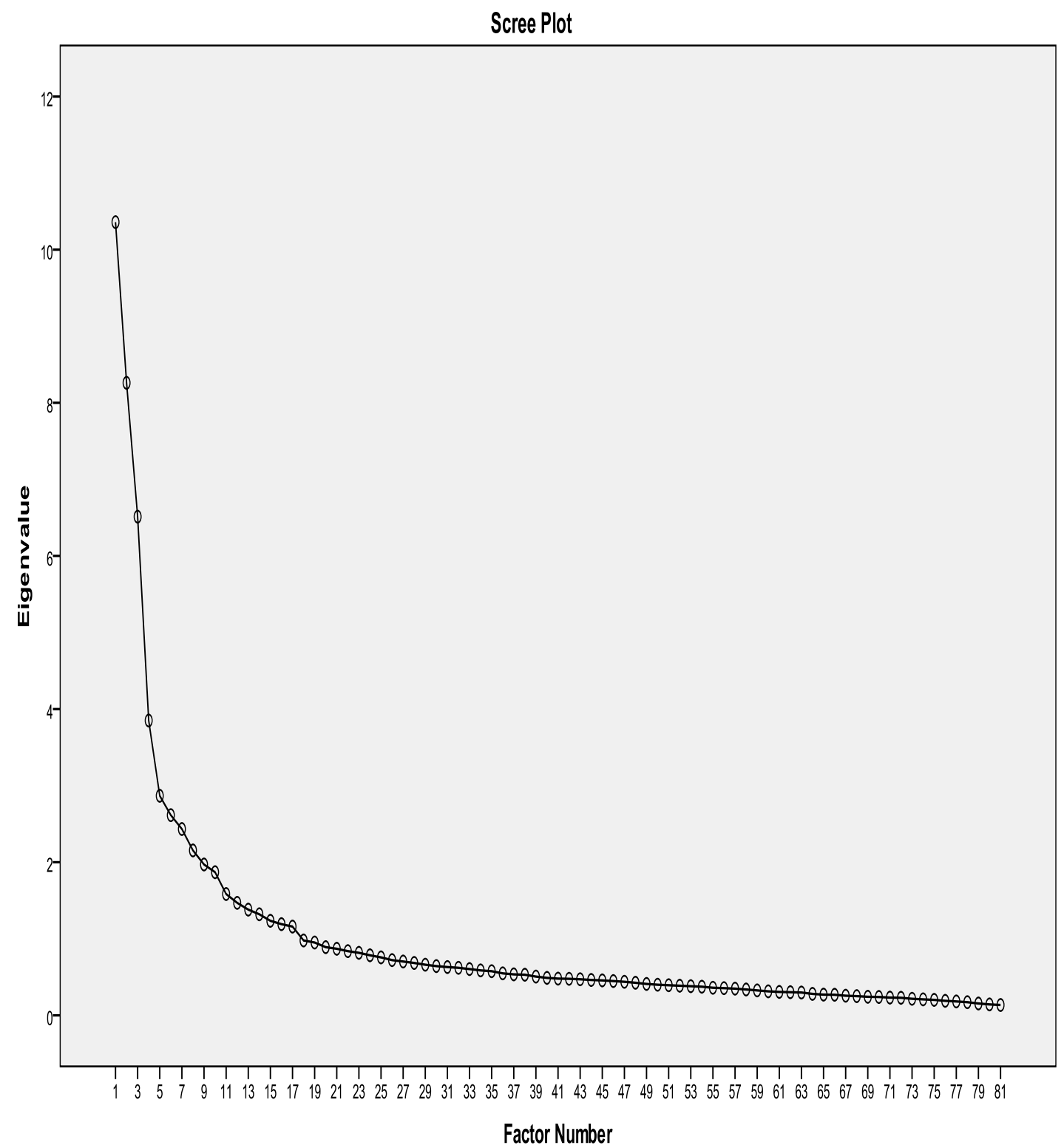


Figure 10

Four-Dimensional Model Structural Diagram
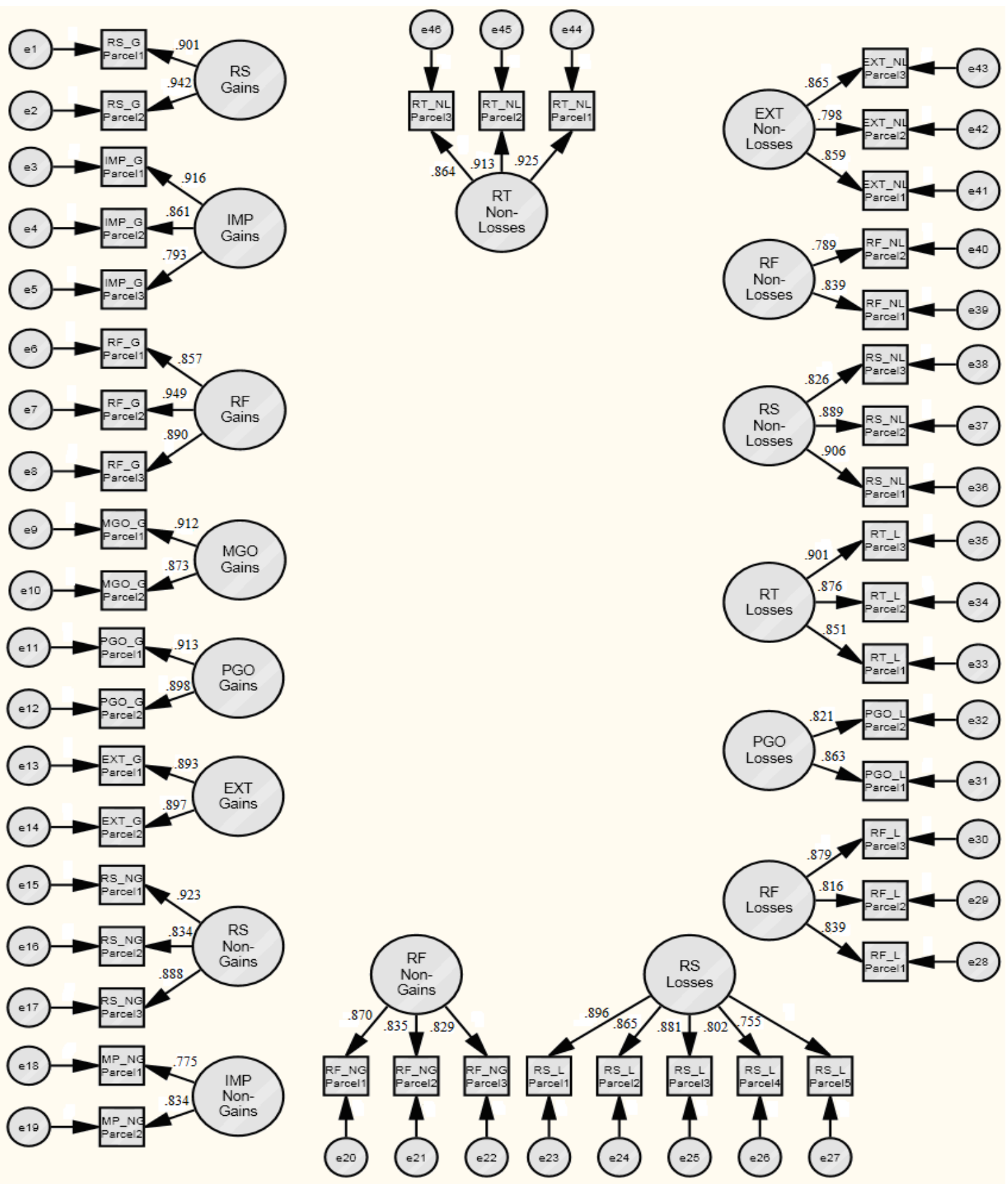

Note. Standardized factor loading estimates are displayed. Inter-factor correlations were estimated, but are provided in Table 7 due to space constraints. e = error; RS = Reinforcement Sensitivity; RF = Regulatory Focus; PGO = Performance Goal Orientation; $\mathrm{RT}=$ Risk-Taking; EXT = Extraversion; IMP = Impulsivity; MGO = Mastery Goal Orientation; $\mathrm{G}=$ Gains; NG = Non-Gains; L = Losses; NL = Non-Losses. 
Figure 11

Hierarchical Four-Dimensional Model Structural Diagram

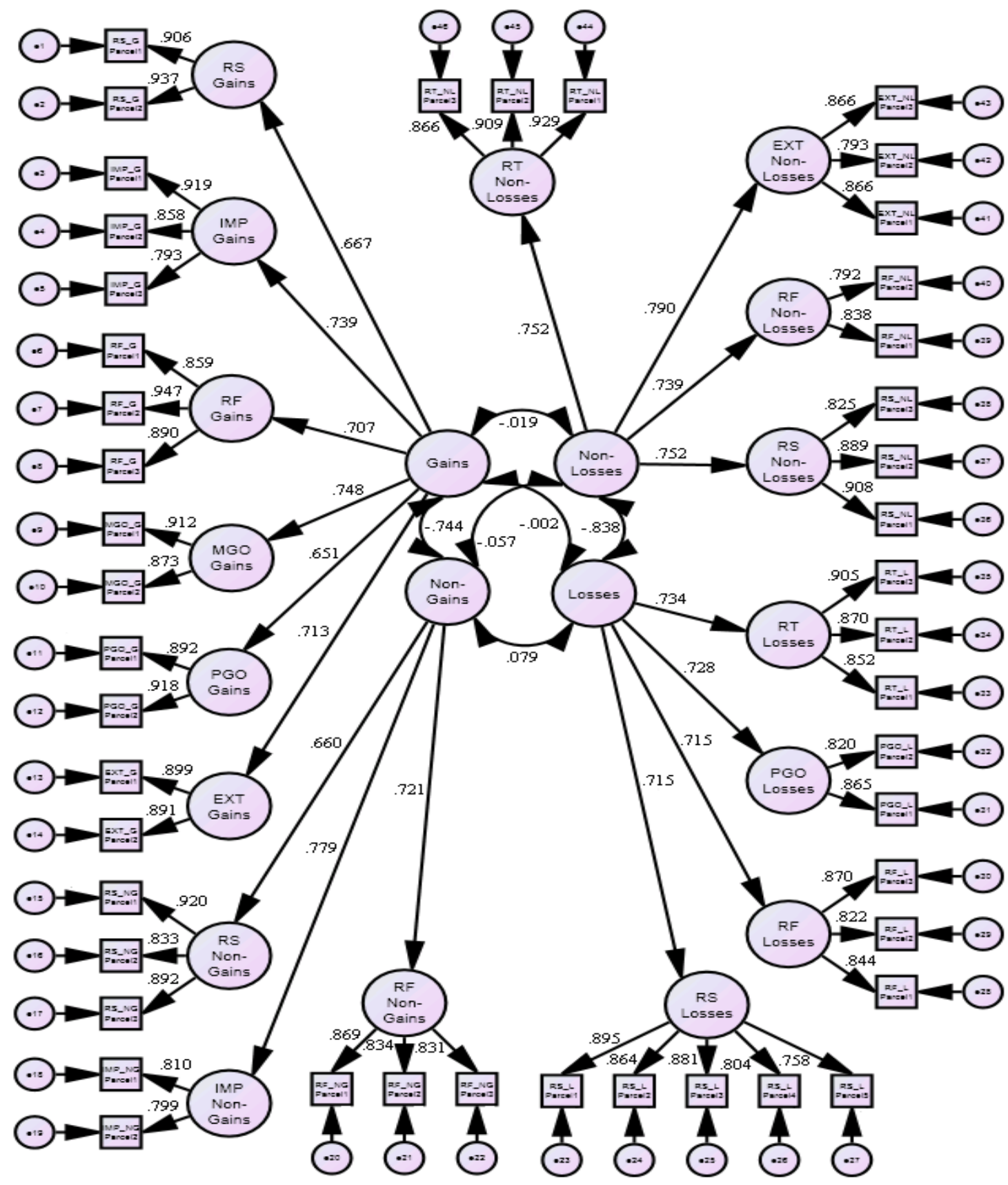

Note. Standardized factor loading estimates and inter-factor correlations are displayed. $\mathrm{e}=$ error; $\mathrm{RS}=$ Reinforcement Sensitivity; RF = Regulatory Focus; $\mathrm{PGO}=$ Performance Goal Orientation; RT = Risk-Taking; EXT = Extraversion; IMP = Impulsivity; $\mathrm{MGO}=$ Mastery Goal Orientation; G = Gains; NG = Non-Gains; L = Losses; NL = Non-Losses. 
Figure 12

Scale-Level Hierarchical Four-Dimensional Model Structural Diagram

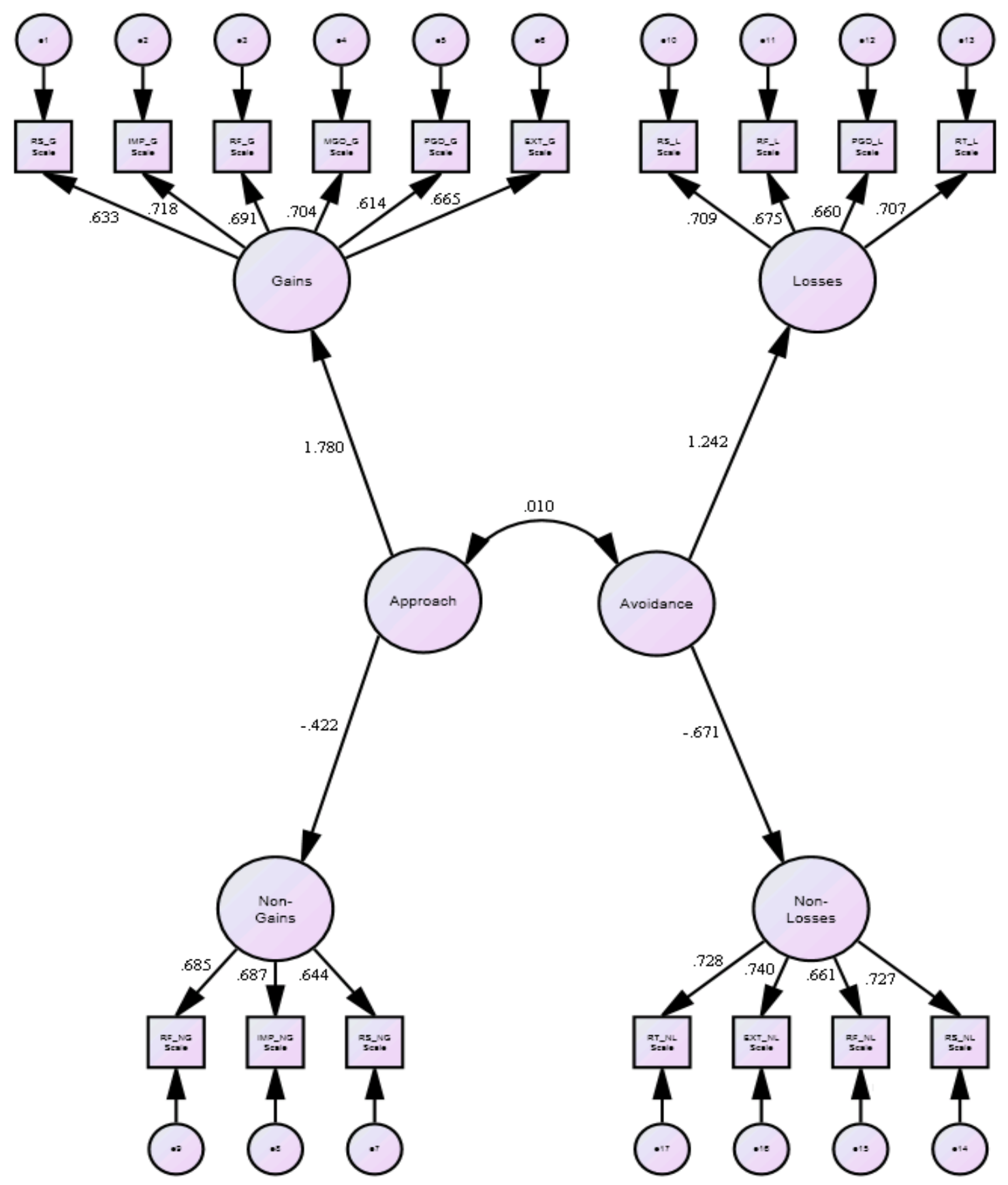

Note. Standardized factor loading estimates and inter-factor correlations are displayed. $\mathrm{e}=$ error; RS $=$ Reinforcement Sensitivity; RF = Regulatory Focus; PGO = Performance Goal Orientation; RT = Risk-Taking; EXT = Extraversion; IMP = Impulsivity; $\mathrm{MGO}=$ Mastery Goal Orientation; $\mathrm{G}=$ Gains; $\mathrm{NG}=$ Non-Gains; $\mathrm{L}=$ Losses; NL = Non-Losses. 
Figure 13

Implied Outcomes Model Structural Diagram

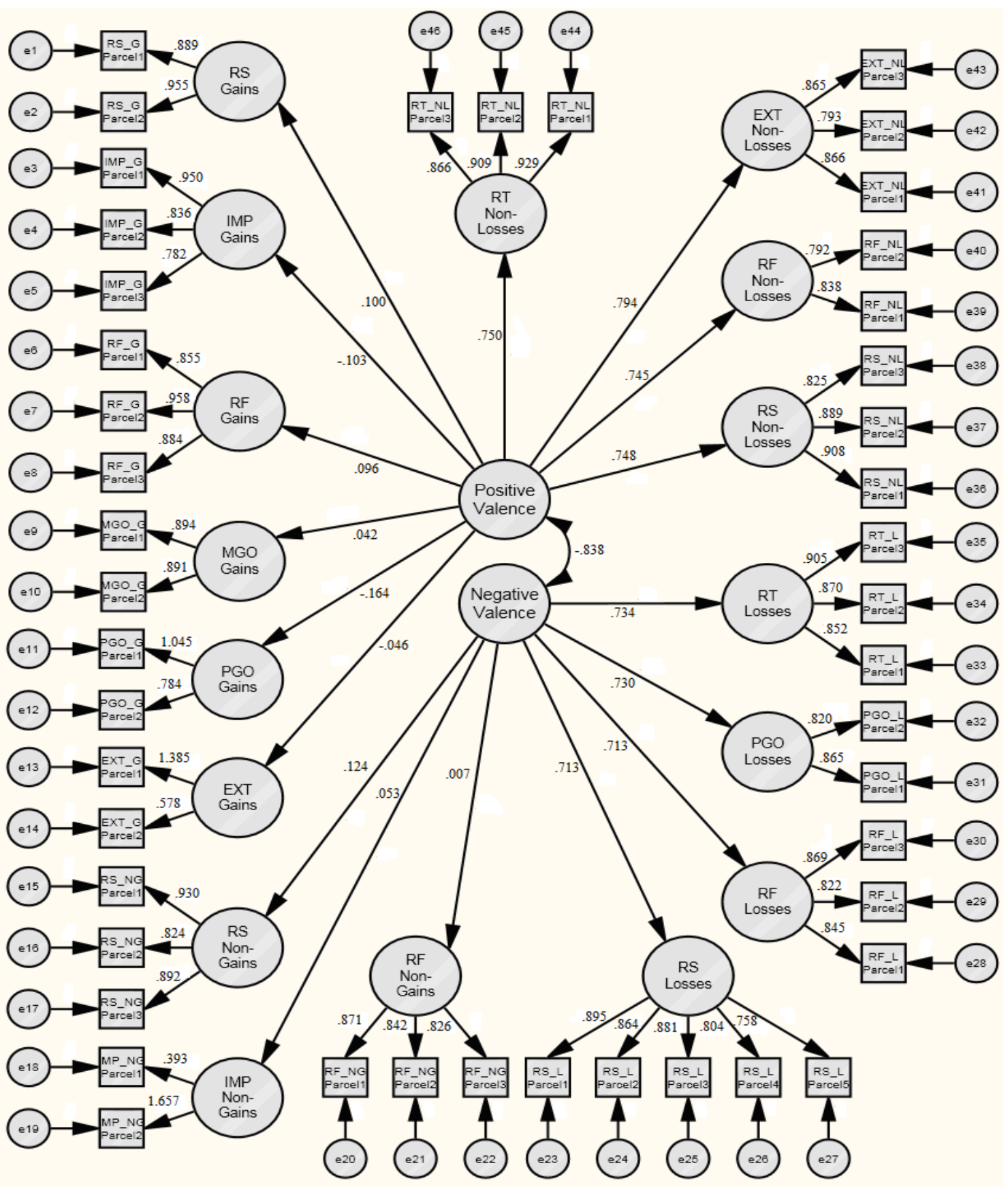

Note. Standardized factor loading estimates and inter-factor correlations are displayed. $\mathrm{e}=$ error; $\mathrm{RS}=$ Reinforcement Sensitivity; RF = Regulatory Focus; PGO = Performance Goal Orientation; RT = Risk-Taking; EXT = Extraversion; IMP = Impulsivity; MGO = Mastery Goal Orientation; G = Gains; NG = Non-Gains; L = Losses; NL = Non-Losses. 


\section{Appendix A}

Informed Consent Form

Study Title: "Approach-Avoidance Personality Questionnaires and Job Performance”

\section{Purpose:}

Thank you for considering participation in this research. This study session is conducted by researchers at Virginia Tech and is for academic purposes. The purpose of this research is to develop a valid, encompassing measure of approach-avoidance personality that predicts job performance.

\section{Procedure \& Compensation:}

This study will take approximately 60 minutes and you will be given 1 credit in return for your participation.

During this study you will be asked to respond to various personality questionnaires.

If you are employed at least part-time, you will have the opportunity to receive 1 additional credit and an opportunity to win a \$25 VISA gift card by providing your supervisor's contact information (i.e., company, name, position, and e-mail) in order for us to verify their status and ask them to complete a brief online job performance questionnaire that will be linked to your personality data. You will receive an additional extra credit point and be entered into the drawing once contact information is provided and verified. While we appreciate it if you would encourage your supervisor to complete this confidential evaluation, neither the additional extra credit, nor the odds of winning the drawing, will be affected by whether or not your supervisor decides to complete the job performance questionnaire.

\section{Risk:}

There is no more than minimal risk involved in this study.

\section{Benefit:}

The benefit of this research is in contributing to academic knowledge in the areas of personality and job performance. Any such knowledge obtained during this research will be shared with the academic community via publication in the relevant journals. Any and all data will be reported in aggregate form. You may also have the opportunity to learn more about psychological research through your participation in this research.

\section{Confidentiality and Anonymity:}

Your participation is entirely confidential. Your name and identity cannot be associated with any of the information or data you provide here today. You will be assigned a random ID number that cannot be linked to your name. Only the researchers themselves will have access to your data and it will be kept on a password protected computer at all times.

\section{Freedom to Withdraw:}

You are free to withdraw from the study at any time with no penalty. Should you choose to terminate your participation at any time for any reason, you will be compensated for the portion of the time you have spent in the study. 


\section{Contact Information:}

If you have any questions, please feel free to ask the researcher at any time during this study session. Should you have questions after this study is over, please feel free to contact the graduate researcher,

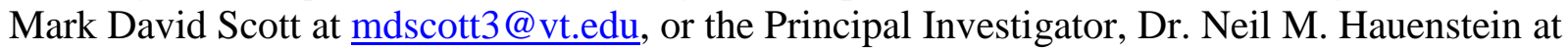
nhauen@vt.edu.

If you should have any questions about the protection of human research participants regarding this study, please contact (a) Dr. David W. Harrison, Chair of Psychology Department Human Subjects Committee, telephone (540) 231-4422, email: dwh@vt.edu, address: Mail Code 0436, Department of Psychology, Virginia Tech, Blacksburg, VA 24061, or (b) Dr. David Moore, Chair Virginia Tech Institutional Review Board for the Protection of Human Subjects, telephone (540) 231-4991, email: moored@vt.edu, address: Research Compliance Office, 1880 Pratt Drive, Suite 2006 (0497), Blacksburg, VA 24061.

\section{Subject Permission:}

If you wish to participate in this study please type your initials below:

I have read the Consent Form and conditions of this project. I have had all my questions answered. I hereby acknowledge the above and give my voluntary consent:

Initials:

**Consent form may be administered on the computer with participants' typing in their initials serving as their consent; these initials cannot be linked to their data** 


\section{Appendix B}

\section{Debriefing Form}

Thank you for your participation in this study.

The purpose of this study is to develop a valid, encompassing measure of approach-avoidance personality that predicts job performance.

Should you have questions, please feel free to contact the graduate researcher, Mark David Scott at $\underline{\text { mdscott3@vt.edu, }}$ or the Principal Investigator, Dr. Neil M. Hauenstein at nhauen@vt.edu.

If you should have any questions about the protection of human research participants regarding this study, please contact (a) Dr. David W. Harrison, Chair of Psychology Department Human Subjects Committee, telephone (540) 231-4422, email: dwh@ vt.edu, address: Mail Code 0436, Department of Psychology, Virginia Tech, Blacksburg, VA 24061, or (b) Dr. David Moore, Chair Virginia Tech Institutional Review Board for the Protection of Human Subjects, telephone (540) 231-4991, email: moored@vt.edu, address: Research Compliance Office, 1880 Pratt Drive, Suite 2006 (0497), Blacksburg, VA 24061. 


\section{Appendix C}

\section{Full Item Content of the Approach-Avoidance Scales}

Reinforcement Sensitivity - Gains:

1) "When I get something I want, I feel excited and energized" *

2) "When good things happen to me, it affects me strongly" *

3) "When I see an opportunity for something I like I get excited right away" *

4) "My emotional sensitivity to potential rewards pays off" $X$

5) "I have good instincts when it comes to acquiring rewards" $X$

6) "I'm effective when I expect positive outcomes" $X$

7) "I effectively and accurately anticipate rewards" $X$

8) "I intensely feel the excitement of earning a reward"

Reinforcement Sensitivity - Non-Gains:

1) "I can look foolish because I'm so in tune with acquiring rewards"

2) "I get overly excited about trivial rewards"

3) "My immediate reactions often overestimate how much I want something"

4) "People tell me that I get overexcited about things"

5) "I have difficulty controlling my excitement"

6) "My reactions to rewarding events come across as desperate"

7) "I'm too focused on potential rewards"

8) "People are turned off by my overexcited nature"

Reinforcement Sensitivity - Losses:

1) "I am overanxious about potential threats"

2) "I'm too jumpy"

3) "I have a negative gut reaction to criticism" $X$

4) "I worry too much about bad things"

5) "I am overly sensitive to punishments"

6) "I startle too easily"

7) "When bad things happen to me, it affects me strongly"

8) "I am bothered by intense stimuli"

Reinforcement Sensitivity - Non-Losses:

1) "My keen sense of threats has kept me safe"

2) "I have good instincts about threats in my environment"

3) "My vigilance keeps bad things from happening"

4) "I avoid bad things by anticipating of what might go wrong"

5) "I'm effective because I anticipate all the ways things could go bad"

6) "My nature helps me avoid things going wrong"

7) "I accurately identify potential threats" 
8) "I see the problems that others miss"

Impulsivity - Gains:

1) "My first response is usually the most effective" $X$

2) "I'm decisive"

3) "I do not waste time over-thinking a problem"

4) "By acting quickly, I don't miss out on opportunities"

5) "I'm effective when I act on my impulses"

6) "I'm efficient because I act quickly"

7) "I make decisions quickly and effectively"

8) "People respect my decisive manner"

Impulsivity - Non-Gains:

1) PRF Impulsivity item \#1 $1^{X}$

2) $P R F$ Impulsivity item $\# 2^{X}$

3) PRF Impulsivity item \#3

4) PRF Impulsivity item \#4

5) PRF Impulsivity item \#5

6) "I miss out on opportunities because I'm impulsive"

7) "I should think more before I respond"

8) "I'm too hasty"

Impulsivity - Losses:

1) "I tend to over-analyze" $X$

2) "I think too much about what can go wrong" $X$

3) "My focus on the details often prevents me from making a decision" $X$

4) "When faced with a problem, I get so caught up in things that I never enact a solution" $X$

5) "I become overwhelmed when presented with many options" $X$

6) "People tell me that I over-analyze problems" $X$

7) "Excessive details often prevent me from completing a task at hand" $X$

8) "I have difficulty handling a lot of information at once" $X$

Impulsivity - Non-Losses:

1) "I'm effective because I keep my options open" $X$

2) "I seem to make better decisions when I wait until a decision is really needed" $X$

3) "Waiting allows me time to fully develop my ideas" $X$

4) "It is better if I collect my thoughts before acting" $X$

5) "I'm better when I have time to think about what I should do" $X$

6) "I avoid mistakes by being patient" $X$

7) "I delve into issues and ideas before making decisions" $X$

8) "I take time to carefully consider my options" $X$ 
Regulatory Focus - Gains:

1) "What I do today is guided by my hopes and aspirations"

2) "I have a clear vision of my life goals"

3) "I am focused on my hopes and aspirations"

4) "I tend to eagerly pursue that which I want to accomplish"

5) "I have a vision of the person that I would ideally like to be"

6) "I live by a set of internal standards"

7) "Pursuing my hopes and aspirations is when I'm most effective"

8) "Following my internal standards has led to personal growth"

Regulatory Focus - Non-Gains:

1) "My life goals are too abstract"

2) "My hopes and aspirations are unrealistic"

3) "I focus on grand plans that lack the details of how to accomplish them"

4) "I'm too focused on the big picture"

5) "I waste time daydreaming"

6) "My ambitions are too vague"

7) "My desires for the future are impractical"

8) "I have missed out on opportunities by chasing my dreams"

Regulatory Focus - Losses:

1) "I follow rules too much"

2) "I blindly follow social norms"

3) "I focus too much on the responsibilities in my life"

4) "I never question authority, even when I should"

5) "I am too sensitive to the expectations of others"

6) "I only do things that others will like"

7) "I focus too much on the person others tell me I ought to be"

8) "I fail to recognize when "playing by the rules" can be a bad thing"

Regulatory Focus - Non-Losses:

1) "I'm sensitive to keeping my promises"

2) "I think about the person that I ought to be"

3) "I am attentive to fulfilling assigned duties"

4) "I can be counted on"

5) "I keep my promises"

6) "I fulfill others' expectations of me" $X$

7) "I effectively avoid letting others down"

8) "My responsible nature has kept me safe" $X$

Mastery Goal Orientation - Gains: 
1) "I enjoy challenging and difficult tasks where I'll learn new skills" *

2) "I enjoy opportunities to extend the range of my abilities" *

3) "The opportunity to learn new things is important to me" *

4) "The opportunity to do challenging work is important to me" *

5) "I feel good when I am doing something that helps me grow" *

Performance Goal Orientation - Gains:

1) "I want others to recognize that I am one of the best" *

2) "It is important to me to perform better than others" *

3) "I feel good when I can prove to myself that I am better than others" *

4) "It makes me feel good to have an audience when I outperform others" *

5) "I enjoy proving my ability to others on tasks" *

Performance Goal Orientation - Non-Gains:

1) "I tend to show off" $X$

2) "I turn friendly games into serious competitions" $X$

3) "My competitive nature gets the best of me" $X$

4) "My desire to win has hurt my chances at forming new relationships" $X$

5) "Winning is too important to me" $X$

6) "I am a sore loser" $x$

7) "People are turned off by my hypercompetitive nature" $x$

8) "I miss out on opportunities by being overly competitive" $X$

Performance Goal Orientation - Losses:

1) "I try to avoid discovering that others are better than me" *

2) "When I know my work will be compared to that of others, I get so nervous that I procrastinate" *

3) "I am reluctant to ask questions because others may think I'm incompetent" *

4) "I try to hide from others that they are better than me" *

5) "It makes me anxious when I know my family and friends will compare my failures to those of others" *

Extraversion - Gains/Losses:

1) "I am the life of the party" *

2) "I feel comfortable around people"

3) "I start conversations"

4) "I don't mind being the center of attention" *

5) "I take charge"

6) "I take control of things"

Extraversion - Non-Gains:

1) "I talk too much" $X$ 
2) "I don't listen to others well" $X$

3) "I tell others what to do" $X$

4) "I interrupt others" $X$

5) "Others tune me out" $X$

6) "I dominate conversation" $X$

7) "I miss out on things by not listening well" $X$

8) "I'm too eager to state my opinions" $X$

Extraversion - Non-Losses:

1) "I have a quiet strength"

2) "I learn by listening"

3) "I use silence to gather my thoughts"

4) "I project a calm confidence"

5) "I seek depth over breadth"

6) "People like me because I'm a good listener"

7) "I use my quiet demeanor to be heard amid the noise"

8) "I avoid missing important information by paying attention to others"

Neuroticism - Losses:

1) "I have frequent mood swings" *

2) "I get upset easily" *

3) "I get overwhelmed by emotions"

4) "I worry about things"

5) "I get caught up in my problems"

6) "I get upset by unpleasant thoughts that come into my mind"

Risk-Taking - Gains:

1) "When I go after something I use a 'no holds barred' approach" * $X$

2) "I am interested in money to the point of being able to do risky jobs" * $X$

3) "I like displaying my physical abilities even though this may involve danger" $* X$

4) "When I want something I usually go all-out to get it" * $X$

5) "People admire my ability to make the right risky decisions" $X$

6) "I tend to be successful when using an 'all-out' approach" $X$

7) "I'm willing to risk it all for a big pay off" $X$

8) "I prefer riskier investments that have the potential for big returns" $X$

Risk-Taking - Non-Gains:

1) "My reckless nature has proven ineffective" $X$

2) "I'm irresponsible when it comes to risk" $X$

3) "I take unnecessary risks" $X$

4) "I tend to overlook 'a sure thing' because of my risky nature" $X$

5) "I miss out on things because I'm poor at assessing risk" $X$ 
6) "My tolerance for risk-taking can be a bad thing" $X$

7) "I have missed out on opportunities by being too risky" $X$

8) "I'm too eager to engage in risky activities" $X$

Risk-Taking - Losses:

1) "Taking too many precautions has held me back in life"

2) "People tell me that I'm too cautious"

3) "I'm too slow to adopt new ways of doing things"

4) "My unwillingness to try new things has left me "stuck in a rut",

5) "I get left out because I avoid risky behaviors"

6) "I stick to what I know too much"

7) "I have lost competitions by being too cautious"

8) "I am too sensitive to risk"

Risk-Taking - Non-Losses:

1) "My decisions are always made carefully and accurately" $X$

2) "I'm quite cautious when I make plans and when I act on them"

3) "I tend to take precautions"

4) "The best investments are where my money is safe even though the returns are small"

5) "I have kept out of trouble by not taking risks"

6) "My careful nature has kept me safe"

7) "I avoid losses by investing conservatively"

8) "I'm effective because of my aversion to risk"

Note. Items that were dropped on the basis of simple structure criteria are indicated with a superscript $X\left({ }^{X}\right)$; items that met simple structure criteria in prior factor analytic research (i.e., Scott \& Hauenstein, 2011) are indicated with an asterisk (*). 